INTERNATIONAL FOOD POLICY

RESEARCH INSTITUTE

sustainable solutions for ending hunger and poverty

IFPRI ${ }^{\circledR}$ A member of the CGIAR consortium

IFPRI Discussion Paper 01242

February 2013

\title{
Evidence on Key Policies for African Agricultural Growth
}

\author{
Xinshen Diao \\ Adam Kennedy \\ Ousmane Badiane \\ Frances Cossar \\ Paul Dorosh \\ Olivier Ecker \\ Hosaena Ghebru Hagos \\ Derek Headey \\ Athur Mabiso \\ Tsitsi Makombe \\ Mehrab Malek \\ Emily Schmidt
}

Development Strategy and Governance Division 


\section{INTERNATIONAL FOOD POLICY RESEARCH INSTITUTE}

The International Food Policy Research Institute (IFPRI) was established in 1975 to identify and analyze national and international strategies and policies for meeting the food needs of the developing world on a sustainable basis, with particular emphasis on low-income countries and on the poorer groups in those countries. IFPRI is a member of the CGIAR Consortium.

\section{PARTNERS AND CONTRIBUTORS}

IFPRI gratefully acknowledges the generous unrestricted funding from Australia, Canada, China, Denmark, Finland, France, Germany, India, Ireland, Italy, Japan, the Netherlands, Norway, the Philippines, South Africa, Sweden, Switzerland, the United Kingdom, the United States, and the World Bank.

\section{AUTHORS}

Xinshen Diao, International Food Policy Research Institute

Deputy Division Director, Development Strategy and Governance Division

X.Diao@cgiar.org

Adam Kennedy, International Food Policy Research Institute

Senior Research Analyst, Development Strategy and Governance Division

Ousmane Badiane, International Food Policy Research Institute

Director for Africa, West \& Central Africa Office

Frances Cossar, International Food Policy Research Institute

Research Analyst, Development Strategy and Governance Division

Paul Dorosh, International Food Policy Research Institute

Director, Development Strategy and Governance Division

Olivier Ecker, International Food Policy Research Institute

Research Fellow, Development Strategy and Governance Division

Hosaena Ghebru Hagos, International Food Policy Research Institute

Postdoctoral Fellow, Development Strategy and Governance Division

Derek Headey, International Food Policy Research Institute

Research Fellow, Poverty, Health, and Nutrition Division

Athur Mabiso, International Food Policy Research Institute

Postdoctoral Fellow, Development Strategy and Governance Division

Tsitsi Makombe, International Food Policy Research Institute Program Manager, West \& Central Africa Office

Mehrab Malek, International Food Policy Research Institute

Research Analyst, Development Strategy and Governance Division

Emily Schmidt, International Food Policy Research Institute

Program Coordinator, Development Strategy and Governance Division

\section{Notices}

IFPRI Discussion Papers contain preliminary material and research results. They have been peer reviewed, but have not been subject to a formal external review via IFPRI's Publications Review Committee. They are circulated in order to stimulate discussion and critical comment; any opinions expressed are those of the author(s) and do not necessarily reflect the policies or opinions of IFPRI.

Copyright 2013 International Food Policy Research Institute. All rights reserved. Sections of this material may be reproduced for personal and not-for-profit use without the express written permission of but with acknowledgment to IFPRI. To reproduce the material contained herein for profit or commercial use requires express written permission. To obtain permission, contact the Communications Division at ifpri-copyright@cgiar.org. 


\section{Contents}

Abstract $\quad$ V

Acknowledgments $\quad$ vi

Abbreviations and Acronyms vii

1. Introduction 1

2. Agricultural Input Policy Reform 2

3. Policy to Encourage Private-Sector Investment 15

4. Land Tenure Policy and Practice in Africa 23

5. Openness and Food Price Stabilization 31

6. Agriculture, Food Policy, and Nutrition 36

7. Institutional Architecture for Improved Policy Formulation 44

References $\quad 55$ 


\section{Tables}

2.1-Green Revolution technology utilization, by developing region, 1982 and 2002

2.2-Estimated public and private agricultural research and development investments, $2000 \quad 6$

2.3 - Simulation result of rural household welfare effects of input subsidy policy (in percentage change in real income)

4.1-Examples of innovative land tenure reforms

6.1-Benefits and costs of biofortifying staple crops by nutrient under pessimistic and optimistic scenarios in disability-adjusted life years (DALY)

6.2-Select impacts of homestead food production programs in Bangladesh

6.3- Some tentative conclusions about agriculture-for-nutrition policies

7.1-Policy effectiveness, funding requirements, and achievable growth and poverty-reduction outcomes

\section{Figures}

2.1-Conceptualizing farmers' demand for modern inputs 3

2.2-Net machinery and equipment stock in agriculture, per 1,000 hectares of arable land 11

3.1-The growth of the Ethiopian Commodity Exchange 22

5.1-Competing visions of staple food market development 33

7.1-Progress toward achieving the Comprehensive Africa Agriculture Development Programme 10 percent budget target (annual average 1995-2003) 50

7.2- Progress toward achieving the Comprehensive Africa Agriculture Development Programme 10 percent budget target (annual average 2003-10)

7.3 - Funding requirement of meeting the Comprehensive Africa Agriculture Development Programme growth and millennium development goal poverty targets

\section{Box}

7.1-The L'Aquila Food Security Initiative 


\begin{abstract}
It is widely agreed that reducing poverty in Africa south of the Sahara (SSA) depends largely on stimulating growth in agriculture. To this end, heads of state in Africa rallied to form the pan-African Comprehensive African Agriculture Development Programme (CAADP) with the goal of raising investments and improving strategy implementation. However, while implementing an agricultural agenda under the CAADP framework, more and more countries have realized that increasing public investment in agriculture alone is not enough. Policy can play an important role not only to make public investment more efficient, but also is crucial for incentivizing private sector and farmer investment in agriculture. Against this backdrop this paper takes stock of current agricultural policies in SSA with a view to identifying policies that are working as well as areas for improvement. The paper examines policies to encourage the adoption of agricultural inputs, initiate greater private-sector investment in agriculture and agro-industries, and manage price volatility while encouraging openness. The paper further reviews successful land tenure policies and property rights systems, reviews the evidence on the synergies between agriculture and nutrition, and examines how CAADP is laying the institutional architecture for improved policy formulation in Africa. In general, the paper finds that although substantial progress has been made, there is considerable scope for improvement. This is not surprising given the relatively primitive and deeply rooted nature of smallholder farming in Africa. Evidence synthesized in the paper supports the view that most policies cannot be implemented in isolation. Rather, policies tend to be most effective when implemented along with complementary policies and public investments.
\end{abstract}

\title{
Keywords: agricultural policy, input policy, land tenure, CAADP, nutrition policy, private sector, policy evidence
}




\section{ACKNOWLEDGMENTS}

We would like to thank the following for their comments and suggestions on earlier drafts: Sam Benin, Steve Haggblade, Bart Minten, Ephraim Nkonya, Marie Ruel, and David Spielman. We particularly thank Margaret McMillan and Jim Oehmke, who carefully reviewed the whole document and provided valuable comments and suggestions. 


\section{ABBREVIATIONS AND ACRONYMS}

ACGSF

ADMARC

AFSI

AMSEC

ATOR

CAADP

CGIAR

DALY

DP

ECOWAS

ECX

EHPEA

FDI

GDP

IFPRI

IPR

$\mathrm{M} \& \mathrm{E}$

MDAs

MDG

MDG1

METASIP

MfDR

MOFA

NAIP

NEPAD

NRA

PP

PrOpCom

$\mathrm{R} \& \mathrm{D}$

REC

ReSAKSS

SAKSS

SSA

VCR
Agricultural Credit Guarantee Scheme Fund

Agricultural Development and Marketing Corporation (Malawi)

L'Aquila Food Security Initiative

agricultural mechanization service center

Agricultural Trends and Outlook Report

Comprehensive Africa Agriculture Development Programme

Consultative Group on International Agricultural Research

disability-adjusted life years

development partner

Economic Community of West African States

Ethiopian Commodity Exchange

Ethiopian Horticulture Producers and Exporters Association

foreign direct investment

gross domestic product

International Food Policy Research Institute

intellectual property rights

monitoring and evaluation

ministries, departments, and agencies

millennium development goal

first millennium development goal

Medium Term Agriculture Sector Investment Plan

managing for development results

Ministry of Food and Agriculture

national agricultural investment plan

New Partnership for Africa's Development

nominal rates of assistance

Partnership Platform

Promoting Pro-Poor Opportunities in Commodity and Service Markets

research and development

regional economic community

Regional Strategic Analysis and Knowledge Support System

Strategic Analysis and Knowledge Support Systems

Africa south of the Sahara

value-cost ratio 



\section{INTRODUCTION}

Agricultural development can have significant welfare effects given that the majority of poor households in Sub-Saharan Africa (SSA) depend on agriculture for their income and food. Recent work examining the potential impacts of agricultural growth on poverty reduction in SSA has found that agricultural growth has the potential to be more pro-poor than industrial growth (Diao, Hazell et al. 2010, Diao, Thurlow et al. 2012; Christiaensen, Demery, and Kuhl 2011; de Janvry and Sadoulet 2010) and that investments in the agricultural sector bear high returns (Mogues and Benin 2012; Fan, Mogues, and Benin 2009; Fan and Zhang 2004; Fan, Hazell, and Thorat 1999; Fan, Yu, and Jitsuchon 2008). However, SSA has thus far largely not been able to leverage the potential of agriculture. Agricultural productivity in Africa still lags far behind the rest of the world.

This is not because SSA lacks productive potential. Analysis by Fischer et al. (2002) has shown that SSA as a whole is well endowed with agricultural potential and that with proper technologies has the potential to be quite productive. With this in mind many observers suggest that now is the time for a Green Revolution in Africa (Pingali 2012; Evenson and Gollin 2003; Djurfeldt, Holmen, and Jirstroml 2005). This Green Revolution largely will need to be technology driven given the low levels of productivity (Nin Pratt, Johnson, and Yu 2012) and the complex environmental challenges of climate change (Parry, Rosenzweig, and Livermore 2005).

Investment in agricultural research and development $(R \& D)$ and extension is instrumental for improving productivity and can yield high returns to agricultural growth and in turn reduce poverty (Thirtle, Lin, and Piesse 2003). However, expenditures on agricultural R\&D and extension in most countries in SSA historically were low or declined in the 1980s and 1990s as part of structural adjustment reforms (Beintema and Stads 2006; Pardey, Roseboom, and Beintema 1997). Only in the past decade, spurred by the Comprehensive Africa Agriculture Development Programme (CAADP) initiative, has there been a broad increase in agricultural expenditures (Beintema and Stads 2011), but larger and more efficient spending is needed to transform African agriculture.

However, productivity-enhancing technologies are only one component of the broader agriculture development agenda. Pro-poor agricultural development needs to be market driven and can be realized only if smallholders are able grow through linkages with value chains. Other public investments such as infrastructure that links farmers to markets remain critical after decades of underinvestment (Foster and Briceño-Garmendia 2010).

Government policies also must play a critical role in correcting many of the market failures that still exist. These policies must be targeted at modernizing and improving the competitiveness of African agricultural systems by assisting the private sector in coordinating value chains and supporting the distribution of fertilizers at lower costs (Hazell 2012; Jayne and Tschilerly 2009). Complementary policies that secure land rights are needed to encourage farmer investment in their land amid growing concerns about environmental degradation and climate change. Government policies that limit intervention-inefficient markets during times of price stability but protect poor consumers during price spikes and keep these households from falling into irreversible poverty traps should be encouraged (Timmer 2011).

This paper provides a synthesis of the evidence base on these types of policies. We examine policies to encourage the adoption of agricultural inputs, initiate greater private-sector investment in agriculture and agro-industries, and manage price volatility while encouraging openness. We further review successful land tenure policies and property rights systems, review the evidence on the synergies between agriculture and nutrition, and examine how CAADP is laying the institutional architecture for improved policy formulation. 


\section{AGRICULTURAL INPUT POLICY REFORM ${ }^{1}$}

After decades of poor performance there is newfound optimism that African agriculture is making a resurgence, with annual agricultural growth rates in the past decade considerably higher than rates in the previous two (Binswanger-Mkhize et al. 2012; Morris et al. 2012). Many have debated the source of this growth and have come to the general consensus that Africa is finally reaping the benefits of the institutional reforms and policy changes of the 1980s and 1990s as part of the structural adjustment programs (Nin Pratt and Yu 2008; Block 2010; Fuglie and Rada 2011). However, this optimism must be tempered by the fact that nearly two-thirds of Africa's agricultural growth rate from 2001 to 2010 is attributable to increasing domestic prices and that real growth, which averaged 3.5 percent during the same period, largely has been driven by efficiency gains and not technological change (Nin Pratt, Johnson, and $\mathrm{Yu}$ 2012). Modern agricultural technologies including the use of improved seeds, fertilizer, and mechanization and good husbandry practices have not been at the center of the recent recovery but must be integral going forward (Pingali 2012).

Modern agricultural technologies coupled with key investments in public infrastructure and extension and conducive policy were essential to boosting productivity during the Asian Green Revolution (Hazell 2009), and analysis for Africa has shown that the potential exists for doubling or tripling yields for basic staples following a similar technology-led growth principle (Nin Pratt et al. 2011). For instance, among staple crops in Africa, sorghum and millet have the potential to realize average yield gains of up to 3 times their current levels, rice up to 2 times its current yields, and cassava, another important staple in the western African region, up to 1.5 times its current yields.

Agricultural R\&D and extension have also historically shown high rates of return. In fact, returns

Public investments in agricultural $R \& D$, coupled with policy that enables private-sector investment in agricultural $R \& D$, have very high payoffs.

to agricultural R\&D are high for most countries, commodities, and circumstances (Alston et al. 2000; Evenson 2009), including in Africa (Oehmke and Crawford 1996; Masters, Bedingar, and Oehmke 1998). The rates of return for agricultural $R \& D$ and extension are also relatively high (Mogues and Benin 2012) and have strong implications for poverty reduction (Thirtle, Lin, and Piesse 2003; Diao, Hazell et al. 2010). This suggests that public investments in agricultural $R \& D$, coupled with policy that enables private-sector investment in agricultural R\&D, have high payoffs (Naseem, Spielman, and Omamo 2010).

In the following we outline key policy reforms that have been effective at promoting the use of modern inputs leading to increased production and productivity. Principally we focus on the following:

- Factors causing the low use of modern inputs in Africa and the value of policy that increases expenditure on agricultural research and extension

- The need for reform of laws governing seed generation, multiplication, and trade to encourage private-sector investment and stimulate modern variety dissemination

- How reform to fertilizer subsidies, price controls, and import procedures can induce privatesector participation in markets, increase availability, and reduce marketing margins

- The role that public policy can play in creating an enabling environment for mechanization and increased demand for mechanized services

\footnotetext{
${ }^{1}$ Written by Adam Kennedy, Xinshen Diao, and Frances Cossar.
} 


\section{Agricultural Technology Policy: A Conceptual Framework for Accelerating Adoption ${ }^{2}$}

Figure 2.1 lays out a basic model of the demand for technology adoption through increased use of modern inputs adapted from Kelly (2005). A farmer's profits depend on the extent to which revenues exceed costs, although we note that a farmer's objectives will typically relate to some combination of risk and return, which in turn influences the farmer's practices including crop choice and decisions about input use. The most common proxy for farm-level profitability of modern inputs is the value-cost ratio (VCR), which is the value of increased output divided by the cost of additional inputs. Although any VCR greater than 1 literally indicates a technology is profitable, VCRs of greater than 2 are common benchmarks for profitability given the additional costs of labor with higher outputs, and VCRs of 3 or 4 may be required to compensate farmers who lack resources to compensate for what are often substantial price and weather risks.

Figure 2.1-Conceptualizing farmers' demand for modern inputs

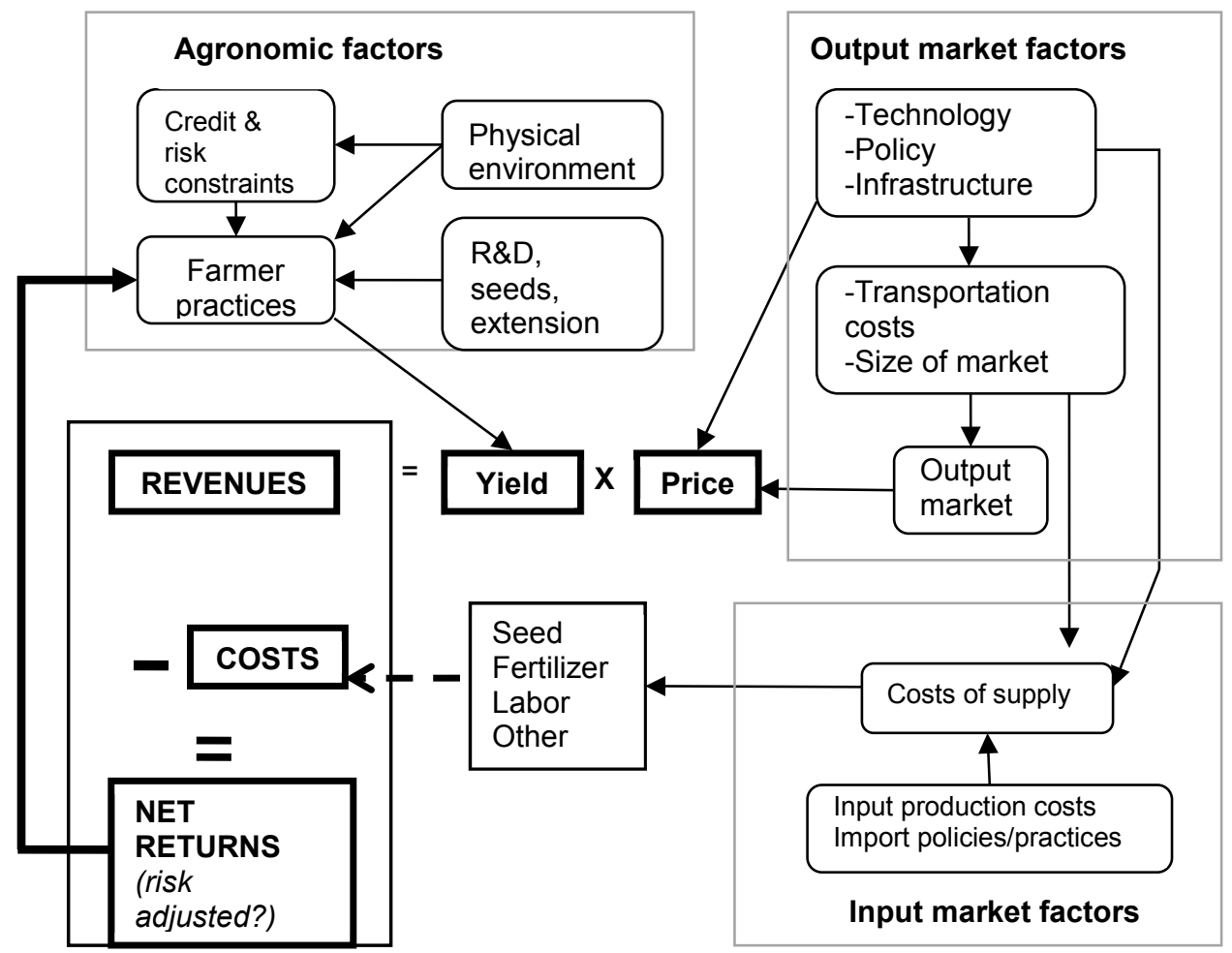

Source: Adapted from Kelly (2005) and Crawford et al. (2003).

Note: $\quad R \& D=$ research and development.

On the revenue side, modern inputs influence yields, and these yield responses vary by crop, seed type, and other technologies, such that overall response is conditioned by the availability and quality of $\mathrm{R} \& \mathrm{D}$ and extension services. Crop response is also affected by the physical environment, especially land supply, soil quality, and rainfall patterns. This environment also conditions risk, which in turn influences the choice of farming practices.

\footnotetext{
${ }^{2}$ Based on an earlier unpublished review by Derek Headey and Adam Kennedy.
} 
In addition to yields, output and input prices codetermine revenue and hence demand for modern inputs. Output prices are often a function of policies, institutions, market conditions (including market demand and margins), technology, and infrastructure. Institutional issues are extremely relevant in determining output/input price ratios, particularly when there is some form of vertical integration, either state led (that is, parastatals/marketing boards) or private led (that is, contract farming).

Finally, the most direct means by which modern inputs determine farm profits is what they cost. In many cases higher input prices are related to many of the factors that simultaneously constrain the proper functioning of output markets, not least transport infrastructure, the size of the market, and the structure and quality of the policy environment. Given that fertilizer prices in Africa greatly exceed those in Asia and elsewhere, cost-side issues have justifiably received considerable attention in recent years (Bumb, Johnson, and Fuentes 2012).

Public investment and policies that are able to exert influence on each of the factors above (agronomic conditions, output markets, and input markets) are key to creating conditions for technology adoption and increased use of modern inputs. The Green Revolution in Asia was largely based on technology that increased crop yields, but Asian governments were able to provide the knowledge and incentives for farmers to adopt new technologies through complementary investments in extension and infrastructure such as irrigation, credit systems, and market development (Hazell 2009). Africa has historically struggled to provide the same levels of either technology or complementary investments and a conducive policy environment. For instance, taxes on exports and commodity movement and price controls, which have historically been in place in many African countries, create a disincentive for producers to invest in intensive agricultural technology by lowering the returns to agricultural investment. The removal of export taxes and the dismantling of marketing boards have not generated a strong supply response because liberalization policies have been only partially implemented (or reversed) and because poor rural infrastructure creates high marketing costs and a lack of financial services available to the poor dissuades input purchase (Binswanger 1990; Kydd and Dorward 2004).

Additionally, although policy factors and investment decisions have largely driven the success of the Green Revolution in Asia, the underlying conditions already may have been in place for the Asian transformation. For instance, because of severe land constraints, farmers in Japan, China, and elsewhere in Asia had for centuries begun to intensify production through rice-breeding efforts, and organic fertilizer use was a common practice (Hayami and Ruttan 1985). Contrast this with Africa, where even though there have been some of the highest rates of population growth during the past half century, population densities in the rural areas are still far below those of most large Asian countries (Headey, Bezemer, and Hazell, 2008). Further, agricultural production statistics show that Africa's ratio of used to unused land suitable for crop production is the lowest in the world (Fischer et al. 2002). The majority of the increased production's resulting from land expansion rather than productivity growth is a case in point.

Likewise, rice- and wheat-breeding advances were at the heart of the Green Revolution, but the development of improved crops for Africa has been much slower. Unlike rice and wheat, which are readily grown throughout Asia, there were virtually no existing databases of genetic material potentially suitable for improved varieties of traditional African crops (Pingali 2012). Prior to the 1970s most African varieties were based on landraces that had been improved by farmers through natural selection. Crops introduced to Africa, such as maize and rice, largely lacked the adaptive research necessary to make them viable in an environment with different climates, day lengths, and pests. For example, it was only in the 1970s that the first researcher-bred improved varieties of maize were released in western Africa, with much of the genetic material coming from the International Maize and Wheat Improvement Center (Evenson and Gollin 2003). Otherwise, traditional African crops such as beans, lentils, cassava, sorghum, millet, and sweet potato have largely lacked the improved genetic material to initiate a Green Revolution, not to mention that international breeding centers for most of these crops were not established or functioning properly until the 1970s or 1980s (Evenson and Gollin 2003). 
Although seed technology constraints may be important in many countries, there is considerable indirect evidence that improved seed adoption is not as binding a constraint as poor access to fertilizers. For example, the 2008 World Development Report summarized adoption statistics from various sources and found that around a quarter of Africa's cereal area was planted with improved varieties, compared to around 80 percent in Asia. Fertilizer use per hectare of arable and permanent cropland in Africa was around 8kilograms per hectare (kg/ha) in 2002 yet around $100 \mathrm{~kg} / \mathrm{ha}$ in Asia. Even if one argues that Africa is currently at an earlier stage in its Green Revolution, it remains the case that current fertilizer use in Africa is still only around one-fifth of the level used by south or east Asia in 1980 in the middle of its Green Revolution (see Table 2.1). Overall, then, it does indeed look like application of both fertilizer and improved seed is lagging behind in Africa.

Table 2.1—Green Revolution technology utilization, by developing region, 1982 and 2002

\begin{tabular}{l|cc|cc|cc}
\hline \multirow{2}{*}{ Region } & \multicolumn{2}{|c|}{ Improved Seeds (\%) } & \multicolumn{2}{c|}{ Irrigation (\%) } & \multicolumn{2}{c}{$\begin{array}{c}\text { Fertilizer Use } \\
\text { (kilograms per hectare) }\end{array}$} \\
\cline { 2 - 7 } South Asia & $\mathbf{1 9 8 2}$ & $\mathbf{2 0 0 2}$ & $\mathbf{1 9 8 2}$ & $\mathbf{2 0 0 2}$ & $\mathbf{1 9 8 2}$ & $\mathbf{2 0 0 2}$ \\
East and southeast Asia & 45 & 77 & 29 & 39 & 38 & 101 \\
Latin America & 42 & 85 & 31 & 29 & 53 & 96 \\
Africa south of the Sahara & 22 & 59 & 9 & 41 & 43 & 78 \\
Middle East and north & 2 & 24 & 3 & 43 & 7 & 102 \\
Africa & 17 & 48 & 24 & 33 & 52 \\
\hline
\end{tabular}

Source: World Bank (2008).

Irrigation in Africa, one of the other components in Asia's Green Revolution package, lags behind that in Asia even more than fertilizer use, with just 4 percent of crop areas irrigated in 2003, compared to 39 percent in south Asia and 29 percent in east and southeast Asia. Given that large parts of Africa have vulnerable or intermittent rainfall, and that rainfall constrains the response of high-yielding varieties and fertilizers, irrigation should indeed be considered a potentially binding constraint in some parts of Africa.

In the general absence of irrigation, rainfall patterns are typically the limiting factor on production potential and crop choice in Africa. Production potential and crop choice, by interacting with risk, also constrain farmers' demand for high-yielding seeds. For instance, the adoption rates of highyielding varieties of wheat and rice in Asia in the 1980s were nearly 100 percent in irrigated areas but only around 15-20 percent in less favorable environments (Byerlee 1996; Byerlee and Morris 1993). The indirect effect of low rainfall is to increase the risks associated with fertilizer use. Dercon and Christiaensen (2011) estimate the impact of ex ante rainfall risk on Ethiopian farmers' decisions to use fertilizers. They show that at average rainfall levels, fertilizer yields a healthy financial return but that the return becomes negative below the $30^{\text {th }}$ percentile of rainfall and above the $70^{\text {th }}$ percentile. Rainfall risks may also play a part in explaining why only 11 percent of African fertilizer use is directed at dryland crops such as sorghum and millet, despite 20 percent of the crop area's being planted with these crops.

\section{Seed Policy Reform: Seed Generation, Multiplication, and Trade}

Technological innovation is essential to enhancing productivity, and agricultural research was at the heart of the Green Revolution. The Consultative Group on International Agricultural Research (CGIAR) system, funded largely through international public expenditure, was one of the chief purveyors of improved genetic materials during the Green Revolution (Evenson and Gollin 2003). National agriculture research systems with limited capacity and financial means largely drew from CGIAR's pool of genetic material and adapted plant lines for local agroecological conditions and preferences (Byerlee and Traxler 2002). 
The use of traditional breeding methods, which relied on open pollination, limited the appeal of private investment in agricultural R\&D because of the inability to capture profits and protect intellectual property (Pingali 2007b; Nin Pratt 2010). Open-pollinated grains are generally saved by the farmer and used as next year's seeds without significant loss of genetic integrity. The development and wider availability of hybrids, which experience significant yield loss with seed recycling (as much as 30 percent with maize; Pixley and Banziger 2002), gave private seed breeders greater control over innovations, and the progress of intellectual property rights (IPR) in developing countries provided the impetus for greater private investment in seed technologies. Private investments in developed countries have now eclipsed that which is spent on public research (see Table 2.2) and dwarf the amount destined for international public research in the CGIAR system (Byerlee and Fischer 2002).

Table 2.2-Estimated public and private agricultural research and development investments, 2000

\begin{tabular}{l|ccc|cc}
\hline \multirow{2}{*}{ Region/Group } & \multicolumn{3}{|c|}{$\begin{array}{c}\text { Expenditures } \\
\text { (in millions of } \mathbf{2 0 0 0} \text { international dollars) }\end{array}$} & \multicolumn{2}{c}{$\begin{array}{c}\text { Share } \\
\text { (in percentages) }\end{array}$} \\
\cline { 2 - 6 } & Public & Private & Total & Public & Private \\
\hline Africa south of the Sahara & 1,461 & 26 & 1,486 & 98.3 & 1.7 \\
Developing countries & 12,819 & 652 & 13,682 & 93.7 & 6.3 \\
Developed countries & 10,191 & 12,086 & 22,277 & 45.7 & 54.3 \\
\hline
\end{tabular}

Source: Pardey et al. (2006).

Public expenditures in agricultural R\&D still make up the bulk of research investments in much of the developing world, but these investments have been on a downward trend since the 1980s (Beintema and Stads 2011), having increased only in recent years with the Comprehensive African Agriculture Development Programme agenda. Moreover, large gaps remain in the research portfolio of private agriculture research companies, meaning that many smallholders are underserved (Pingali 2007b). First, private research investments generally target crops that have wide appeal, particularly rice, wheat, and maize. However, African staples are much more varied and include crops such as sorghum, millet, plantains/bananas, and various tuber crops such as cassava and sweet potato. Second, private research focuses on high-input systems with adequate water and fertilizer, whereas the developing world's poor are generally concentrated on the most marginal lands with poor access to fertilizer and credit. Public research therefore has an integral role to play in developing crops for marginal lands that are not served by private seed markets (Pingali 2012).

That is not to say that the private sector does not have a role to play in developing country agriculture - quite the opposite in fact. Hybrid and genetically modified crops offer enormous potential for raising the productivity of the developing world's smallholders. However, to leverage private agricultural investment to develop technologies that are productivity enhancing, the appropriate infrastructure investments and policy environment are needed.

Improved IPR and strong enforcement mechanisms to ensure appropriability of technologies have been shown to stimulate private investment in agricultural R\&D (Naseem, Spielman, and Omamo 2010; Lele, Lesser, and Horstkotte-Wesseler 2000). For instance, using cross-country panel data, Kanwar and Evenson (2003) found an empirical relationship between the protection of IPR and R\&D investment even when controlling for countries' education levels, political stability, degree of openness, and funds available for R\&D expenditure. Recent work by Kolady, Spielman, and Cavalieri (2012) found that enforceable IPR in India encouraged greater private-sector investment in hybrid crop improvement and ultimately was responsible for improving yields. However, others have found that patents and other forms of IPR did not have as strong a relationship in stimulating private research in Asian countries (Pray and Fuglie 2001). 
Others have suggested that quality control and regulatory systems play an important role in encouraging private investment in agricultural R\&D and protecting farmers from mislabeled or counterfeit farm inputs (Tripp and Louwaars 1997; Gisselquist and Van der Meer 2001). A strong regulatory framework can spur demand among consumers by giving them confidence that their fertilizers, seeds, and insecticides are of high quality and encourage private-sector entry by providing the private sector a platform to more accurately transmit information about the product to farmers (Naseem, Spielman, and Omamo 2010). It therefore limits the risk to consumers and the liability of the private sector.

Trade policies governing the movement of improved seed varieties in Africa south of the Sahara (SSA) have also undergone slow reform (Tripp and Rohrbach 2001; Rohrbach, Minde, and Howard 2003). In some countries there can still be taxes on imported seed, raising prices for consumers. Similarly, a lack of standardization of seed policies across countries has limited international trade, whereas registering varieties at the point of origin can be cumbersome, and understanding and meeting the standards in all potential importing countries is even more difficult (Langyintuo et al. 2010). Seed classification and inspection procedures vary greatly and further slow the release process (Rohrbach, Minde, and Howard 2003).

Evidence has shown that relaxing restrictions on licensing and certification procedures can lead to increased private-sector investment in seed production. For instance, India has had some success in attracting investments and firms in the seed sector through policy reforms (Pray, Ramaswami, and Kelley 2001). In 1991 economywide industrial licensing policies restricting the entry of foreign firms and jointowned firms were abolished to allow for greater foreign ownership and investment in Indian companies. Additional reforms within the seed sector were made in 1987 to reverse policy restricting the entry of large firms (in terms of assets). This was followed by reforms in 1988 allowing for the importation of all vegetable seeds as well as loosening restrictions on imports of coarse grains (maize, sorghum, and millet), pulses, and oil seeds provided that parent lines were provided after two years for domestic breeding. Both wheat and rice seed imports were not allowed.

Pray, Ramaswami, and Kelley (2001) find that the reforms were directly responsible for the entry of large seed companies, which accounted for nearly one-third of total R\&D expenditures in 1997. In addition, they estimate that there was more investment in R\&D due to increased competition in the seed sector and that even these modest reforms to the sector were responsible for generating private investment equal to nearly half of the total R\&D expenditures in the country.

There is also strong evidence that similar policies in Turkey have likewise been effective (Gisselquist and Grether 2000). The ministry of agriculture had since the early 1960s maintained control of seed variety trade, variety registration, and seed pricing, limiting variety registration primarily to public research institutions. Following years of little uptake of hybrid maize varieties and extensive smuggling of seeds, Turkey liberalized the seed market by removing price controls, relaxing foreign investment controls, and easing registration and testing procedures between 1982 and 1984. Following these reforms, between 1982 and 1994, hybrid maize, soybeans, sunflowers, and wheat varieties in the country increased by 670 percent or more (soybeans by 3,400 percent), and the number of private seed companies grew from 5 to 80. In only three years following reforms, hybrid seed imports were larger than domestic production. Gisselquist and Pray (1997) estimate that these reforms and the influx of hybrid maize were responsible for yield increases of approximately 50 percent witnessed after reforms compared to those that otherwise would have been projected based on data for 1960-82.

Evidence of the effectiveness of seed policy reforms from Africa is only recently starting to emerge. Waithaka et al. (2011) reviewed the impacts of an Association for Strengthening Agricultural Research in Eastern and Central Africa program to harmonize seed policy in Kenya, Uganda, and Tanzania by moving to a seed certification system consistent with Organization for Economic Cooperation and Development regulations and improving both import and export procedures and phytosanitary standards between 2002 and 2008. Their study concludes that these measures have reduced the variety release period from more than three years to less than two years. Likewise, local seed 
production has nearly tripled, while imports have increased 60 percent. There is also some evidence of greater price stability of improved seed.

The evidence above suggests that liberalizing seed markets offers opportunities for private-sector entry to complement public institutions' efforts. This has been particularly effective when these policy actions are coupled with the creation of a strong IPR framework guaranteeing the appropriability of technologies. Similarly, reducing cumbersome registration processes and variety-testing restrictions can encourage the movement of improved technologies across borders and aid regional R\&D initiatives and seed trade. Seed and agricultural technology policy, however, must strike a balance between deregulation, which encourages private investment, and consumer protection, which ensures that farmers have access to high-quality seed.

\section{Input Subsidies and Policy Reform}

Input subsidy policies can provide governments a ready solution to the otherwise difficult problems of developing input markets and associated financial services to small farmers, including reducing the high costs of modern inputs that constrain adoption (Minot and Benson 2009). Although other ways of overcoming such problems are complicated, with success uncertain, a subsidy is a relatively straightforward measure to implement. Politically, subsidies are also highly visible gestures to rural voters as well as potentially instruments of patronage (Banful 2010).

The broad argument that input subsidies can lead to higher incomes, reduced poverty, and improved food security is based on specific claims about a range of underlying objectives. Most of these underlying objectives either have an economic efficiency rationale (that is, reflect a market failure of some kind) or are concerned with reallocating income to a particular constituency (a social objective). However, to fully understand the rationale for fertilizer subsidies it is necessary to review them against the historical backdrop of policy changes made in the two decades since structural adjustment programs.

Structural adjustment programs were forcefully implemented in many African countries in the 1980s and 1990s at a time of serious macro-economic imbalances due to overvalued exchange rates, rising import and export costs, and the inability to pay the interest on accumulated foreign debt. Measures of heavy state intervention in domestic agricultural production and marketing activities were eliminated. However, when subsidies were removed and the private sector was allowed to participate in the importation and distribution of fertilizers, fertilizer prices subsequently soared. Across Africa many governments were forced to implement other types of interventions, such as safety net programs, that were often relatively small in scale while smallholder-dominated agricultural production continued to decline throughout the 1990s. In most cases, structural adjustment programs did not deal with the real structural constraints to improving living conditions for the majority of smallholders (Tshibaka 1992).

In the absence of a comprehensive and realistic fertilizer policy, fertilizer subsidies have frequently been revisited as a policy when agricultural production has fallen due to droughts or other weather shocks. For example, the government of Malawi reintroduced fertilizer subsidies and distributed hybrid seeds in 1987 when a drought caused significant maize production shortfalls, although this was short-lived with donor pressure to proceed with economic liberalization (Smale 1995). The government of Malawi, through the formation of its Maize Productivity Task Force that included scientists, economists, and policymakers (Levy 2005; Blackie and Mann 2005), again reintroduced fertilizer and seed subsidies in the late 1990s for smallholders under the universal Starter Pack Scheme. This intensive public-sector spending on subsidies to smallholders was scaled down again in the early 2000 s, which, combined with adverse weather conditions, was seen as a main factor eventually leading to severe food crises in the 2002/03 and 2004/05 seasons (Stevens, Devreux, and Kennan 2002).

The new fertilizer policy implemented in Malawi in 2004/05 has therefore come about through a series of intense political debates. The high cost of maize imports, which constituted the second largest item of the Malawian budget (Stambuli 2002), and stagnant domestic maize production are the main factors argued in favor of an input subsidy policy (Chinsanga 2007). Despite the success of Malawi's input subsidy policy in boosting maize production, balancing the need to ensure food security through 
subsidized fertilizer and encouraging private-sector investment in input markets remains difficult for the government. Some research suggests that smart subsidies implemented through the private sector would be the preferred approach, as it could achieve both goals (Minot and Benson 2009).

Still, input subsidies, by tackling the problem indirectly rather than developing effective input markets, risk inducing unintended secondary effects. In this respect, it is important to consider the disadvantages and drawbacks associated with input subsidies. As outlined in Brooks (2012) the arguments against subsidies include the following: (1) Subsidies may be ineffective in raising use of inputs and increasing yields after they are removed; (2) heavy subsidies on inputs potentially distort the relative costs of factors, leading to inefficient allocation of inputs, with the subsidized inputs substitute for other factors; (3) subsidies intended to benefit specified groups of farmers, or to stimulate particular crops, may be less effective than intended as leakages occur; (4) subsidy programs may be implemented in ways that repress the development of private supply of inputs by delivering inputs through state agencies and bypassing nascent local input dealers (Bumb, Johnson, and Fuentes 2011; Fan, Yu, and Jitsuchon 2008); (5) in the absence of effective targeting, input subsidies are likely to benefit larger farmers, whose use of inputs is highest, and may fail to reach the poorest and most vulnerable households (Mason and Ricker-Gilbert 2012); and (6) when subsidized inputs dominate the supply of a particular input, then subsidies may become closely linked to government budget cycles or to electoral cycles with pronounced swings in availability so that supplies, whether or not they are subsidized, may not be regular, reliable, and timely.

However, often the main objection to subsidies is their high cost (Fan, Zhang, and Rao 2004). In the three cases outlined in Brooks (2012), input subsidies in India, Malawi, and Sri Lanka have taken up 10 percent, 15 percent, or more of the total government budget - sometimes more than education expenditures. Costs can be driven up further when state agencies are used to distribute subsidized inputs, and there may be little incentive for them to economize on logistics. Last, once in place, subsidies can be difficult to remove as farmers sometimes form electorally powerful lobbies for their continuation.

Using the Development Policy Evaluation Model, Brooks et al. (2012) simulate the welfare effect of various agricultural policies, including input subsidies on different types of rural households in six countries, including two from Africa - Ghana and Malawi. They find that all rural households benefit from the input subsidy in all countries, but the benefits received by medium and large farm households are higher than those received by smallholders. In the model simulation farmers received the equivalent of a 10 percent input price subsidy through a voucher system. The welfare effects (as the percentage change from the base) are presented in Table 2.3 for different types of farm households.

Table 2.3-Simulation result of rural household welfare effects of input subsidy policy (in percentage change in real income)

\begin{tabular}{lcc}
\hline & Ghana & Malawi \\
\hline Nonfarm & 0.28 & 0.14 \\
Small remote & 0.77 & 0.56 \\
Small nonremote & 0.46 & 0.53 \\
Medium remote & 1.25 & 0.80 \\
Medium nonremote & 0.88 & 0.88 \\
Large farm & 1.14 & 1.03 \\
\hline
\end{tabular}

Source: Brooks (2012, Annex 1 [Development Policy Evaluation Model simulation results]).

The authors also simulate the welfare effect of removing transaction costs for households located remotely from markets. Under this simulation, the welfare gain is larger for small and medium remote farmers in Ghana than their gain from an input subsidy, but it is not the case for the same types of farmers in Malawi. 
The relative benefits and costs of the well-documented Malawi input subsidy program remain controversial (Wiggins and Brooks 2012). Supporters point out that maize production has increased remarkably since the introduction of the subsidies, with harvests' exceeding the estimated national requirement of around 2.4 million tons, from around 1.0 to 1.5 million tons in the early $1990 \mathrm{~s}$. Although some of the production increase in the past four years may be the result of favorable rains, it would be hard to deny the positive impact of the subsidies on maize yields.

The Malawi fertilizer subsidy program, however, has not been without difficulties. Targeting has been imperfect, and some of the vouchers have been distributed to political supporters (Mason and Ricker-Gilbert 2012). Although vouchers are used, fertilizer has been distributed by a state company in recent years, marginalizing small private dealers in rural areas. Additionally, estimates indicate that the voucher program has displaced 20-30 percent of commercial fertilizer sales in some years, leading also to second-round effects on maize prices, rural employment, and wages because maize is so central to the economy.

Other countries have had similar experiences. Recent evidence from Nigeria has shown that fertilizer subsidies may have crowded out 19-35 percent of the demand for commercial fertilizer (Takeshima, Nkonya, and Deb forthcoming). In the Nigerian case, many large farms that had access to private markets were able to purchase subsidized fertilizers, thus displacing commercial sales. In Ghana, Banful (2009) found that the fertilizer subsidy program gave exclusive government contracts to large fertilizer distributers to the detriment of smaller, rural distributers and discouraged long-term input market development in rural areas.

The costs of fertilizer subsidies can also be enormous. In Malawi it was estimated that the fertilizer subsidy made up 74 percent of the Ministry of Agriculture and Food Security budget in 2008/09 and 6.6 percent of gross domestic product (GDP) (Dorward and Chirwa 2011). Similar criticisms have been leveled at Zambia, where between 2004 and 2011 fertilizer and seed subsidies made up 40 percent of the government's agricultural-sector budget (Mason and Ricker-Gilbert 2012), and India, where agricultural subsidies cost between 15 and 25 percent of total government expenditure, exceeding that for education in a country with only 61 percent literacy (Wiggins and Brooks 2010). Fertilizer subsidies may offer a short-term solution to develop input markets (Morris et al. 2007); however, in the long term there are questions about their financial sustainability and at what cost they come to other public-sector investments in infrastructure, education, and health.

An alternative approach is to develop private-sector input distribution markets without the use of subsidies through policy actions. Evidence from Kenya suggests that removing price controls, import quotas, and fertilizer donations can be effective at attracting the private sector, raising on-farm application rates, reducing marketing margins, and increasing fertilizer availability in the longer term (Ariga, Jayne, and Nyoro 2006). Since the liberalization of the fertilizer market in the early 1990s, fertilizer use on small farms in Kenya has increased from 43 percent in 1995/96 to 69 percent in 2003/04, and fertilizer purchases increased from 250,000 tons in the early 1990 s to 352,000 tons in $2004 / 05$. There has been greater usage on tea plantations, which expanded during this period, buoyed by higher international prices, but there has also been a steady increase in application rates on maize in the high potential zones in the highlands. This is in part because fertilizer has become more accessible with the mean distance from small farmers to the nearest retailer dropping from 8.4 kilometers $(\mathrm{km})$ to $4.1 \mathrm{~km}$ between 1997 and 2004. Commercial imports are also three times higher than in the 1980s and early 1990s, and increased competition has reduced margins (primarily by improving logistics) from $\$ 245$ per ton to $\$ 140$ per ton $^{3}$ while keeping farmgate prices approximately the same at a time of rising international prices.

\footnotetext{
${ }^{3}$ Here and throughout the paper all dollars are US dollars.
} 


\section{Mechanization Policy-Creating an Enabling Environment for Private-sector Investment}

Intensification of production systems has created power bottlenecks around land preparation, harvesting, and threshing operations. The adoption of mechanical technologies has helped enhance agricultural productivity and lowered the unit cost of crop production even in the densely populated countries of Asia (Pingali 2007a). Mechanization of agricultural operations is highly selective and sequential, and demand for it is determined by the stage of agricultural transformation, which reflects the use of complementary inputs, the intensity of farming, population density, and rural labor supply. The evolution of mechanization often starts with mechanizing power-intensive activities (for example, land preparation). However, with appropriate machines and attachments the mechanization of control-intensive farming practices such as seeding, weeding, harvesting, and postharvest processing can be hastened. The adoption of power-intensive mechanization is triggered by the intensification of production practices. Controlintensive operations are more labor intensive; therefore, these operations are mechanized when relative wages increase.

Much of the research has focused on the 1980s era of mechanization efforts, when governments across developing countries, particularly in Africa, were taking the primary role in providing mechanization capacity to farmers. In the past two decades, labor-saving technologies adopted by farmers in Asian and Latin American developing countries have reached an unprecedented level, partially due to improved technical efficiency and reliability of farm equipment and, more important, to the downward trends in prices for farm equipment increasingly produced in developing countries such as China and India. However, SSA continues to have low levels of mechanization, and available data indicate declining rather than increasing levels of adoption (see Figure 2.2). Thus, in recent years, governments in some African countries such as Ghana, Sierra Leone, and Nigeria have expressed the need for mechanization and once again devoted significant resources to promoting agricultural machinery and tractor-based mechanization. Although real prices for smaller farm equipment such as power tillers has gone down, in Africa where smallholder farming dominates and all tractors are imported, the ownership of machinery by a majority of individual farmers is still difficult given their relatively low land productivity and small scale. The mode of delivery seen frequently across Africa, for smallholder farms, is through tractor-hire services, with accompanying support services such as repair services, spare parts supply, and tractor imports. Large-scale commercial farms are able to own and operate their own machinery due to economies of scale and access to capital.

Figure 2.2 - Net machinery and equipment stock in agriculture, per 1,000 hectares of arable land

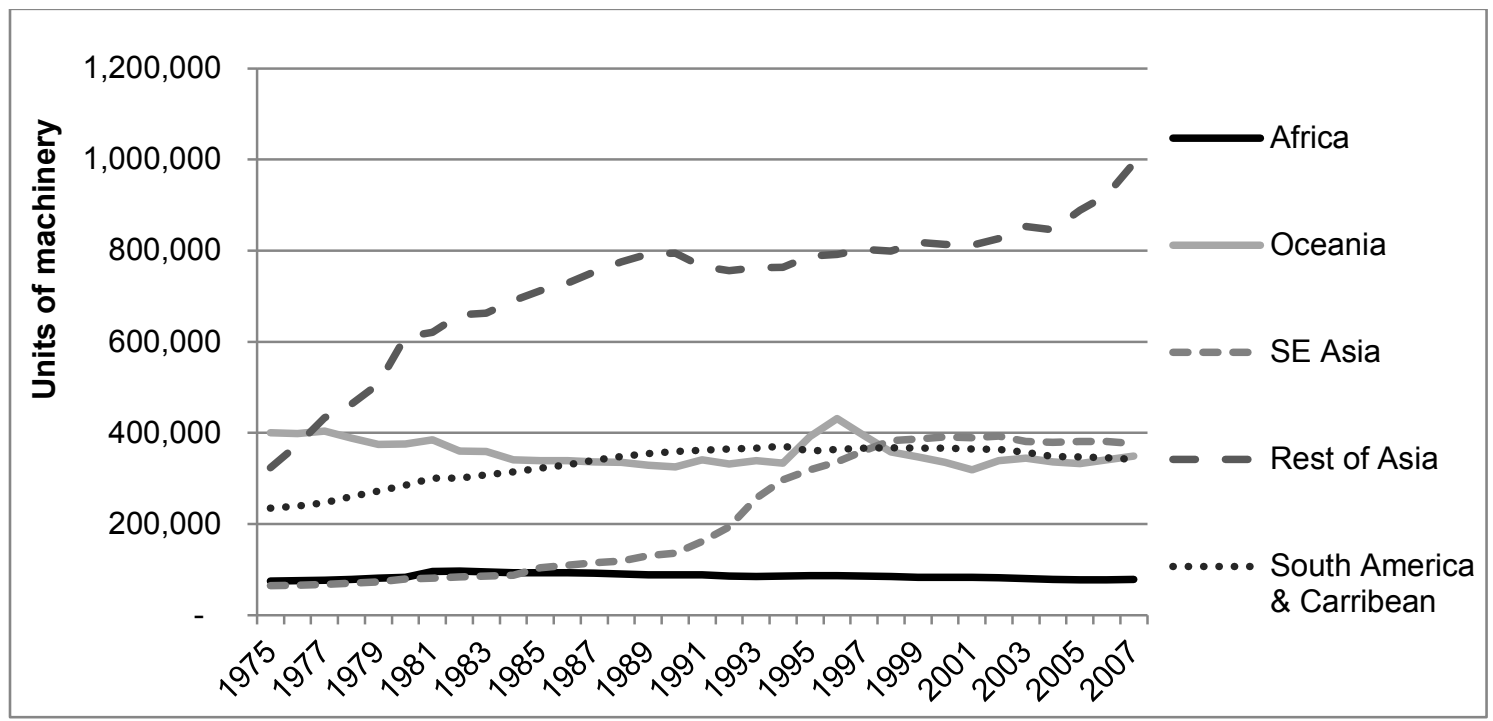

Source: Food and Agriculture Organization of the United Nations Statistical Databases (2012).

Note: $\quad \mathrm{SE}=$ Southeast. 
The role of tractors in Asia's Green Revolution is reflected in Figure 2.2. The stock of tractors available in southeast Asia was at a level similar to Africa's up to the mid-1980s. As agricultural production intensified, the tractor stock more than doubled to meet the demands of farmers. Tractor stocks in the rest of Asia also increased during the period, in particular since 2000, as wages have increased. There are several possible explanations to the stagnant growth of machinery stock across Africa. One is that supply and demand for mechanization are at a low-level equilibrium, which reflects the low level of intensive agriculture production that dominates Africa. Another explanation is that there is scope for use of agricultural machinery in Africa, but there has been an underinvestment in supply, creating a bottleneck and preventing agricultural productivity growth.

Government investment in mechanization schemes has often been premature, inefficient, and unsustainable due to a lack of demand. The policies of African governments in the 1980s were to provide mechanization services to farmers directly by the public sector. For example, Ghana's government owned and operated tractors through state farms and hired them out to private farmers. There are three key pitfalls with such heavy government involvement in mechanization. First, if the conditions for mechanization are not in place, the productivity benefits of mechanized operation will be limited. Use of tractors for ploughing has limited impact on yields (Herdt 1983) unless complementary inputs and intensive farming practices have increased profitability and the need for timely ploughing. Controlintensive operations are not mechanized until rising wages make the use of machinery cheaper than labor. Without such triggers, the application of mechanical operations will bring little productivity growth.

Second, publicly administered schemes are usually less efficient than those run by the private sector. When public and private hire schemes are compared, private tractor-hire service providers have much higher hours of use than public providers (Pingali, Bigot, and Binswanger 1987). Under public tractor-hire schemes, operators are often government employees with no link between number of acres ploughed and their pay, creating a disincentive to work efficiently or increase service delivery. Several attempts to encourage mechanization by the government of Sierra Leone through the importation of tractors were also financially unsuccessful because financing, fuel, and equipment arrived late, leading to the poor timing of service availability.

Third, schemes that are not well aligned with the current stage of agricultural transformation will face a lack of demand and potential collapse after government support is removed. Pingali (2007a) documents that most of the schemes studied in the late 1980s subsequently failed after government support was withdrawn under structural adjustment. The consensus from the literature (Pingali 2007a) is that these schemes failed because of insufficient demand for mechanization services. Once government subsidy or investment was withdrawn, the schemes collapsed. For example, efforts to encourage tractorhire services in Kenya after independence were ineffective and ended because between 1975 and 1986, the utilization rate for tractors was only 43 percent, making them financially unsustainable.

In some countries, there is now growing demand for mechanization as complementary investments in agricultural inputs are being realized and the urbanization rate increases. Since attempts to mechanize agriculture in the $1980 \mathrm{~s}$, demand for mechanization has changed. In the 1980s, agriculture in Africa was characterized by extensive cultivation systems, low population density, and relatively cheap labor. As the urbanization process has sped up in many SSA countries, intensification of agriculture has been stimulated in some areas. This trend, combined with an increased opportunity cost of labor in rural areas due to various income-generating activities outside agriculture (although mostly informal without secured wages), has created upward pressure on the cost of hired labor in agricultural production. To fully benefit from the adoption of improved seed varieties and increased use of fertilizers, farmers must also adopt control-intensive husbandry practices, such as weed control, row planting, and maintenance of optimal plant populations. These farming practices also generate high outputs, requiring more harvest and postharvest operations. Thus, they demand higher labor inputs while also generating individual incentives to meet new quality requirements. Although hired labor is a common phenomenon among smallholder farmers in Africa, these practices are still traditional. Farmers therefore are often hesitant to adopt highyield agricultural technologies unless they can closely supervise hired labor. The supply of skilled labor at critical times in the season at affordable wages has already constrained smallholders in some African 
countries and limited opportunities for double cropping and further expansion of crop areas even where land is available (Benin et al. 2012). Therefore, demand for mechanization is growing, creating opportunity for increased investment in the supply of mechanized equipment.

If markets are working well, private-sector investment in the import of machinery, repairing services, provision of tractor-hire services, and so on should meet the growing demand. However, the perception is that the capacity of the private sector to play this role is limited, and some governments have been stepping up their interventions to actively promote mechanization. Governments have stepped back from direct provision of tractor-hire services, but governments such as those in Ghana, Nigeria, and Sierra Leone are playing a central role in the import and distribution of tractors and other agricultural

Policy reform that reduces the barriers to modern input importation, licensing, and trade has been essential to inducing the private sector to participate in seed, fertilizer, and agricultural machinery markets. machinery. These renewed public-sector efforts at mechanization promotion are distinct from efforts in the 1980s as there is a greater emphasis on partnership with the private sector, at least in rhetoric. Similar to fertilizer provision in Africa, almost all tractors are imported by only a few companies appointed by the government. Although tractors and other agricultural machinery can be privately owned, prices are typically subsidized. Moreover, the government decides to whom the machines will be sold. Such "publicly run" tractor provision is a dominant model in many countries. A number of

examples have shown the low efficiency of this model of mechanization (Ashburner and Kienzle 2011; Pingali 2007a).

In the absence of private-sector investment, some governments are becoming involved in the import and distribution of agricultural machinery to overcome the deficit of machinery stock. The danger is that similar pitfalls from the 1980s of operational inefficiency and unsustainability will recur if renewed mechanization efforts are not private sector driven. There are several examples wherein private-sector growth has been stifled by government in Africa. In Nigeria, the Kaduna State Tractor Hiring Cooperative Society waited for more than two years to receive the 55 tractors through the government for which it laid down deposits (10 percent of asset cost). The Ogun State chapter of the Tractor Owners and Operators Association of Nigeria decided not to participate in the new government's tractor public-private partnership initiative on learning that the price, tractor model, and level of after-sales services were not to its liking (Promoting Pro-Poor Opportunities in Commodity and Service Markets [PrOpCom] 2011). Likewise, Ghana's Ministry of Agriculture and Food provides a package of highly subsidized tractors to privately run agricultural mechanization service centers (AMSECs). A recent review found that the payment recovery rate for most AMSECs is far behind schedule, even though these centers have already been given equipment at about 50-70 percent of the import price. The lack of a transparent selection process in establishing AMSECs has also resulted in low operating efficiency for many centers. The high maintenance cost and hence low profitability not only relates to the lack of qualified tractor operators hired by the centers but also relates to the lack of affordable spare parts (Benin et al. 2012). The sudden increase in tractor imports by the government as well as the diversity of tractor brands imported each year has discouraged the private sector from investing in the supply of parts and repair services for any one tractor brand.

In contrast, in Asia, private investment appears to have stepped in to meet growing demand for mechanization. For example, the Ministry of Agriculture in Thailand introduced various machinery including four-wheeled tractors during the 1960s (Thepent and Chamsing 2009). This machinery was frequently too expensive, and the adoption rate was low. However, local manufacturers began adapting imported two-wheeled power tillers and reproducing them at much lower cost. These small machines became popular and were adopted widely in Thailand. Similarly, tractor-hire services in China have been supported by subsidized prices for some agricultural machinery and information sharing, but the machinery-hire market has evolved into an efficient privately led industry. Agricultural machinery owners have grouped together into specialized cooperatives that travel across regions, following the seasons, to provide services to farmers. 
Further research is needed into the menu of investments and policy actions to ensure mechanization takes place within broader agricultural transformation in Africa. Public policy to support agricultural mechanization must create an enabling environment for the private sector to develop supply chains (Ashburner and Kienzle 2011). Heavily subsidized tractor imports in Ghana eliminated the market demand for new tractors imported by the private sector and damaged the well-established private-sector business for secondhand tractor imports that had existed for more than two decades. In contrast, the PrOpCom program in Nigeria focuses on stimulating new sales channels to equip private tractor service providers with new, functional tractors on demand. This allows private tractor owner-operators greater choice, more ownership over the transaction, and an alternative to the dysfunctional state-run schemes on which they have become dependent. The impact assessment undertaken by PrOpCom in July 2011 shows that 9,476 small and poor farmers were reached during the 50-tractor pilot scheme between 2010 and 2011 during the peak seasons. It is expected that competition will likely further reduce the costs of purchasing such services in the future.

At the appropriate stage of agricultural transformation, mechanization can play a critical role in alleviating power bottlenecks. Public promotion has often failed in the past, and renewed efforts in this area should be well focused. It is only if there is unmet demand for mechanization and the private sector is failing to invest and meet that demand that government should play any significant role in promoting mechanization. Government policies should focus on enabling private-sector investment by reforming policies that are preventing investment (for example, import policies) and reducing transaction costs for the private sector where weak markets are discouraging investment. Anything beyond this scope is likely to fail in establishing the sustainable adoption of mechanized operations.

\section{Summary}

The recent agricultural GDP growth and total factor productivity trends for Africa must be put in their proper context. The major driver of this growth has not come from productivity growth through technological change but rather has been largely driven by moving resources into more profitable crops and products for which prices have risen in recent years. Although price increases can be an important source of agricultural growth, a lack of productivity growth will challenge their sustainability. Productivity growth is highly correlated with the use of modern inputs, but adoption levels still remain abysmal in most areas of Africa compared to the rest of the world and even to that of Asia at the early stages of its Green Revolution.

There are important roles for both the public and private sectors in stimulating the use of modern inputs and technology adoption. The public sector can play an important role in creating the conditions

that make such inputs and technology profitable and less risky, whereas the private sector is best placed to manage the procurement and distribution of modern agricultural technologies, which will also indirectly encourage farmer adoption. Moreover, public research and extension have been and will remain critical in the areas underserved by the private sector, and these investments must be increased. 


\section{POLICY TO ENCOURAGE PRIVATE-SECTOR INVESTMENT4}

Despite some noteworthy successes in certain export-oriented high-value agriculture through value chain development, the potential for private-sector investment to lead to broad-based agricultural transformation in Africa remains largely untapped. However, there is substantial evidence that appropriate policies and public investment in infrastructure such as roads and electricity can encourage private investment and help promote private-sector-led agricultural growth. There is some indication that liberalization and market reforms have begun to lead to private investment in agriculture, particularly in value-added processing (Mhlanga 2010).

Increased urbanization in Africa has brought about greater spatial concentration of consumers and increased domestic market sizes for some agricultural products, opening new opportunities for the development of domestically oriented value chains. Such markets include horticulture, particularly

There is substantial evidence that appropriate policies that encourage private investment, including public investments in roads and electricity, can help promote efficiency and growth in both domestic food markets and in export markets. vegetables, pulses, and oil crop products; livestock products; and processed foods, part of which are experiencing an increasing influx of large retail businesses and supermarkets that offer opportunities for smallholders to commercialize, although their share still remains small. Nonetheless, there is a large and expanding market for domestically produced food products, fueled by population growth, rising per capita incomes, and urbanization, as well as displacement of imports such as cereal imports, which account for 25 percent of food imports in SSA (Diao,

Dorosh, and Rahman 2003). These markets remain marked by low productivity systems that have high transaction costs but that through appropriate policy and investment can begin to transform.

There are also examples of successful policy implementation that has encouraged private-sector entry into both traditional and nontraditional export markets while engaging smallholders, boosting incomes and productivity, and more effectively capturing value-addition opportunities.

In the following we provide examples to show which policies have been successful at encouraging private-sector investment in value chains in both domestic and export markets. Primarily we focus on the following:

1. How well-timed investments in capacity building, infrastructure, logistics, and R\&D can support the development of agro-industries

2. How policies aimed at attracting foreign direct investment (FDI) can be effective at stimulating agroprocessing industries and accessing export markets

3. How policy supporting risk management, farmer-based groups, and small- and medium-sized businesses may offer greater opportunities for helping broad-based agricultural transformation

\section{Policy to Encourage Private Investment in High-Value Agricultural Exports}

There are many success stories in which traditional export-crop value chains have been rehabilitated and revitalized through policy reform aimed at limiting marketing board control and supporting market development. In some cases governments have tried to develop nontraditional export infant industries and to encourage private-sector investment through logistical and institutional support. Moreover, there is emerging evidence to suggest that creating an environment conducive to value chain development may offer opportunities for smallholder-inclusive growth in high-value, commercialized agriculture.

\footnotetext{
${ }^{4}$ Written by Adam Kennedy and Xinshen Diao.
} 
Reforming the activities of the Ghanaian Cocobod has largely contributed to a rise in production, productivity, and poverty reduction among cocoa farmers (Vigneri 2008; Kolavalli and Vigneri 2011). Following pressure from multilaterals in the 1980s Ghana began slowly to liberalize the cocoa market. Slowly the purchase and transport of cocoa were transferred to the private sector and continue to operate under a bid process and subsidies for inputs were phased out. The government also initiated the Cocoa Rehabilitation Project whereby farmers were compensated for removing trees infected with swollen shoot virus and planting new ones, leading to the spread of high-yielding varieties developed by the Cocoa Research Institute of Ghana. The state-controlled Cocobod has also initiated programs to improve farming practices, developed mass spraying programs, and tried to promote subsidy packages with mixed success. Although the adoption of new varieties was a success despite their higher labor requirement, the provision of inputs on credit had poor repayment rates and high dropout rates. However, these investments and the high perception of the quality of Ghana's cocoa have increased private-sector investment in washing stations and cocoa-processing facilities, improving real export earnings of processed cocoa from $\$ 32$ million in 1991 to $\$ 105$ million in 2005. Increased growth in the cocoa sector has also contributed to a reduction in poverty among cocoa-producing households from 60.1 percent in the early 1990 s to 23.9 percent in 2005. By shifting some responsibilities to the private sector, the number of Cocobod staff was reduced to 5 percent of its peak in the early 1980s, thus reducing operating costs. At the same time, Cocobod has encouraged traders to pass on a greater share of the free-on-board price to growers.

Similarly, cotton reforms in Burkina Faso were a gradual process that when coupled with investments in local institutions allowed for a smooth transition toward market liberalization (Kaminski and Headey 2009). The state-led company SOFITEX engaged the private sector to provide functions for which it had no comparative advantage such as input provision, transport services, and cotton refinement, and the state maintained research facilities and established an interprofessional association around the cotton sector consisting of cotton farmers, bankers, government officials, the private sector, and research institutes. Following reforms, cotton production tripled between 1995 and 2007, resulting in increased export earnings of $\$ 165$ million. Households farming cotton nearly doubled from 95,000 to 175,000 , which in turn has generated additional employment totaling 235,000 new jobs that have directly and indirectly benefited around 1.8 million people. Ultimately though the reforms had their largest effect on household incomes, which grew between 19 and 43 percent (depending on estimates), and poverty, which declined from 62 to 47 percent.

In contrast, reforms in the Rwandan coffee sector happened relatively quickly with the assistance of United States Agency for International Development-supported programs to establish strong linkages with the private sector and foreign buyers. The 2002 National Coffee Strategy put in place a framework to strengthen cooperatives, identify and support the building of washing stations, and improve quality throughout the domestic value chain (Boudreaux 2011). These reforms and investments have led to a shift in the market from low-quality to high-value specialty coffee, which earns a premium on the market: One-third of Rwanda coffee exports are now high quality, compared to negligible amounts in 2000 (Bihogo, Weatherspoon, and Oehmke 2011). Analysis by Murekezi and Loveridge (2009) has found that farmers who sell coffee cherries to washing stations are able to increase their total household expenditures by 17 percent and their food expenditures by 15 percent per adult equivalent compared to those who sell regular coffee. Lyambabaje et al. (2012) found that participation in the premium-quality coffee value chain was associated with an income increase of more than $\$ 1,700$ per household from 2000 to 2010 relative to nonparticipant incomes and that the development of the high-value coffee chain directly contributed to an additional 14.3 percentage point poverty reduction among participating households relative to nonparticipating households.

The general forecast is also bright for several countries participating in the nontraditional export sector, where market opportunities offer prospects for significant growth. Newer, niche markets (fresh vegetables, cut flowers, for instance) may have the highest growth potential because they face fewer demand constraints in both the short and the medium term. For example, in the European market, imports of fresh and chilled leguminous vegetables rose by more than 130 percent in a period of 10 years, with almost three-quarters of the imports coming from Africa south of the Sahara (Diao and Hazell 2004). 
Some African countries - Ethiopia, Ghana, Cote d'Ivoire, Kenya, and Zambia among themhave achieved notable success in increasing nontraditional exports. Fruit and vegetable exports from Kenya have increased more than fourfold in constant dollar terms since 1974, and horticulture has become one of the largest sources of foreign exchange earnings. In Zambia exports of fresh vegetables and cut flowers rose by five times in 10 years, accounting for 40 percent of total agricultural exports. Moreover, the bulk of these exports is grown on smallholder farms, although there may be some evidence that this is changing with the implementation of Global Good Agricultural Practice (GLOBALG.A.P) quality standards, which favor large farms (Ouma 2010; Maertens and Swinnen 2009). Although favorable geography and climate have played a major role in the expansion of horticultural production, market, policy, and institutional conditions are critical in realizing this growth. Replicating these gains requires appropriate investments and policies, including improvements in transportation infrastructure, limitations on direct government intervention in markets, incentives for private and international investment, and development of international commercial links.

With horticulture in Kenya, the government's recognition and encouragement of the development of a wide range of private marketing institutions, local producer associations, and self-help groups has been important, as has access to credit and other financial services as well as transport, refrigeration, and storage. Such institutional development, however, does not necessarily fully depend on government; the private sector and nongovernmental organizations have also made important contributions (Minot and Ngigi 2003).

Ethiopia's cut flower industry is also impressive. Ethiopia has a number of advantages over competing African countries in the cut flower industry including a reliable state-owned airline and closer proximity to European markets, but until as recently as 2000 there had been little initiative by the government or private sector to develop this potentially lucrative enterprise. Beginning in 2002, the newly formed Ethiopian Horticulture Producers and Exporters Association (EHPEA) approached the government for support. In response to these requests the Ethiopian government supported this new industry through air freight transport coordination through the state-owned Ethiopian Airlines, access to land and credit on favorable terms, solicitation of foreign investment in the cut flower industry, and the removal of restrictions on the bulk import of pesticides and fertilizers for the flower industry study (Gebreeyesus and Sonobe 2012). In addition, the government, with support of the Dutch government and EHPEA, had an active role in the development of a course curriculum to build capacity in the new cut flower industry and has worked with the private sector to develop certification procedures to ensure quality of exports. In response to these efforts the number of cut flower firms has grown significantly from 10 in 2004 to 81 by the end of 2009, and earnings grew from $\$ 3.7$ million to $\$ 100$ million during the same period. The sector is now one of the top five foreign exchange earners in the country and a significant source of jobs for rural labor.

Madagascar has also had success in the development of the fresh vegetable industry through the creation of the Export Processing Zone in 1989 (Minten, Randrianarison, and Swinnen 2009). This zone provides investors who export 95 percent of their goods a corporate income tax holiday for 2 to 15 years and import duty and tax immunity. Textile and apparel manufactures make up the bulk of the firms located in this area, but in recent years there has been increased investment in high-value vegetable production destined primarily for European markets. The production of export vegetables, primarily French-cut green beans, through micro-contracts has now grown to include almost 10,000 smallholder farmers in the highlands of Madagascar. Survey analysis has shown that these farmers on average have higher wages and greater income stability than noncontract growers. In addition, with greater exposure to new agricultural products and hence new farming techniques provided through contract farming (a common arrangement for many high-value value chain developments) there have been spillovers from the development of the green bean value chain into household food production with rice productivity 64 percent higher on contract farmers' plots than on those of their neighbors (Minten, Randrianarison, and Swinnen 2009). Contrasting previous studies of contract farming (Delgado 1999; Reardon and Barrett 2000; Reardon et al. 2003), the Madagascar case also shows that smallholders are able to successfully participate and integrate into global value chains (Minten, Randrianarison, and Swinnen 2009). 


\section{Policy to Attract FDI in Agro-Industries}

To increase the value addition of primary agricultural products and to create more job opportunities along the value chain from farms to manufacturing, many countries have been active in establishing agroindustries through policy actions aimed at attracting FDI (Mhlanga 2010). For example, Ghana's liberal investment climate allows 100 percent ownership of local companies by foreign companies and corporate tax rebates of 40-75 percent. Lease laws are also favorable, providing foreign investors 50-year contracts that are renewable. Import duties on farm equipment and processing machinery are also waived for establishing new agroenterprises.

Nigeria similarly has begun to introduce incentives to encourage private-sector investment (Mhlanga 2010). The Agricultural Credit Guarantee Scheme Fund (ACGSF) guarantees up to 75 percent of loans for agricultural production. With an eye toward developing the domestic cassava-processing industry, policies have also been implemented to encourage investment, such as the Interest Drawback Program Fund, which provides 60 percent of interest payments to those borrowing through the ACGSF program to produce or process cassava. New agroprocessing industries also are exempt from taxes for the first five years and are not charged duties on imported agricultural machinery.

Under Ethiopia's Industrial Development Strategy (August 2002), the private sector is identified as the main driver of the leather and leather products industry initiative to build an export-led and laborintensive manufacturing sector. The livestock population in Ethiopia is the largest in Africa and is estimated to comprise approximately 59 million cattle, 35 million sheep, and 31 million goats, offering opportunities for the processing sector (Negassa et al. 2012). Prioritizing this sector, the government has developed and supported the Leather Industry Development Institute and recently signed agreements with the Central Leather Research Institute and the Footwear Design and Development Institute of India to exchange knowledge and improve productivity (Economic Times 2011). Complementary industrial policies for agro-industry and processing have also been put in place. Land is provided at reduced leasing rates (Brautigam and Tang 2012), and new companies are exempt from income taxes for two to eight years, depending on the size and location of the investment and

Policies and investment to support agro-industries development have been effective at attracting private investment and creating job opportunities along the value chain. export volume (regulation no. 84/2003). The government also encourages knowledge exchange by providing tax exemptions on the salaries of foreign experts. With an improved investment environment and encouraging policies, the private sector has become a driving force for accelerating agriculture-related industrialization. Although many foreign companies are newly established, case studies conducted by International Food Policy Research Institute (IFPRI) researchers Deborah Brautigam and Xiaoyang Tang in June and July 2012 have shown an encouraging upward trend in investment. The researchers conducted interviews at factories set up by Chinese, Italian, and German entrepreneurs outside Addis Ababa. The oldest of these, China-Africa Overseas Leather Products, opened in 2009 after investing \$27 million in the leather industry. It now employs 350 local employees and 25 Chinese nationals. The factory is already profitable and intends to invest another \$25 million to add processing potential. The Indian firm Tata is also investing in the Ethiopian leather industry by working with a local tannery to upgrade its capacity to produce export-quality leather for Tata's factories in India and China.

\section{Active Support of the Private Sector in Food Staples}

Stimulating private-sector investment in value chains for domestically oriented food products such as grains and other staple crops has had less success. Fundamentally, staples frequently lack sufficient profit incentive to attract private investment and a price premium sufficient to convince smallholders to engage in contractual arrangements. This is illustrated well by the example of tomato in Ghana, where processors contracted local growers but were unable to provide sufficient prices to convince them not to sell to local traders (Robinson and Kolavalli 2010). A similar situation was found in Madagascar, where commercial 
production of French green beans was profitable for export sale but where contracting for the domestic market has failed because people were unwilling to pay the price premium for higher-quality beans (Minten, Randrianarison, and Swinnen 2009).

The policy environment for staple crops has also not always been conducive to private-sector investment. Policies that are aimed at stabilizing domestic market prices can confuse private-sector investors and create disincentives in value chain development for staple food (Jayne and Tschirley 2009). Although market reform and liberalization during the 1980s and 1990s introduced more room for privatesector investment and competition and the evidence shows that this has been beneficial for producers and consumers alike (Ariga and Jayne 2009; Jayne, Negassa, and Myers 1998; Kherallah et al. 2002), it has been easy for governments to return to direct state intervention to manage food shortages and price spikes during times of crisis. As reported in Jayne, Zulu, and Nijhoff (2006), during the decade from 1995 to 2004, government marketing board maize purchases fluctuated: 15-57 percent of total output in Kenya, 3-32 percent in Malawi, and 11-45 percent in Zambia. These policies and tools have been effective at stabilizing prices, which has been beneficial both politically and to consumers who struggle to cope with rising prices (Chapoto and Jayne 2009; Jayne, Myers, and Nyoro 2008). However, these actions continue to influence the pricing of cereals and the decisions of the private sector. Market interventions are frequently unpredictable and introduce additional risk to private-sector investment and trade (Jayne, Zulu, and Nijhoff 2006).

Additionally, by providing a guaranteed buyer and price floor, marketing boards conditioned much of the risk of producing for competitive markets. Local collection points minimized the need for producers to bear the high costs of moving products to distant markets over poor infrastructure and masked the problems of poor market integration. Artificially low prices did little to incentivize farmers to adopt productivity-enhancing technologies. The removal of state intervention in food markets has exposed many of the underlying problems of poor productivity and lack of market integration (Wiggins 2000). In some cases such as those outlined above liberalization has appeared to remedy some of these challenges, but in others it has not. Additional liberalization is still needed, and policy reforms must make the actions of these boards transparent and predictable to incentivize private investment in value chains (Jayne and Tschirley 2009).

Benin provides a good example: From 1991 to the early 2000s most sectors of the economy were liberalized under a structural adjustment program (Lutz, Kuiper, and van Tilburg 2006), and the food market was deregulated by the restructuring of the cereal marketing board (Office National d'Appui à la Sécurité Alimentaire) (Badiane 2000). These reforms were aimed at strengthening the private market by introducing transparency, strengthening competition, and improving market integration. However, survey-based analysis shows that despite these reforms, the domestic maize market did not become well integrated, and responses to price changes were sluggish (Lutz, Kuiper, and van Tilburg 2006), suggesting that the success of reforms depends on more than the withdrawal of the public sector from markets (Badiane 2000).

\section{Roads and Infrastructure}

Improving the condition of roads and other infrastructure is one of the most important public policy tools for generating investment in agriculture (Mogues and Benin 2012). This is because road networks reduce transportation and transaction costs, leading to market development and integration, and also indirectly help growth and poverty reduction by improving access to education and health (Foster and BriceñoGarmendia 2010). Stifel and Minten (2008) also find that transportation-induced transaction costs influence productivity. In Madagascar, rice yields are 33 percent less in the most rural areas and 50 percent less for maize and cassava because rural households employ less family labor and use less fertilizer (Stifel and Minten 2008). Likewise, high seasonal price variation caused by poor market connections can alter relative prices of products sold, thereby reducing input use because of price risk. This example emphasizes that smallholder access to markets through feeder roads can smooth price fluctuations and reduce transaction costs, allowing them to intensify and commercialize production. 
Gollin and Rogerson (2010) similarly find that in Uganda improvements in road infrastructure have an important effect on improving productivity.

Although improved access to markets will support smallholders' participation in food markets, survey data from East Africa show that landholdings and a lack of sufficient capital are also critical (Guiding Investments in Sustainable Agricultural Markets in Africa 2010). The study finds that even if smallholders were linked to markets, these smallholders would not be able to produce a surplus sufficient to market. Governments could help by investing in improved farm technology and ensuring that these smallholders have access to inputs at low costs. This requires investments in agricultural R\&D complemented by access to credit and improved rural roads to reduce marketing costs. Thus, although infrastructure is necessary to foster commercial agriculture and market growth, by itself it is not sufficient to jump-start agricultural transformation.

\section{Risk Management through Insurance}

Managing risk also remains a critical component to inducing farmers to commercialize food production. With agriculture in Africa dominated by rainfed systems that are susceptible to climatic shocks, many smallholders remain at a subsistence level, with low use of improved technology, low productivity, and low risk. Evidence from Ethiopia suggests that farmers with insurance were more willing to invest in fertilizer (Vargas-Hill and Viceisza 2010). The private sector can become a leading force in risk management if the right policies and infrastructure are put in place. For example, managing risk through index-based insurance not only has been shown to provide an effective, market-mediated solution for promoting agricultural development but also can make disaster relief more effective (Hazell et al. 2010).

There are a number of avenues through which policy can contribute to developing index-based insurance operations (Hess and Hazell 2009). Weather station infrastructure and data systems are still lacking in many countries, making accurate and timely index-based insurance calculations difficult. In Malawi, the existence of 22 functioning weather stations has been essential to the operation of weather insurance programs (Hess and Syroka 2005), and in Ethiopia automating weather stations was found to improve the efficiency and rapidity of settling insurance contracts (Meherette 2009). The promotion and provision of publicly subsidized insurance may also initiate insurance market creation and has been shown to be effective at managing disaster relief efforts (Mahul, Belete, and Goodland 2009). Finally, a proper legal and regulatory framework must be in place to enable private-sector entry into the insurance market and to develop and enforce insurance contracts (Hazell et al. 2010).

\section{Scale}

The scale of public investment and support to initiate commercialization is also important. Far too often public investment has focused on the development of large-scale commercial enterprises to substitute for food imports, with poor results (Binswanger-Mkhize et al. 2012). A smallholder-led commercialization strategy similar to that which occurred in Thailand, Vietnam, and China can drive agricultural growth and lead to large-scale reductions in poverty. Smallholders are generally the most efficient and low-cost producers of staples (Hazell et al. 2007). Others have reviewed several African case studies and found similar results whereby the successful commercialization of staple foods has been accomplished primarily by smallholders and in all cases commercialization was for domestic markets (Poulton et al. 2008). Analysis of rice in Rwanda (Stryker 2010) and in Indonesia (Timmer 1974) has found that small- and medium-sized mills are more efficient than large-scale processing facilities and have an easier time of operating in a supply-constrained environment.

In this way, nurturing smaller enterprises may offer better opportunities for staples commercialization. Recent work by Zhang and Hu (2011) details how governments at the regional level in China have been effective at developing cluster industries with a regional comparative advantage. In their example, local government worked with small-scale producers to overcome a series of hurdles in the potato industry. Here, small grants were given to improve terracing to better capture and concentrate water. As potato cropping intensified, local public agricultural research institutions supported farmers 
with agriculture $R \& D$ to combat diseases endemic in large potato monocrops to remove supply-side constraints. Local government also facilitated negotiations to increase rail service to transport potatoes to markets and provided credit opportunities to induce local production of storage units.

More recently, because of increasing market saturation and the inelastic demand for potatoes, the local government has been supportive of the potato cluster's efforts to diversify into processing for the fast food industry. To entice private investors, in 2003 the government made land available at a discount price for factories and ensured that complementary infrastructure such as water and electricity were available. To guarantee an adequate supply of potatoes for the factories, local government worked with farmers and investors to segregate farmers by region into growers for the starch industry and growers for household vegetable consumption. By 2006, 12 private firms had invested in processing facilities, and the production line had been expanded to include separate facilities for potato starch, flour, chips, and fries.

\section{Farmer-Based Organizations}

Given that agricultural markets have become more complex due to globalization and that the demand for high-quality and safe foods is increasing, there is now a greater need for the skills and networks to coordinate small farmers (Narrod et al. 2007). Overcoming the challenges and costs of obtaining market information, enforcing business contracts, and complying with safety standards generally favors economies of scale for these fixed costs can be distributed over a large volume of produce. Cooperatives may offer opportunities to minimize and spread the costs of entering into commercial production and can play an important role in developing export-oriented value chains.

The evidence on the effectiveness of farmer-based organization development is mixed. Where cooperatives have been developed and sustained, they have primarily been in perishable or export products (Stringfellow et al. 1997). For instance, in Kenya membership in a milk cooperative was found to reduce the amount of milk lost to wastage, raise the prices received by farmers, and help farmers to conform to regulatory institutions (Sinja et al. 2006). Membership in a milk cooperative also increased the probability of a trader's being established in informal milk marketing. Narrod et al. (2007) also detail how Kenyan green bean farmer groups were able to assist small commercial growers to pool resources to invest in the facilities needed to comply with food safety standards such as cold storage, sorting facilities, and pesticide storage. Other successes in developing farmer group cooperatives in high-value crops have been found for coffee in Ethiopia (Kodama 2007) and cotton in Mali (Tefft 2004).

Cooperatives for staples markets also offer many advantages but have had less success (Coulter 2007). By leveraging the power of collective action, cooperatives can aggregate surplus outputs to secure a better marketing and trade position in the marketplace while also becoming a platform for farmers to voice their concerns about local governance. Still, Minten, Stifel, and Tamiru (2012) find that only a limited number of smallholders participate in cooperatives for staples in Ethiopia, and these numbers have been decreasing over time. Bernard et al. (2010) find that with staple crops, the membership costs frequently outweigh the benefits. In the Ethiopian case, membership on average improved cereal prices by 7.2 to 8.9 percent, which for small farmers with limited surplus output is not sufficient to warrant joining the cooperative and paying membership dues. Others have suggested that the hidden costs of joining a collective such as loss of autonomy or the opportunity cost of joining meetings can deter smallholders from collectively marketing low-value staples (Coulter 2007).

\section{Market Information Systems}

The private sector can also help the development of marketing information systems, which can aid in the commercialization of smallholder agriculture. Gabre-Madhin (2003) found that in Ethiopia high market transaction costs, in part because of lack of market information and trust among market actors; poor contract enforcement; and a lack of storage limited market actors' willingness to expand trade to distant markets with new partners, thus hampering market performance. In some cases, these transaction costs were as much as 40-60 percent of the final price (Gabre-Madhin and Goggin 2005). Much of this was due to poor infrastructure, which contributed as much as 70 percent to marketing costs, though market 
transaction costs were significant as well. Based on these challenges, Gabre-Madhin and Goggin (2005) suggested that a market exchange would increase market liquidity and volumes and engage smallholders in the market economy.

The Ethiopian Commodity Exchange (ECX), which began operations in April 2008, is the most successful example of this approach (Gabre-Madhin 2012; Paul 2011). The development of a wellfunctioning ECX required a number of interlinked institutions and policy reforms and initiatives including a market information system, a system of product grading and certification, a regulatory framework and appropriate legislation, a warehouse receipts system, an inspection system, and an arbitration mechanism. Although ECX has not yet engaged domestic producers and traders of cereals on a major scale, it has had success in facilitating trade, improving grades and standards, and in at least some cases, enabling farmers and cooperatives to enjoy higher prices in coffee and sesame markets. Each of these was supported through policy reforms in Ethiopia leading to the formation of ECX, which has seen increased membership and trade in the past three years (see Figure 3.1) in part because of government regulations requiring most exports of coffee and sesame to pass through ECX.

Figure 3.1-The growth of the Ethiopian Commodity Exchange
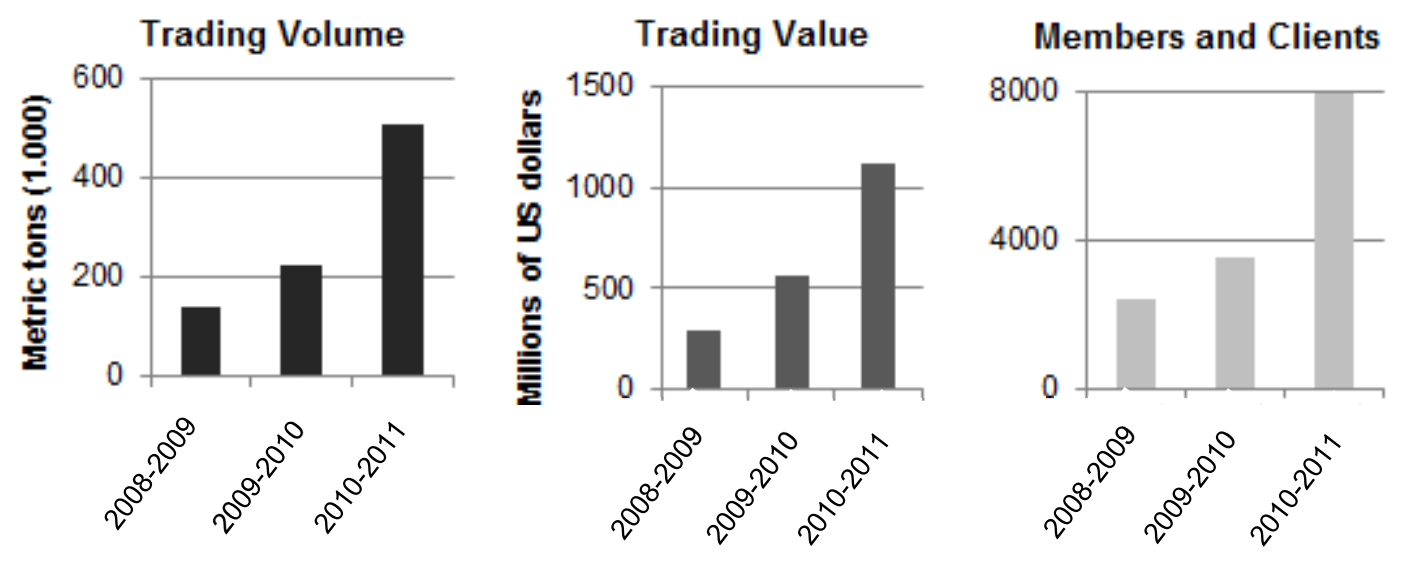

Source: Gabre-Madhin (2012).

Other commodity exchanges in Africa south of the Sahara, however, including those in Kenya and Uganda, have yet to achieve a significant scale. The exception is the commodity exchange for maize in the Republic of South Africa (Rashid, Winter-Nelson, and Garcia 2010), which trades more than 100,000 futures contracts monthly and traded more than 600,000 tons of maize in the month of July 2010 alone.

\section{Summary}

The potential for private-sector investment to transform agriculture beyond high-value exports through market development remains largely untapped. There have been many success stories in high-valueagriculture value chain development, from which we can draw lessons. Evidence indicates that policies and investments that support the commercialization of agriculture can be effective at spurring the development of agroprocessing and a trading system that is dominated by small- and medium-size domestic enterprises. There is also evidence that policies such as tax holidays, favorable land tenure arrangements, and adequate infrastructure such as roads and electricity can be effective at attracting FDI both in agriculture and agro-industry. Finally, there is still the need for continued reform to avoid direct government interventions that discourage or crowd out private investment. 


\section{LAND TENURE POLICY AND PRACTICE IN AFRICA5}

\section{Introduction}

The impact of land tenure systems in Africa south of the Sahara (SSA) on agricultural investment and productivity continues to be the subject of intense scrutiny. Recent food security crises in Africa have revived the debate about whether current land tenure systems constrain farmer innovation and investment in agriculture. Recognizing the importance of good land governance, in 2009 the African Union heads of state agreed to a framework and guidelines for land policy initiatives in Africa, which has led an increasing number of countries to implement far-reaching programs to improve land tenure security. These changes in tenure systems can potentially have major implications for agricultural transformation. ${ }^{6}$ This chapter summarizes the arguments about how best to provide land tenure security in SSA and reviews recent experience and evidence arising from innovative interventions.

\section{Revolutionary (Redistributive) Land Reforms and the Land-Titling Debate}

Land tenure has long been a thorny issue. In the 1960s and 1970s the main concern was equity and security as the debate mostly concerned bringing about justice in land allocation in countries that emerged from colonialism. Since the collapse of the Soviet Union, a different kind of debate has emerged about land tenure centered on efficiency issues and sustainability of resource use in the context of transitions from a socialist mode of production toward a more market-oriented system (Cotula, Toulmin, and Hesse 2004). The purpose of this subsection is not to look at these debates in any detail. Instead, an attempt is made to briefly summarize the theoretical issues surrounding land tenure security and the evolution of property rights. Although there is wide recognition about the desirability of tenure security for agrarian development, there is no clear and universally applicable blueprint as to the most appropriate property rights regime as this depends on underlying sociocultural and geographic factors.

Land tenure reform toward an individual freehold system has long been seen as a prerequisite for development in SSA (Feder and Noronha 1987; Migot-Adholla et al. 1994). The arguments in favor of reforming the customary African land tenure system were mainly based on the neoclassical economic theory of property rights (Demsetz 1967; Barzel 1997) that predicts greater productivity as land tenure becomes more secure and individualized. Reflecting neoliberal thinking about private property rights, Besley (1995) identified three channels through which secure property rights can, in principle, affect positive economic outcomes, namely, (1) tenure security and higher land investment incentives, (2) smooth functioning of the land markets (tradability) that lubricate factor-ratio adjustment, and (3) facilitation of access to institutional credit by allowing land to be used as collateral. These hypothesized effects of tenure security heavily rely on the neoclassical framework that presupposes markets for all goods and services (including credit and insurance markets) exist and that, therefore, market clearing prices determine demand and supply choices of households (Bardhan 1989; Hoff, Braverman, and Stiglitz 1993).

However, in areas where risk, information asymmetry, and moral hazard are pervasive and transaction costs (mainly information and enforcement costs) are prohibitively high, such hypothesized effects of individualized property rights may not hold. As Stiglitz (1986) argues, this is so because the efficiency of the market economy and its allocation of resources (property rights) rely on the conditions of perfect information and the existence of complete markets. When high transaction costs characterize the market, which cause absences or imperfections in the input, output, or both markets, household production and consumption decisions become nonseparable (Singh, Squire, and Strauss 1986; de Janvry, Fafchamps, and Sadoulet 1991; Sadoulet and de Janvry 1995).

\footnotetext{
${ }^{5}$ Written by Hosaena Ghebru Hagos and Emily Schmidt.

${ }^{6}$ Daley and Englert (2010) provide a comprehensive list of past land reform and legislation in Sub-Saharan Africa.
} 
This implies, regardless of the security of tenure, that absence of or imperfections in the market undermine farm households' ability to undertake profitable investments (Holden, Shiferaw, and Pender 2001) and participate in any form of exchange process (Kranton 1996). Farm households internalize such imperfections by producing a limited range of goods and services for their own consumption, especially when social protection for food security is absent, making the household decisionmaking process more responsive to their initial resource endowment rather than market signals (Sadoulet and de Janvry 1995; Holden, Shiferaw, and Pender 2001). For instance, the size and strength of the investment demand effects of tenure security depend on the attractiveness of the investment (Deininger et al. 2003), which ultimately depends on the development of rural input-output and other intertemporal markets. In areas with no or few off-farm employment opportunities or other safety nets, improved tenure or secure property rights may not be enough to incentivize farmers to install improved farming technology (which normally comes with higher risks).

Hence, with such imperfections in the markets and limited institutions to support the functioning of markets in developing countries, liberalization, in the form of individualization of property rights, has sometimes failed to achieve the promised benefits of reducing the investment disincentives associated with a communal property rights system (Shiferaw, Obare, and Muricho 2008). This scenario is even more compelling in rural areas of SSA where land not only is a productive asset but also performs the important functions of social safety net and old age insurance (Deininger and Feder 1998; Holden 2007). For instance, one of the great advantages of many common property regimes in Africa is that community members can claim access to land for farming when necessary and rent it out as a coping response to ease short-term consumption needs. Hence, in high-risk environments, individualization of communal land rights that neglects the safety net function of access to land may reduce poor people's options for risk management and may leave everybody worse off (Deininger and Feder 1998). This implies that policy interventions in the form of granting only usufructuary rights (use rights) that limit any land alienation may come to the rescue in an effort to avoid the myopic sale of land by individuals.

Empirical evidence on the effects of the land-titling programs of the past on access to credit, smallholder investment, and overall production is mixed. Studies in Kenya and Burkina Faso found no effects of land titling on access to credit (Carter and Wiebe 1990; Brasselle, Gaspart, and Platteau 2002). Earlier cross-sectional research in Ghana, Kenya, and Rwanda on land tenure did not show increased investment in land or improved agricultural yields when comparing restrictive land laws to more flexible policy allowing land transfers (Migot-Adholla et al. 1991). A study in a rice-growing area in Madagascar suggests that formal title had no effect on plot-specific investment and little impact on productivity (Jacoby and Minten 2007). In Uganda, in contrast, the likelihood of new investment on titled land was found to be twice that of investments on merely occupied plots by owners-cum-occupants (Deininger and Ali 2008).

In Ethiopia, recent studies that aimed to investigate the low-cost and scalable approach that provides perpetual user and leasing rights to farm households suggest increased economic benefits of tenure security in the form of a land use registration and certification program. Deininger and Jin (2006) found that transfer rights to land and tenure security were associated with higher investments in a study from 2001 covering four regions of Ethiopia. In a more recent cross-sectional survey in four regions in Ethiopia, Deininger et al. (2008) found a positive association between land certification and investment whereby certified plots had 4.4 percent greater investments than noncertified plots receiving investments. Using four-period panel data, a study by Deininger, Ali, and Alemu (2011) found that the land certification program in Ethiopia has increased tenure security, land-related investment, and rental market participation and yielded benefits significantly greater than the cost of implementation. Holden, Deininger, and Ghebru (2009) found similar positive significant effects of low-cost land certification on investment in trees and maintenance of soil conservation structures in the Tigray region of Ethiopia, which was the first region to implement low-cost land certification in Ethiopia, utilizing a household-plot panel with baseline data from just before land certification and the last survey round seven to eight years after the land registration and certification took place. They also found that land productivity had increased by about 40 percent on farm plots with land certificates compared to plots without certificates. 
Similarly, Ali, Deininger, and Goldstein (2011) evaluated cross-sectional data of 3,554 households to test for increased land tenure effects in Rwanda (based on a land tenure regularization program implemented by the Government of Rwanda beginning in 2004) on a variety of outcomes. Households within the land tenure regularization program were 10 percentage points more likely to invest in or maintain soil and water conservation structures such as bunds, terraces, and check dams. ${ }^{7}$ Improved land tenure security had an especially large effect on female-headed households whereby these households had a 19 percentage point increase in the likelihood of measures to construct or maintain soil and water conservation structures compared to male-headed households. These results echo findings by Place and Hazell (1993), whereby improved land tenure security in Rwanda had a positive effect on investment. Smith (2004) used cross-sectional survey data of 266 farmers from the southern provinces in Zambia to compare farm performance under statutory and customary tenure; results suggest land tenure is positively correlated with smallholder investments in some areas. Research conducted in South Africa by Graham and Darroch (2001) suggests that households with tenure security are more likely to seek out and receive credit for agricultural inputs. Hayes, Roth, and Zepeda (1997) found that the probability of longterm investments in fences, wells, and trees were positively correlated with complete land tenure rights (individual right to sell and right to use) and that higher long-term investments were positively associated with higher commercial input use and higher land productivity in a study in three villages under customary tenure in Gambia.

However, land registration and titling can create rather than reduce uncertainty and conflicts over land rights (Atwood 1990; Benjaminsen et al. 2009; Green 1987; Bruce 1986; Mackenzie 1993). Place and Hazell (1993), in their assessment of indigenous tenure systems in SSA, found that lack of credit access, insufficient human capital, and labor shortages had adverse effects on investment decisions more often that tenure insecurity. Inappropriate timing of land reforms (Bruce 1986; Roth 1993), "elite capture" and marginalization of the poor and minority groups due to inefficient and corrupt bureaucracies and high costs of conventional land titling (Barrows and Roth 1989; Roth 1993; Platteau 1996; Benjaminsen et al. 2009; Cotula, Toulmin, and Hesse 2004), and contradictions between customary land rights and emergent statutory land rights (Mackenzie 1993) have been largely outlined as major causes of past failures of landtitling programs to create such investment and tenure security effects.

Recent literature on land property rights (Larson and Bromley 1990; Bromley 1991; Schlager and Ostrom 1992; de Janvry et al. 2001) acknowledges that privatization and individualization is not a priori the most efficient means of achieving tenure security. This was the basis for the revision of the 1975 World Bank land policy, which called for the introduction of private land rights in Africa, acknowledging that communal tenure systems can increase tenure security and provide a basis for land transactions that are more cost effective than freehold titles (Deininger and Binswanger 1999). Although few African countries have gone through revolutionary land reforms or government-induced (land-titling) tenure changes, ${ }^{8}$ there is evidence to indicate that tenure regimes are evolving toward individualized land rights in response to increased demand for secured land rights over scarce land resources (Peters 2004; Udry 2011).

\footnotetext{
${ }^{7}$ The authors also tested for increased use of improved seeds. They find a positive but insignificant effect and relate this to the short-term benefits that improved seed yields, concluding that longer-term investments may be more correlated with tenure security (and decreased risk of future landholding status).

${ }^{8}$ Land reform and land titling are often used interchangeably. But as Burns (2007) explains, land titling is a process of adjudication that is employed to recognize an existing right to land, whereas on the other hand, land reform usually seeks to reassign rights to land, a process that has far greater potential for disputation and usually attracts a significant degree of political attention and community sensitivity. Land registration and titling, by themselves, can take various forms that range from a system of converting registered rights to freehold to a mere record (register) of existing rights to land (Cotula, Toulmin, and Hesse 2004).
} 


\section{The New Wave of Land Policy Reforms and the Continuum Tenure}

After the land redistributive reforms dominating the land tenure debate during the last decade of the twentieth century, there is now a renewed global interest in land policy and legal reforms in part due to rapidly increasing population pressure and high food and fuel prices (International Fund for Agricultural Development 2001; Bonfiglioli 2003; Deininger 2003). Against this backdrop, there is now a growing consensus that, even in rural African contexts where individual titling of land may not be desirable or feasible, simple recognition of the different breadths of rights individuals and communities have under the existing customary tenure system (by providing poor land owners or users with options to have their rights documented) can yield significant benefits (Deininger et al. 2008).

With this recognition, a new and innovative approach is found in the continuum of land rights rather than a narrow focus on individual land titling. In this approach, a range of possible forms of tenure are considered as a continuum from informal tenures (customary, occupancy rights) toward more formal land rights (leases or freehold rights), where each step in the process of securing the tenure can be formalized (UN-HABITAT 2008). This approach has gained momentum in the past decade due to the recognition of the aforementioned limitations of past land-titling programs and the argument that, given population density is low and land is relatively abundant, the usufructuary rights given under the customary tenure rights system do not impose large losses as long as markets for output, capital, and insurance are poorly developed, which ultimately is the case in the SSA context. Rather than involving a narrow focus on individual land titling, this approach involves a form of localized recording and documentation of rights (including secondary or derived rights to land), adapting and expanding existing tenure and land administration systems where possible and introducing new ones selectively (Augustinus and Deininger 2005).

Since the turn of the new millennium, experience with implementation of the continuum of land rights approach has moved ahead in Uganda, Tanzania, Mozambique, Ethiopia, Benin, Côte d'Ivoire, and Burkina Faso. In a number of countries, land policies and laws have been passed that aim to integrate customary and formal land rights and tenure systems.

Proponents of the approach (including the World Bank) argue that, with the prevalence of high transaction costs and market imperfections, costs associated with communal land rights are low. Under such circumstances, though customary systems can meet social and economic needs and can be secure, population pressure, urbanization, commercial pressures, and the monetization of customary land transactions are eroding the social cohesion that gives customary tenure its legitimacy (Augustinus and Deininger 2005). No single form of tenure can meet the different needs of all social groups. Hence, the progressive/incremental approach, whereby tenure rights are gradually formalized or upgraded over time, is widely accepted as the alternative to costly or difficult titling programs (see Table 4.1 for a few examples of countries that adopted this new approach). 
Table 4.1-Examples of innovative land tenure reforms

\begin{tabular}{|c|c|}
\hline Nature of Intervention & Countries \\
\hline 1. Recognition of customary land rights & - Mozambique, Uganda, Ghana \\
\hline $\begin{array}{l}\text { 2. Legal protection of individual use/occupancy rights } \\
\text { (issuance of certificates of occupancy) }\end{array}$ & $\begin{array}{l}\text { - Tanzania, Ethiopia, Malawi, Botswana, Lesotho, } \\
\text { Nigeria (being planned) }\end{array}$ \\
\hline 3. Community land demarcation and group/family titles & - Uganda, Mozambique, Ghana, South Africa \\
\hline $\begin{array}{l}\text { 4. Decentralized land administration system } \\
\text { - Establish land boards } \\
\text { - Village-level land administration } \\
\text { council/committee }\end{array}$ & $\begin{array}{l}\text { - Botswana, Mozambique, Namibia, Uganda, } \\
\text { Ghana, Lesotho } \\
\text { - Tanzania, Ethiopia }\end{array}$ \\
\hline 5. Sporadic (demand-driven) land titling & - Tanzania, Uganda, Rwanda \\
\hline & $\begin{array}{l}\text { - Uganda (tribunals, local government mediators) } \\
\text { - } \quad \text { Tanzania (village land administration council) }\end{array}$ \\
\hline 6. Forms decentralized dispute resolution mechanisms & $\begin{array}{ll}\text { - } & \text { Botswana (district land boards) } \\
\text { - } & \text { Ethiopia (local conflict mediators) } \\
\text { - } & \text { Malawi (land tribunals-proposed) } \\
\end{array}$ \\
\hline
\end{tabular}

Source: Authors' compilation based on reviews of national land policies and regulations.

Although the many customary land tenure arrangements across SSA have served their peoples well in the past, they need to be adjusted to the new demands being put on land by population increase, urban migration, and the globally increasing rush for commercial farming land. The challenge facing governments in the region, and the aid agencies assisting them, is to find a development model that will facilitate economic growth without causing widespread dispossession and the poverty and social dislocation that would result.

In adjusting customary land tenures there are many options available for governments to choose from and many difficult issues to address. Political leadership, however, is the most important requirement. The continuum approach avoids blanket solutions to the land problems wherein each country must work out the solution that suits its needs best. Under this approach the most sensible method is to proceed step by step — without trying to do too much — focusing on the priority areas, adapting existing tenures rather than abolishing them, and trialing reforms in pilot projects before introducing them more generally (UN-HABITAT 2008). Along the range of incremental tenure options, the first and basic reform option is the recognition of customary tenure rights - under which the land ownership of groups is protected and individuals are given the security they need to invest in land development. In economic terms, such reforms are demand driven, not supply driven. Customary groups can be protected, and individuals are given the security they need for investment in land development.

Hence, depending on the local demands, if the objective is to formalize rights as they exist on the ground, this will generally require the formal codification of customary institutions. Possible ways to do this are diverse (Kanji et al. 2005) and have met with varied results. Fitzpatrick (2005) distinguishes between three methods. The essence of the "minimalist approach" is captured by the statement that for certain areas, "customary rights to land are recognized" without any further interference. According to Fitzpatrick, this approach allows customary rights to evolve over time in response to population changes and economic needs, without undue restriction or imposition by a formal legal regime. Such a basic intervention could act as a targeted answer to the problem of encroachment by outsiders, particularly in circumstances where this constitutes the primary cause of local tenure insecurity. This approach informs the 1997 Land Law in Mozambique, where the Land Law proposes a broad demarcation of customary areas and leaves land issues within those areas subject to unregulated customary processes (Tanner 2002; Toulmin and Quan 2000). Other examples of this type of approach may be found in Uganda, Ghana, Ecuador, Colombia, and Panama (Hvalkof and Plant 2000). 
Conversely, it would not be appropriate where tenure insecurity arose from matters internal to the group. This is usually the case with the ever-growing population pressure and urbanization in many SSA countries, which requires enhancement of occupancy rights that can take the form of proclamations against forced evictions and relocations. Addressing such issues, the new tenure types that are considered innovative best practices are the issuance of occupancy right certificates (generally critical for customary tenure rights if they are not protected specifically, including secondary rights of vulnerable groups) that protect against eviction and expropriation (in the latter case, without subject of fair compensation). Hence, only in the event of considerable tenure insecurity within a group, particularly as a result of individualization tensions (mainly caused by the population pressure and urbanization), the emergence of land dealings with foreigners, or both, would the benefits of recording individual interests potentially outweigh the considerable costs and risks of the recording process. This said, a number of African countries do allow for the issue of certificates of individual customary rights to land, including Botswana, Lesotho, Tanzania, Malawi, Namibia, Swaziland, and Uganda (see Alden Wily 2003; Toulmin and Quan 2000; Toulmin, Lavigne Delville, and Traore 2002).

\section{Emerging Challenge to Land Governance in Africa (Large-Scale Land Acquisition)}

Growing interest in land potential for commercial investment in agriculture, mineral extraction, and urban expansion has caused a noticeable shift in the attitude of chiefs in some customary areas away from perceiving themselves to be trustees on behalf of their communities to being essentially private owners of the land, with the result that subsidiary and undocumented customary interests are increasingly vulnerable. Often, such land deals are also made in partnership with local entrepreneurs and district government officials that have varying interests beyond that of the community (Borras, Fig, and Suárez 2011 in Mozambique; Nonfodji 2011 in Benin). Hence, in the face of lucrative deals with outsiders, the customary tenure system (normally headed by the traditional chiefs trusted as custodians of the communal land) may not always act in the interests of the group. As a result, many SSA countries with customary land tenure system are now moving toward land boards or village committees (as a form of granting group tenure rights) on which traditional chiefs may (or may not) sit in an ex officio capacity (Alden Wily 2003). The best-known and pioneer example is Botswana, where the 1968 tribal land act transferred the authority over traditional land from tribal chiefs to district and subdistrict land boards (Quan 2000). Similar approaches were adopted in Lesotho (1979), Mozambique (1997), Uganda (1998), Tanzania (1999), Namibia (2002), and South Africa (2004). Ethiopia (since 2007) has established a decentralized land administration system similar to the land board system in the form of village land administration committees that allocate land within their jurisdiction, adjudicate disputes, and implement policies for land use and administration (Holden and Ghebru 2012).

Although property rights regimes have evolved in Africa to cope with the ever-changing profile of the land, the recent rush in acquiring agricultural land has caused an unprecedented pressure on the customary tenure system as most of the land deals target areas with poor land governance. Analysis by Deininger, Ali, and Alemu (2011) suggests that lower recognition of land rights increases a country's attractiveness for land acquisition. Although these areas are often identified as not previously used or owned land, some analysis suggests that this may not always be the case. Such lack of clarity in the property rights system and the existence of overlapping interests in land may erode the confidence of domestic as well as foreign investors to inject much-needed investment in the rural farm sector. For example, investors' multiple compensations to various hierarchies in Ghana remained one of the most challenging issues concerning transnational agricultural investment in the country mainly due to overlapping claims and strained relations between local chiefs and individuals. Similarly, in Mozambique the total area provided to investors for land use rentals overlapped the community-delineated area by 1.4 million hectares, encompassing 418 cases of land leases. Analysis of recent satellite imagery in Zambia suggests a similar finding (Deininger, Ali, and Alemu 2011). 
The other challenge related to the recent land rush is that local communities and land users are not provided with comprehensive information about the benefits and costs of foreign investments and acquisitions. For example, German et al. (2011) found that benefits were oversold and costs were downplayed when negotiating land acquisitions in Ghana, Tanzania, and Zambia. Employment opportunities are often a perceived benefit to private investment, although studies in the Democratic Republic of the Congo, Ethiopia, and Madagascar suggest considerably lower employment levels than in preinvestment environments (Deininger, Ali, and Alemu 2011; Andrianirina-Ratsialonana and Teyssier 2010). However, in reality, in an effort to attract foreign investment, low rental rates and long-term leases cause speculative acquisitions that remain undeveloped (Deininger, Ali, and Alemu 2011 found that only 20 percent of investments were realized), yet these acquisitions obstruct entry of smallholder farmers to use productive land. Finally, it is not clear that contracts efficiently outline investors' legal obligations about terms for transferring land, timing, remuneration, employment of local people, and nature and quality of infrastructure provision (Cotula 2011; Colchester et al 2006).

The lack of capacity of local communities (which implied large farms' superior bargaining power) in making the land deals and the nontransparency of the process have sparked a growing concern about the potential role the private sector can play in overcoming long-standing bottlenecks in the provision of infrastructure and technology in the farm sector and in linking the rural sector to global markets. This concern is intimately linked to the ongoing debate about the suitability of large-scale versus small-scale farming as development models for transforming the agricultural sector and facilitating economic growth (Deininger, Ali, and Alemu 2011; Deininger and Byerlee 2012; Hanlon 2011).

Deininger and Byerlee (2012) outline a series of economic and policy factors that may contribute to better developmental outcomes from the recent rush for land acquisition. Their analysis of recent land demand from large investors suggests that, if such investment is to live up to expectations in providing economic and social benefits, in addition to greater clarity in the definition of property rights and their recognition, the public sector needs to set suitable policies, provide complementary public goods, and assist local people in screening investments and investors. Three priority areas for attention are (1) clarity about property rights and proper valuation of land, (2) labor market impacts and technical as well as economic viability of the projects, and (3) the ability to flexibly reallocate land in case an investment fails.

The establishment of donor-supported Community Land Funds in Mozambique makes Mozambique one of the few countries in SSA that has been publically proactive in responding to the recent rush for agricultural land. The program's participatory land delimitation and demarcation process aims to protect community-based land rights, facilitate community consultation with prospective investors, and obtain tenure security for investors. Tanzania, Ethiopia, and Ghana are other African countries to have recent reforms in the land governance sector to cope with the growing demand for land globally and identify land that can be allocated to investors.

Further research assessing land tenure policy as it relates to land certification and tenure security will be important as agricultural land constraints become more prevalent and countries continue to seek out agricultural investment opportunities. In addition, public access to land certification data and information, as well as clear guidelines that identify the varying responsibilities of institutions, is important for large-scale land acquisitions and foreign investment opportunities. However, recent research does suggest the need for improved transparency and greater local land user participation in domestic and international acquisitions. Some of the initiatives that can facilitate mutual understanding include but are not limited to well-defined compensation definitions including terms for transferring land, agreement on timing of land redistributions, clearly specified contractual obligations about employment of local people, and clear expectations as to the nature and quality of infrastructure provision. 


\section{Summary}

Although past land-titling programs in Africa were often unsuccessful, there is a renewed political commitment to improve the tenure security of individuals and communities given increasing pressure on land. The success of these land tenure reforms in enhancing tenure security hinges on the appreciation of the diversity and dynamic nature of existing agrarian structures and tenure systems, which ultimately rejects the one-size-fits-all policy prescriptions. These demand context-specific analyses and interventions that recognize the plurality of the forms of access to and control over land. In rural areas of Africa, land not only is a productive asset but also performs as a social safety net against consumption and production risks. Unless alternative mechanisms are available to insure households against such risks through the development of markets, ongoing efforts to improve land rights will not be sufficient to enhance smallholder investment and agricultural productivity in Africa. Increased demand for land in SSA by foreign investors has brought a sense of urgency to the question of how best to increase land tenure security in SSA. Public policy must assist local people in screening commercial investments in land by providing clarity about property rights and proper valuation of land as well as the economic viability of the projects. By the same token, clear and transparent policies vis-à-vis land rights should encourage productive foreign investment. 


\section{OPENNESS AND FOOD PRICE STABILIZATION9}

Since the early 1980 s, there has been a growing body of theoretical literature, simulation results, and empirical evidence that outward-oriented trade and development strategies involving liberalized trade and exchange rate regimes are associated with rapid economic growth (Dollar 1992; Sachs and Warner 1995; Frankel and Romer 1999; Rodrik 2008; Johnson, Ostry, and Subramanian 2010). Beginning with the Asian tigers (South Korea, Taiwan, Singapore, and Hong Kong) of the 1980s and 1990s, Indonesia, Malaysia, and Thailand, and followed by China after major liberalizations in the 1980s and early 1990s, East Asia's economies with outward-oriented policies expanded rapidly (Barro 1998). Likewise, following internal and external market reforms, India and Brazil ${ }^{10}$ experienced rapid growth in the 1990s and 2000s after years of only slow growth.

Countries in Africa south of the Sahara (SSA) have a more mixed record, however. In the 1960s and 1970s, many adopted an import-substitution development strategy favoring industry, often at the expense of agriculture. When the commodity boom of the 1970s and early 1980s ended, most countries were faced with major declines in export earnings that resulted in a serious balance of payment and fiscal deficits. Almost all SSA countries subsequently adopted structural adjustment policies (urged by the

Outward-oriented trade and development strategies involving liberalizing trade and exchange rate regimes are associated with rapid economic growth.
International Monetary Fund and World Bank) that focused on trade liberalization and fiscal policy (mainly cuts in spending). Several countries that liberalized their economies in the late 1980s and early 1990s, and then maintained these policies, such as Ghana, Uganda, Mozambique, and Ethiopia, have recently experienced rapid economic growth. However, structural adjustment often suffered from lack of country ownership due to resentment about the imposition of policies from outside, deeply unpopular cuts in subsidies, and a lack of effective safety nets to mitigate adverse effects on the poorest households. Moreover, the cuts in public investment implied a lower base of infrastructure for future economic growth.

Cross-country regressions by Rodrik (2008) indicate that a 50 percent real exchange rate undervaluation increases the annual growth rate of per capita GDP by 1.2 percentage points. Additional regressions provide lower-bound estimates that a 50 percent undervaluation would increase annual GDP per capita growth rate by 0.8 percentage points. Generally, this effect of real exchange rate overvaluation is larger for lower-income countries. Thus, for example, Ethiopia's elasticity of per capita real GDP growth with respect to real exchange rate overvaluation is -0.029 , and a 50 percent real exchange rate overvaluation implies a decline in per capita real GDP growth of 1.5 percentage points. ${ }^{11}$ Separate regressions show that the share of agriculture in GDP increases with real exchange rate overvaluation (or decreases as the real exchange rate depreciates), but this effect is smaller than the GDP growth effect, implying agricultural GDP growth also increases with real exchange rate depreciation. Christiaensen, Demery, and Kuhl (2011) present cross-country econometric analysis showing that agricultural growth is pro-poor (in fact, more pro-poor than nonagricultural growth). ${ }^{12}$

Looking explicitly at agricultural trade and price policy distortions, Anderson and Masters (2009) show that the nominal rates of assistance (NRA), a measure of the total price distortion induced by policy, ${ }^{13}$ fell sharply in absolute terms for many African countries. For example, in Ghana, the taxation on

\footnotetext{
${ }^{9}$ Written by Paul Dorosh, Athur Mabiso, and Mehrab Malek.

${ }^{10}$ Ferreira and Rossi (2003) show that Brazil's reduction in industrial protection (as measured by nominal tariff and effective rate of protection) in the 1980s through 1990s was associated with an estimated 6 percent increase in total factor productivity.

${ }^{11}$ This calculation is based on a coefficient measuring the effects of the level of per capita gross domestic product on the real exchange rate-growth relationship.

${ }^{12}$ See also Ravallion and Datt (2002), Bravo-Ortega and Lederman (2005), de Janvry and Sadoulet (2009), and Loayza and Raddatz (2010) on pro-poor agriculture.

${ }^{13}$ Note that trade restrictions remain among the most important government interventions in African agriculture. (Domestic taxes/subsidies on agricultural inputs/outputs constitute only a small share of total distortions to farmer incentives in Africa.)
} 
agricultural exportables was reduced from 76.3 percent in $1980-84$ to only 19.6 percent in $2000-04$ (a change in the NRA from -76.3 to -19.6). Similarly, in Mozambique taxation on agricultural exportables was reduced from -73.0 in 1980-84 to -3.9 in 2000-04. In spite of the substantial reduction relative to the 1980s, average rates of taxation on agricultural exports for the set of 16 countries were still high in the early 2000 s (24.6 percent), only slightly less than the level of the late 1960 s ( -30.1 percent). Even in 2000-04, the average burden of taxation on SSA farmers was $\$ 6$ billion or $\$ 41$ for each person working in agriculture (in constant 2000 dollars). This is in contrast to Asia and Latin America, where agricultural NRA and relative rates of assistance (RRAs) were almost zero by the early twenty-first century. Thus, in much of SSA, there remains substantial scope for further reduction in taxation of agricultural exportables.

Before taking a closer look at the evidence demonstrating the benefits of liberalized external trade related to food security, it is important to recognize the political economy behind governments' choice to intervene in the food market. Timmer (2011) argues that food price stability is not a "natural market outcome" but in fact a public good. Further, faced with a severe international price shock, governments' responses will be guided not only by economic analysis but also by political considerations (Timmer 2011).

In light of the sharp rise in international cereal prices in 2007 and 2008 and the rethinking on the part of many developing countries of policies regarding food prices, public-sector food stocks, and reliance on international trade, it is helpful to review the experiences of countries that have implemented price stabilization policies. Indeed there are good reasons why governments intervene in markets to prevent excess price spikes or price declines. These include protecting the welfare of the urban poor and of rural net buyers (by dampening price increases), enhancing incentives for domestic production and farmer incomes (by preventing large price falls), and promoting political and social stability (Timmer 2011).

The following framework (see Figure 5.1) provides a concise summary of competing visions of a government's role in regulating markets (Jayne and Tschirley 2009). In model 1, the role of the state is confined to providing public goods to strengthen markets. This vision relies on the private sector to carry out the main direct marketing functions and is close to the Washington Consensus, which is now generally out of favor. In model 2, the role of the state is expanded to include direct marketing operations based on the premise that markets do fail in certain circumstances and that direct, rules-based, nondiscretionary state operations are necessary to maintain good prices within reasonable bounds (typically defined by long-run import/export parity). Finally, model 3 is a vision in which discretionary state intervention provides the state with the flexibility needed to achieve state policy objectives. Most governments in eastern and southern Africa are characterized by this vision in that they adopt highly unpredictable and discretionary trade policies.

Although model 3 is the most common vision underlying the approaches of governments in food markets, the discretionary approach to food price policy creates risks for the private sector and hampers the private sector from performing the functions envisioned of it in models 1 and 2 . Transitioning from model 3 to model 2 is likely to promote market predictability and lead to greater supplies and price stability in food markets during times of domestic production shortfalls. The challenge in moving from policies motivated by model 3 to those consistent with model 2, however, is convincing people of the credibility of governments' commitments to rules-based policies given the long histories of discretionary state intervention in food markets. 
Figure 5.1-Competing visions of staple food market development

\begin{tabular}{|c|c|c|}
\hline Model 1 & Model 2 & Model 3 \\
\hline $\begin{array}{l}\text { Rely on markets with limited role } \\
\text { of state }\end{array}$ & $\begin{array}{l}\text { Primary reliance on markets with } \\
\text { rules-based role of state }\end{array}$ & $\begin{array}{l}\text { Role for markets with } \\
\text { discretionary state } \\
\text { intervention }\end{array}$ \\
\hline $\begin{array}{l}\text { - Role of state limited to } \\
\text { - } \quad \text { Public goods investment } \\
\text { - } \quad \text { Regulatory framework }\end{array}$ & $\begin{array}{l}\text { - Role for rules-based state } \\
\text { operations } \\
\text { - } \quad \text { Buffer stock release in } \\
\text { response to defend state } \\
\text { ceiling price }\end{array}$ & $\begin{array}{l}\text { Based on the premise } \\
\text { that the private sector } \\
\text { cannot ensure adequate } \\
\text { food supplies in response } \\
\text { to production shortfalls }\end{array}$ \\
\hline $\begin{array}{l}\text { - Strengthening of institutions } \\
\text { and property rights } \\
\text { - } \quad \begin{array}{l}\text { Policies supportive of } \\
\text { private-sector entry and } \\
\text { competition }\end{array}\end{array}$ & $\begin{array}{l}\text { Marketing board purchases at } \\
\text { statedfloor price announced } \\
\text { in advance }\end{array}$ & $\begin{array}{l}\text { Justification for } \\
\text { unconstrained role for } \\
\text { state intervention in } \\
\text { markets to correct for } \\
\text { market failures }\end{array}$ \\
\hline & Public goods investments & \\
\hline
\end{tabular}

Source: Jayne and Tschirley (2009).

Discretionary interventions in food markets, such as export restrictions, have been used following sharp fluctuations in international food prices, despite there being a large body of evidence that liberalized external trade promotes food security through stabilizing supplies and prices whereas export restrictions (used during the 2008 global price spikes and 2011 Horn of Africa drought) are ineffective and can be detrimental (Bouet and Laborde 2010; Martin and Anderson 2012; Anderson and Nelgen 2012).

A prime example of external trade promoting food security is the large inflow of more than two million tons of private-sector rice imports in Bangladesh that helped offset a reduction in rice production following the massive 1998 floods (del Nino and Dorosh 2001; Dorosh 2001). By removing import tariffs, limiting open market sales, giving instructions to expedite customs clearance of rice imports, and abstaining from the reimposition of antihoarding laws, government policy enabled the private sector to import rice from India. At the same time India had previously liberalized rice exports, allowing for significant imports from India to take place at profitable prices for the private sector. In contrast, uncertainty regarding government policy on the volume of public-sector imports and the official sales price eliminated incentives for private-sector rice imports in Madagascar in 2005, leading to a surge in domestic rice prices and a major rice price crisis (Coady, Dorosh, and Minten 2008). Similarly, in Zambia in the early 2000s, the government's plans for its own commercial imports of maize (which ultimately were not carried out) discouraged private-sector imports and resulted in halved total supply, which led to domestic prices that were more than 20 percent greater than import parity levels (Dorosh, Dradri, and Haggblade 2010; Thurlow and Wobst 2005).

In general export restrictions such as bans create distortions and reduce incentives for domestic production (Anderson and Nelgen 2012), leading to additional marketing costs and lower farm incomes, thus reducing incentives for domestic production. Moreover, export bans are often ineffective at preventing exports from countries with weakly enforceable borders, as is the case in most SSA countries (Govereh, Chapoto, and Jayne 2010; Guthiga et al. 2011). Instead, they increase marketing (transaction) costs for both formal and informal cross-border traders and encourage corruption in the value chain. For example, data from recent field visits to the Tanzania-Kenya and Tanzania-Zambia borders (Diao, Kennedy et al. 2012; Stryker and Amin forthcoming) show that maize exports hardly stopped after Tanzania imposed a maize export ban in 2011. Traders found alternative routes to transport smaller quantities across the border, and truckers on the other side of the border consolidated the smaller quantities to transport them to major city markets. Guthiga et al. (2011) find qualitative evidence that 
nearby Kenyan smallholders benefit from this increased informal border trade by diversifying out of maize production and into cash crops. At the same time large-scale transporters continued their business as usual by paying bribes as well as using illegal brokers with counterfeit export permits (Tanzania Exporters Association 2012). Using the Tanzania computable general equilibrium model, Diao, Kennedy et al. 2012 show that, even when the ban can effectively control maize outflows, it can only marginally contribute to the control of price inflation, as consumer food prices can be lowered by less than one-half of 1 percent and overall consumer prices by even less (Diao, Kennedy et al. 2012). In the meantime, the ban cannot protect the poor, of whom many are rural households. The general equilibrium outcome, by considering the possible effect of the export ban on rural households as producers and consumers, often goes against the intuitive assumption. The real income for the poor rural household group actually falls because the export ban lowers wages for low-skilled labor and reduces returns to farmland, which more than offsets gains from lower purchased food prices. The poor in maize surplus regions suffer more, and the incomes of households in the lowest quintile declines by 1.0-1.5 percent per year (Diao, Kennedy et al. 2012).

Rubey (2004) and Jayne, Zulu, and Nijhoff (2006) provide additional evidence on the distortionary effects of trade restrictions in Malawi; after a shortfall in maize production, the grain trading parastatal, Agricultural Development and Marketing Corporation (Malawi) (ADMARC) announced a fixed price for maize and its intention to import maize from South Africa to defend this price. Because ADMARC's selling price was considerably lower than the landed cost of importing maize, private traders had little incentive to import maize. However, the government imports arrived late and were not sufficient to meet demand. As a result, ADMARC depots began experiencing stock-outs, and prices soared. When it became clear that ADMARC's supplies were insufficient, private traders scrambled to import, but for several months much of rural Malawi experienced grain shortages, and prices were reportedly as high as $\$ 500$ per ton in early 2002 (compared to the world maize price, which was about \$93 per ton in May 2002 and would translate to an upper-bound estimated import parity price of $\$ 210$ per ton).

The episodic and unpredictable nature of government trade restrictions in SSA, for example, ad hoc export bans and import duties, can create risk and uncertainty in markets, which exacerbates food insecurity and increases transaction costs. Discretionary import duties charged on regional cereal imports have been a common and unpredictable intervention by governments in SSA (Nijhoff et al. 2002). Uncertainty about when and whether an import tariff will be waived during a poor crop season usually leads to a temporary underprovision of imports, which then causes shortages where local prices exceed import parity levels for periods of time (Nijhoff et al. 2003). For example, in December 2001 rumors that the Zambian government and millers were making financial arrangements to import maize and sell at below-market price led to many private importers' refraining from imports. However, government imports were delayed due to financing problems, and by the end of May 2002 only 130,000 tons had been imported, yet traders had exited the market, and maize shortages and high prices prevailed.

As recently ascertained in Tanzania (Stryker and Amin forthcoming) maize traders account for the risk of exporting during a ban by raising their prices and often face confiscation of their goods, which pressures them to engage in bribes as well as increase their selling prices while lowering their farmgate buying price. Thus, farmers end up receiving lower farmgate prices - a reduction in the incentive for farmers to grow maize in the following season (Diao et al. forthcoming). Stryker and Amin (forthcoming) also show that even when the export ban is officially lifted, the nontariff barriers persist, for example, the need for an export permit in Tanzania as well as roadblocks that often encourage bribes along the trading routes have persisted despite the official lifting of the 2011 maize export ban. In addition, local taxes (cess) charged by local governments on any grains moving from their areas of production add to the transaction costs that farmers and traders face (Temu, Manyama, and Temu 2010). These grain taxes are officially supposed to be up to 5 percent of the value of traded grain but are reported to often exceed this level, thus seriously restricting trade across regions within Tanzania and regional trade across borders. Karugia et al. (2009) show that taxes on traded maize constitute a major component of the nontariff barriers, which on average cost traders an additional $\$ 0.09, \$ 0.15$, and $\$ 0.11$ per kilometer per ton of maize in Kenya, Uganda, and Tanzania, respectively. 
Evidence on the effects of removing trade restrictions shows that there can be considerable gains, although sometimes at a cost, as was the case with cashew nut exports in Mozambique (McMillan, Rodrik, and Welch 2002). Direct benefits from reducing restrictions on raw cashew nut exports were on the order of $\$ 6.6$ million annually or about 0.14 percent of Mozambique's GDP. However, these benefits were largely offset by the associated costs of cashew factories that closed, leading to increased unemployment in urban areas. The net gain to farmers was estimated to be no more than $\$ 5.3$ million, or $\$ 5.30$ per year for the average household growing cashews.

On the role of free regional trade and its potential to accelerate growth and reduce poverty, Nin Pratt, Diao, and Bahta (2009) demonstrate that increased regional trade that could result from a free trade area in the Southern African Development Community would have a positive but small impact on agricultural growth. Total value of trade creation would amount to only US\$177 million, which is about

Policies that promote open trade have substantial potential to accelerate growth, reduce poverty, and enhance food security in SSA.
1.1 percent of total agricultural trade in the Southern African Development Community region. Most advantages would accrue to lower-income countries (Malawi, Mauritius, Tanzania, and Zimbabwe), whereas Angola and the Democratic Republic of the Congo would be negatively affected. Low productivity and poor road infrastructure are argued to be the major constraints to the potential gains of open regional trade. This shows that although opening up trade can be beneficial, there may be costs and

bottlenecks that need to be addressed to fully benefit from open trade.

Finally, Haggblade et al. (2008) simulate the impact of increased regional trade in food staples in east and southern Africa under various scenarios (for example, in the context of a drought) and show that open trade would lower consumer maize prices in urban centers and increase the returns to maize farmers. This is a result of lower cross-border marketing costs associated with shorter distances between crosscountry surplus and deficit areas compared to distances between in-country surplus and deficit areas. For example, Haggblade et al. (2008) calculate that without trade restrictions it would be cheaper to ship maize produced in northern Mozambique to Malawi and Zambia than shipping it to Maputo. In a scenario wherein Malawi imports 100,000 tons more than normal, the maize price would increase, resulting in a 5.3 percent increase in returns to farmers in northern Mozambique. Although the study does not assess distributional impacts on net sellers versus net buyers in northern and central Mozambique, the study does show that deficit areas of southern Mozambique would also benefit from open regional trade as the costs of importing maize from South Africa would be lower, resulting in lower than baseline consumer food prices in Maputo.

\section{Summary}

Policies that promote open trade have substantial potential to accelerate growth, reduce poverty, and enhance food security in SSA. Sharp fluctuations in international prices have driven many governments to intervene in food markets and restrict trade in an attempt to stabilize food prices and maintain food security. For policy recommendations to be effective, it is important to recognize that these interventions are governed not only by economic analysis but also by political dynamics (Timmer 2011; Naylor and Falcon 2010). Governments should be encouraged to stabilize domestic prices through adopting rulesbased policies (model 2; Jayne and Tschirley 2009) and gradually shifting away from discretionary state interventions.

Nonetheless, governments still have substantial room to open trade through their exchange rate policies and the removal of trade restrictions as well as create a stable policy environment that does not encourage corruption or create risks and uncertainty. Implementing such policies would have to be tempered and complemented by other policies and investments (such as investments in R\&D, roads and irrigation infrastructure, and value chain development) that address bottlenecks to the potential gains to trade. Trade policies alone may not necessarily be transformational but are an important component to increase smallholder incomes and address food shortages and price volatility. 


\section{AGRICULTURE, FOOD POLICY, AND NUTRITION14}

Policy research evaluating the impacts of agricultural and food policies on nutrition outcomes is in its infancy, and currently there is little available in the literature. In this section we outline some of the key pathways between agricultural development, food policy and nutrition, and what existing research has to say about the effectiveness of interventions along these pathways. We focus on six interlinked pathways:

1. Income growth and food price reduction: Generic agricultural investments that increase agricultural productivity and marketable output will increase farm income and rural employment and could also stimulate lower food prices, thus benefiting urban people and other net food consumers. Higher incomes can reduce malnutrition through improved food or nutrition-relevant nonfood expenditures.

2. Agricultural technologies: Pronutrition agricultural technologies include biofortified crops, drought-resistant crops, irrigation schemes that reduce volatility in nutrient supply, and technologies that save labor (especially female labor) or agrochemical usage.

3. Value chain innovations: Processing of foods offers a good opportunity to add nutrients to commonly consumed food products and condiments (fortification), such as the iodization of salt. Also, since many micronutrient-rich foods are perishable (for example, milk, vegetables, fruits, fish), innovations and investments that improve market coordination, product quality, storage, and processing can have significant nutritional benefits.

4. Direct access to quality food: Food-specific extension strategies can promote production and local marketing of foods rich in essential proteins and micronutrients, such as fish, meat, vegetables, and fruits. Examples include initiatives to promote home, school, and community gardens and small-scale livestock husbandry and aquaculture.

5. Influencing the allocation of household resources: Both technological and system-oriented investments change agricultural production patterns and influence the profitability of particular production activities and hence the allocation of household labor. Particularly important are gender aspects such as maternal activities and control of household resources.

6. Synergies with other sectors: Nutritional outcomes are the results of complex interactions between diets, health factors, and care practices. In an operational sense this could mean that there are important synergies between agricultural/food policies and various health, education, nutrition, and infrastructure interventions. Social safety nets could also play a role in improving nutrition by providing access to nutritious food directly or supplementing incomes to prevent consumption shocks.

The importance of each pathway is context specific; policies and comprehensive investments that use the synergies of these pathways might be most beneficial given the multidimensionality of the malnutrition problem. Moreover, there are many nonagricultural investments that might have important synergies with agricultural interventions. Hence the remainder of this section is structured around the six channels above, with some brief mention of synergistic nonagricultural interventions to conclude.

\section{Income Growth and Food Price Reduction}

Agricultural growth, by increasing farm income and lowering food prices, is widely thought to be propoor in most circumstances, and there is abundant empirical evidence in support of that (Chen and Ravallion 2007; Christiaensen, Demery, and Kuhl 2011; Datt and Ravallion 1998; de Janvry and Sadoulet 2010; Thirtle, Lin, and Piesse 2003). A recent cross-country study tested the relative impacts of agricultural and nonagricultural growth on stunting and underweight prevalence and found evidence that agricultural growth has a much larger impact on stunting prevalence than nonagricultural growth (Headey

\footnotetext{
${ }^{14}$ Written by Derek Headey, Olivier Ecker, and Adam Kennedy. This section is partly based on Ecker, Mabiso, et al. (2011).
} 
2011). At the same time, there are circumstances in which agricultural growth can have only a limited impact on nutrition, for example, if household income is not spent on better food or is spent on foods not appropriate for young children, if intrahousehold inequalities limit the consumption benefits that mothers and children receive, or if poor health and sanitation outcomes limit intake and absorption of nutrients (Ahmed 1993; Olack et al. 2011; UNICEF 1990). So although generic agricultural growth might be pronutrition on average, there are clearly many ways to increase the nutritional impact of agricultural growth programs.

\section{Agricultural Technologies}

The majority of research on nutrition-specific agricultural technologies is centered on biofortification. The rationale for biofortification is that the poor often lack (economic) access to the kind of high-value foods that are richer in micronutrients and protein and that farmers are unable or unwilling to partly replace staple food production with horticulture on their land (Meenakshi et al. 2010). The regular consumption of staple foods enriched with key micronutrients such as iron, zinc, and vitamin A can considerably reduce the shortage of these micronutrients in staple-dominated diets. The recent success of the HarvestPlus Challenge Program of the Consultative Group for International Agricultural Research provides convincing evidence that biofortification can be an important strategy to reduce micronutrient malnutrition on a large scale, and several recent studies (for example, Stein et al. 2005, 2007; Low et al. 2007; Jaarsveld et al. 2005) have revealed a high effectiveness of biofortification programs.

In addition to effectiveness, Meenakshi et al. (2010) postulate that biofortification can be a highly cost-effective tool for combating micronutrient deficiencies in the developing world at large, although the impact may significantly differ by crop, micronutrient, and country. Table 6.1 shows the percentage reduction in the disability-adjusted life years (DALY) ${ }^{15}$ burden of micronutrient deficiencies through the dissemination of different biofortified staple crops with different micronutrients under both a pessimistic and an optimistic scenario. ${ }^{16}$ In addition, they calculate the costs per DALY averted of investing in the $\mathrm{R} \& \mathrm{D}$, adaptive breeding, maintenance breeding, and dissemination of biofortified staples in each of these scenarios. Considering the benchmark costs of a highly cost-effective intervention as \$196 per DALY saved in 2004 dollars at today's value (Meenakshi et al. 2010), biofortification of all main staple foods is highly cost-effective. For the dissemination of iron- and zinc-dense rice and wheat, Behrman, Alderman, and Hoddinott (2004) gave a general range of the benefits-costs ratio of about 12:1 to 19:1 and for the dissemination of vitamin A-dense rice (Golden Rice) of about 9:1 to 19:1. These are comparable to the fortification and nutrient supplement approaches discussed further below.

There is little systematic analysis of the nutritional benefits of other agricultural technologies (homestead gardening is considered separately below), such as drought-resistant crops or irrigation. Droughts, of course, are strongly associated with acute malnutrition outcomes in many parts of the world, such as the Sahel and the Horn of Africa, so reductions in acute malnutrition (for example, wasting) are an expected outcome of such interventions. Likewise there is little evidence of the nutritional benefits of irrigation. A recent IFPRI study by Bhagowalia, Headey, and Kadiyala (2012) found that irrigation greatly increased the diversity of crops produced on small and marginal farms in India. Irrigation can also have negative side effects, however, by increasing the local prevalence of malaria. In general, although there seems to be significant potential for other agricultural technologies to improve nutrition, much more analysis is needed to quantify their costs and benefits.

\footnotetext{
${ }^{15}$ Disability-adjusted life years for a disease or health condition are calculated as the sum of the years of life lost due to premature mortality in the population and the years lost due to disability for incident cases of the health condition. Hence they are advantageous in combining both mortality and morbidity into a single summary indicator.

${ }^{16}$ The pessimistic scenario assumes that the coverage rates of adoption are half those of the optimistic scenario, due to lower customer acceptance and the quality of seed systems. Likewise, micronutrient content of biofortified staples can vary; thus, under the pessimistic scenario, biofortified foods produce less of the micronutrient. In addition, the variation in the effectiveness of different crops at reducing the burden of a particular micronutrient deficiency results from different food processing (drying, milling, and so on) and preparation methods, which can be associated with large nutrient losses before human consumption; therefore, under a pessimistic scenario, these losses are 20-50 percent higher than under the optimistic assumptions.
} 
Table 6.1-Benefits and costs of biofortifying staple crops by nutrient under pessimistic and optimistic scenarios in disability-adjusted life years (DALY)

\begin{tabular}{lcccc}
\hline & \multicolumn{2}{c}{ Percentage Reduction in DALY Lost } & \multicolumn{2}{c}{ Costs (US\$) per DALY Saved } \\
\cline { 2 - 5 } & Pessimistic & Optimistic & Pessimistic & Optimistic \\
\hline Vitamin A & & & & \\
Cassava & $3-4$ & $19-32$ & $124-1,006$ & $8-27$ \\
Maize & $1-8$ & $17-32$ & $113-289$ & $11-18$ \\
Sweet potato & 38 & 64 & 30 & 9 \\
Iron & & & & \\
Beans & $4-9$ & $16-36$ & $134-439$ & $20-66$ \\
Rice & $4-8$ & $11-21$ & $17-234$ & $3-55$ \\
Wheat & $6-7$ & $28-39$ & $10-13$ & $1-3$ \\
Zinc & & & & \\
Beans & $3-5$ & $15-20$ & $1,494-5,940$ & $153-576$ \\
Rice & $13-20$ & $33-56$ & $7-55$ & $2-12$ \\
Wheat & $5-9$ & $33-48$ & $11-18$ & $1-2$ \\
\hline
\end{tabular}

Source: Adopted from Meenakshi et al. (2010).

\section{Value Chain Interventions: Fortification, Transport, Storage, and Marketing}

In many countries, fortification has been established as a standard food-based strategy for directly delivering micronutrients added to commonly consumed foods and condiments - the vehicles - to a large share of consumers, most successfully with salt iodization. The advantages and drawbacks of food fortification have been discussed in several studies (for example, Allen et al. 2006; Fiedler, Sanghvi, and Saunders 2008; Dary and Mora 2002). The main advantages include the cost-effectiveness of the intervention and its neutrality toward consumption patterns and program participation, whereas the requirements of centralized processing and adequate market-based supply channels limit the potential of fortification to reduce micronutrient deficiencies in rural, subsistence-dominated systems.

Fortification costs are generally low and mainly concentrated on initial investments. Baltussen, Knai, and Sharan (2004) found that in the African context, the costs of iron fortification are as low as US\$27 per DALY saved to provide access to fortified foods to 50 percent of the target population (considering a 10-year time horizon). Fiedler and Macdonald (2009) examined the cost-effectiveness of fortification programs in 48 countries. Assuming a 30 percent reduction in the micronutrient deficiencies of the persons consuming the fortified product and accounting for consumption patterns and various accumulating costs of producing and sustainably establishing fortified products, Fiedler and Macdonald (2009) estimated substantial cost-effectiveness of wheat flour and vegetable oil but more mixed results for maize and sugar. Horton (2006) and Horton and Ross (2003) estimated the benefits-costs ratio for fortifying staple foods with iron at 8:1 in general, whereas Horton et al. (2010) find the ratio to be 9.1:1 to fortify wheat flour with iron.

However, overenthusiasm for fortification (and biofortification discussed above) must be tempered. First, the pathways by which micronutrients affect child development and growth are poorly understood, and controlled trials have had mixed results (Schroeder 2008). Second, disaggregating the impacts of fortificants and vehicles by which they are delivered presents complex challenges. For instance, separating the impact of nutrients contained within wheat from the iron with which it is fortified is difficult. Others have mistakenly drawn conclusions about the impact of calcium on growth delivered through milk while failing to take into account the many other nutrients contained within milk such as zinc and vitamin A. Calcium supplements alone have shown less conclusive results on growth (Schroeder 2008). 
The nutritional implications of other value chain investments are scarcely analyzed. Hawkes and Ruel (2011) provide a conceptual discussion of the potential for value chain approaches and then review the handful of research pieces on the topic, several of which are biofortification approaches. However, there are some strong reasons to believe that value chain interventions could sometimes have significant nutritional impact. For example, many micronutrient-rich foods are highly perishable (vegetables, fruits, dairy, eggs, and meat to some extent), such that market access to these foods is limited without improvements along the value chain: reducing postharvest losses, improving transport networks and storage systems, and linking farmers to wholesale and retail markets. Consistent with this conjecture, a striking stylized fact from household surveys is that dietary diversity greatly increases with market access (that is, town size or travel times to towns and cities). But although there have been some notable value chain success stories in recent decades (for example, India's White Revolution in dairy development), scarcely any of these have assessed the nutritional consequences of successes.

\section{Food-Specific Farm-Level Interventions (Such as Homestead Gardening)}

Many farming households in the developing world primarily consume foods that they produce. Interventions that increase food production quantity and the diversity of the production therefore have the potential to directly influence the nutritional status of the farm household members. Although many interventions aimed at enhancing dietary diversity through food production diversification, such as smallscale horticulture or livestock-based approaches, have shown positive effects on consumers' diets, evidence quantifying the nutritional impact of such interventions is still limited. Moreover, most of these kinds of interventions include strong components on nutrition education (and in some cases other assets), so it is often difficult to know the extent to which agricultural interventions as opposed to educational components improve nutrition. ${ }^{17}$

For instance, a review by Ruel (2001) found that home gardening programs increased the intake of vitamin A- and iron-rich vegetables among the children of beneficiary households, but significant improvements in their nutritional status (measured by anthropometric indicators) could not be detected due to the insufficient scientific rigor of the available, analyzed studies. Nonetheless, Ruel (2001) showed that projects combining agricultural interventions with nutrition education components were more successful in improving diets than were agricultural interventions alone. Berti, Krasevec, and FitzGerald (2004) also conducted a systematic review of 25 interventions on home gardening, livestock, mixed garden and livestock, cash cropping, and irrigation about the effects on nutrition indicators such as anthropometrics, biochemical and clinical indicators, and morbidity. Most interventions increased food production output but did not necessarily improve the nutritional status of the members of the participating households as measured by anthropometric or biochemical indicators. Of all 25 projects, 19 had a positive effect on dietary intake indicators, and improved nutrient intake was improved in 11 of 13 home gardening projects. Leroy and Frongillo (2007) reviewed 14 studies of animal-sourced food interventions that also generally reported a positive effect on dietary intake, but only four studies evaluated the impact on nutritional status. Among the four there were some observed improvements in micronutrient intake (although not always sizeable or significant), but only one study demonstrated improvement in child growth. Similar to Ruel's (2001) review, Leroy and Frongillo (2007) found that the interventions that had a clear positive effect on diets and nutrition were limited to those that had a nutrition education component or in which women played a key role.

\footnotetext{
${ }^{17}$ An important part in the search for effective interventions is the identification of the factors constraining nutrition improvement. These factors are context specific, and their relevance tends to change with income levels. For example, preliminary results from ongoing International Food Policy Research Institute studies in Ghana (Alpuerto, Diao, and Ecker n.d.) and Cambodia (Ecker et al., n.d.) suggest that the direct access to nutritious food (through home gardens and aquaculture, respectively) and the diversity of consumed diets matter for nutrition outcomes among the poor more than among the rich, ceteris paribus.
} 
Despite the apparent benefits of linking food-specific farm-level interventions with complementary investments in nutritional education and other assets, few studies have assessed the costeffectiveness of dietary diversification interventions. A well-known, long-term program focusing on homestead food production in Bangladesh - established by Helen Keller International in 1988 - provides strong evidence that home gardening and livestock holding sustainably improve beneficiaries' access to vitamin- and mineral-rich vegetables and livestock products, including eggs and meat (Bushamuka et al. 2005; Iannotti, Cunningham, and Ruel 2009; see Table 6.2). What is less well established is whether homestead food production programs are as effective at increasing micronutrient intake as fortification and supplementation programs, given the relatively low concentration of these nutrients in the foods being produced. However, homestead food production does show signs of being highly sustainable given the high degrees of persistence in these activities once the programs terminate.

\section{Table 6.2 - Select impacts of homestead food production programs in Bangladesh}

\begin{tabular}{|c|c|}
\hline Impact Category & Example of Impact \\
\hline \multicolumn{2}{|l|}{ Production } \\
\hline$\overline{\text { More home gardens }}$ & Yearround gardening increased from 3 to 33 percent \\
\hline Increased varieties of foods & Vegetable varieties increased more than twofold \\
\hline Increased quantities of foods & $\begin{array}{l}135 \text { kilograms instead of } 46 \text { kilograms of vegetables in } \\
\text { three months }\end{array}$ \\
\hline \multicolumn{2}{|l|}{ Consumption } \\
\hline $\begin{array}{l}\text { Increased consumption of homegrown vitamin A-rich } \\
\text { foods }\end{array}$ & Egg consumption increased by 48 percentage points \\
\hline Increased expenditures on noncereal foods & Lentils and animal products bought with income earned \\
\hline \multicolumn{2}{|l|}{ Economic status } \\
\hline Employment opportunities & More than 60,000 rural jobs \\
\hline \multicolumn{2}{|l|}{ Women's status } \\
\hline$\overline{\text { Garden management }}$ & 73 percent of gardens managed by women \\
\hline Income decisionmakers & 90 percent of target households represented by women \\
\hline
\end{tabular}

Source: Iannotti, Cunningham, and Ruel (2009).

The program also contributed to strengthening women's status in the household through greater control of income generated by the intervention. Still, in more than 20 years of existence and expansion throughout south and southeast Asia, the cost-effectiveness of programming costs for this intervention have not been reviewed (Iannotti, Cunningham, and Ruel 2009).

\section{Influencing the Allocation of Household Resources}

There is relatively little research on how agricultural interventions influence nutrition outcomes via the allocation of household time and resources. There is a substantive literature on intrahousehold inequality, which is not insubstantial in many countries (Haddad, Hoddinott, and Alderman 1996), as well as gender inequality (Haddad et al. 2003). However, there is little specific analysis of agricultural dimensions of these problems. A recent paper by Headey, Chiu, and Kadiyala (2012) does look at the Indian situation, where there has been substantive research on intrahousehold issues. Headey, Chiu, and Kadiyala (2012) reach three conclusions:

1. Women work much longer hours in agriculture than do men, often to the detriment of their health, nutrition, and child care practices.

2. Women working in agriculture have poorer nutrition outcomes than women working in other occupational categories, except nonfarm manual labor.

3. Women working in agriculture are likely to take less effective care of their children, although the effect is only marginal relative to other occupations. 
These findings imply some adverse effects of female employment in agriculture on maternal and child nutrition, but there is not yet much evidence of a large effect. Moreover, location in rural areas has a larger effect on nutrition outcomes than employment in agriculture, suggesting many nutrition problems are broader rural problems (education, health, infrastructure, poverty) rather than pure agricultural problems.

To what extent these findings carry over into other contexts is not yet known. However, one interesting finding from Iannotti, Cunningham, and Ruel's (2009) review of homestead gardening is that it often seems to increase female workload relative to control groups (by 58-78 percent on average). It is not yet possible to quantify the full economic and nutritional cost of such a sizeable increase in workload, but it does suggest that agricultural interventions need to be mindful of the potentially negative side effects of agriculture-for-nutrition interventions.

\section{Synergies with Other Sectors}

Traditionally, most nutrition interventions have been nutrition specific, that is, interventions directly targeting nutrition via nutrition (food or vitamin/mineral supplements, nutrition education and monitoring), health (for example, vaccinations), or care-based interventions (for example, breast-feeding). In many ways these interventions are quite effective. Nutrient supplement programs, for example, are generally highly cost-effective in reducing micronutrient deficiencies, although sustainability is still a major concern. ${ }^{18}$ It is also widely recognized by nutritionists that various nutrition-sensitive interventions are essential to sustainably address malnutrition problems. Nutrient deficiencies are partly due to poor diets but are also caused by major infectious diseases (for example, schistosomiasis, malaria) — known as secondary malnutrition (as opposed to dietary nutrient deficiencies, which are referred to as primary malnutrition) (Mayer 1976). Hence disease treatment and vaccinations, access to health services, and improved drinking water, sanitation, and general hygiene all contribute to the linear growth of children and to reduced malnutrition (Scrimshaw et al. 1968; Black et al. 2008).

Another complex problem with nutrition is that the determinants of undernutrition and malnutrition are often poorly understood and that micronutrient deficiencies often go unobserved. Hence, informing and educating people - especially adolescent girls and women about breast-feeding and appropriate complementary feeding of young children, for example - can significantly contribute to a reduction in child undernutrition (Horton et al. 2010). We observe that many agriculture-for-nutrition interventions have sizeable nutritional education components that almost certainly contribute to the efficacy of agricultural interventions. For example, analyzing community health and nutrition programs from several countries, Mason et al. (2006) found that among the different factors of child growth considered, targeted nutrition education is particularly effective at changing child feeding and care practices and ensuring long-term behavioral change. ${ }^{19}$ In general, preventive nutrition education instituted as early as possible in children's lives is more effective than a recuperative approach that targets those already assessed to be malnourished (Ruel et al. 2008; Alderman 2007).

\footnotetext{
${ }^{18}$ For example, the effectiveness of iron supplements to reduce anemia in pregnant mothers was shown by Sloan, Jordan, and Winikoff (1992) as well as by Beaton and McCabe (1999). Baltussen, Knai, and Sharan (2004) estimated the costs at US\$66-115 per disability-adjusted life years saved, and Behrman, Alderman, and Hoddinott (2004) reported a benefits-costs ratio of 6:1 to $14: 1$ for treatment of pregnant women and 176:1 to 200:1 per capita in population-wide programs. Rajkumar, Gaukler, and Tilahun (2012) found the benefits-costs ratio to be 8.1:1 for iron supplementation for pregnant mothers and 23.8:1 for iron supplements for mothers and children 6 to 24 months old.

${ }^{19}$ For a community nutrition program in Zimbabwe in the 1980s, Mason et al. (2006) attributed a decline in child stunting within six years by 1.1 percentage points per year to a supplementary feeding intervention in concert with nutrition education, child monitoring, and programs for increasing farm income. Likewise, in a similar program in Tanzania's Iringa region, the prevalence of children underweight dropped from 50 percent in 1984 to 35 percent in 1988 - or a decrease of about 3.8 percentage points per year - thanks to growth monitoring combined with education campaigns and supplementary feeding at the community level.
} 
The importance of parental education — especially of mothers' education —in reducing child undernutrition has been demonstrated in many studies (for example, Christiaensen and Alderman 2004; Semba et al. 2008; Smith et al. 2004; Smith and Haddad 2000) and tends to show large marginal effects in almost any location. However, for the most part only secondary female education has a substantial effect in reducing malnutrition, suggesting that primary school education is basically ineffectual. The precise channel of impact, however, is not very clear. Education might simply raise awareness of health and nutrition problems and improve access to and absorption of information and health services. Another channel of impact is that female education is strongly associated with changes in fertility (Schultz 1997; Headey 2011): later age of marriage, fewer children, and more birth spacing. All three of these factors are quite substantively associated with improved nutrition outcomes. This would also suggest that familyplanning interventions (broadly defined) could substantively affect nutrition outcomes. This could include female empowerment, access to health services, and family-planning counseling.

The benefits-costs ratio for breast-feeding promotion programs in hospitals ranges from 6 to 67; for integrated child care programs including a nutrition component, it ranges from 9 to 16, depending on the program's design (Behrman, Alderman, and Hoddinott 2004). There is also positive evidence about complementary feeding practices (for example, Penny et al. 2005; Santos et al. 2001; Guldan et al. 2000). However, there is less agreement that community-based nutrition-education programs can reduce child undernutrition effectively (Bhutta et al. 2008). The cost-effectiveness of the main service offered (that is, nutrition education) is generally quite high - estimated at US\$53 to US\$153 per DALY saved (Ho 1985; Waters et al. 2006, cited in Horton et al. 2010). The ability of a large-scale program to deliver counseling effectively is also controversial (Linnemayr and Alderman 2011). Moreover, there is scarcely any evidence about how agricultural interventions can be linked to nutritional training at scale.

It is somewhat less clear what impact various types of infrastructure have on nutrition outcomes. This is partly related to poor measurement of improved water and sanitation facilities, but another issue is the public-good nature of the problem. Similarly, infrastructure improvements such as roads and electricity might only have fairly indirect or marginal impacts on nutrition (Headey 2011).

Finally, social safety net interventions, such as conditional cash/food transfer programs and school feeding programs, both of which are increasingly popular in the developing world, can potentially bolster the consumption of higher-quality foods or lessen consumption shocks, thus limiting adverse nutrition impacts. However, the evidence that school feeding programs have been effective is mixed depending on the program, micronutrient content of the food, and measure of cognitive development used (Adelman, Gilligan, and Lehrer 2008), although a review of a number of conditional cash transfer programs in Latin America found quite robust evidence of improved anthropometric outcomes but limited improvement in micronutrient intakes (Leroy, Ruel, and Verhofstadt 2009.) In less developed settings (for example, Ethiopia), however, there is not yet any evidence that safety net programs have had any significant impact on nutrition outcomes, although they were not necessarily designed to do so. ${ }^{20}$

\section{Summary and Conclusions}

Any assessment of potential agriculture-for-nutrition investments needs the following caveat: The evidence on many types of agriculture-for-nutrition investments is limited. Hence in the conclusions drawn in Table 6.3 below, we add information about the quality of evidence. This would suggest the need for more pilot programs and research in those types of interventions where the evidence base is weak.

\footnotetext{
${ }^{20}$ Based on a personal communication with researchers on the Productive Safety Net Programme, John Hoddinott and Alemayehu Seyoum Taffesse.
} 
Table 6.3-Some tentative conclusions about agriculture-for-nutrition policies

\begin{tabular}{|c|c|c|}
\hline Area of Intervention & Conclusions & Quality of Evidence \\
\hline $\begin{array}{l}\text { Income growth and food } \\
\text { price reduction }\end{array}$ & $\begin{array}{l}\text { Agricultural growth generally reduces poverty and malnutrition and } \\
\text { does so more effectively than growth in industry sectors. }\end{array}$ & Poor/moderate \\
\hline $\begin{array}{l}\text { Agricultural technologies: } \\
\text { biofortification }\end{array}$ & $\begin{array}{l}\text { Generally has high to very high returns. There may be challenges } \\
\text { with increasing the popularity of new varieties with visible traits. } \\
\text { Behavior change communication is necessary to improve } \\
\text { acceptability for both producers and consumers. }\end{array}$ & Moderate \\
\hline $\begin{array}{l}\text { Agricultural technologies: } \\
\text { other }\end{array}$ & $\begin{array}{l}\text { Limited evidence on drought-resistant varieties, irrigation, and } \\
\text { other technologies. Irrigation appears to improve dietary diversity. }\end{array}$ & Poor \\
\hline $\begin{array}{l}\text { Value chain innovations: } \\
\text { fortification }\end{array}$ & $\begin{array}{l}\text { Generally has high to very high returns. Cannot address all causes } \\
\text { of malnutrition, however. }\end{array}$ & Good \\
\hline $\begin{array}{l}\text { Value chain innovations: } \\
\text { other }\end{array}$ & $\begin{array}{l}\text { Little evidence of other value chain interventions improving nutrition } \\
\text { because of limited data. In principle, interventions that improve } \\
\text { access to micronutrient-rich foods should improve nutrition. }\end{array}$ & Poor \\
\hline $\begin{array}{l}\text { Homestead food } \\
\text { production }\end{array}$ & $\begin{array}{l}\text { Substantial evidence that they can improve diets, but moderate } \\
\text { evidence that they improve nutritional outcomes. Appear to be } \\
\text { many non-nutrition benefits of income and female empowerment. } \\
\text { Concerns about low nutrient density of homestead gardening } \\
\text { products relative to supplements and fortification and also about } \\
\text { the impact on women's time use and child care. }\end{array}$ & Moderate \\
\hline $\begin{array}{l}\text { Influencing the allocation } \\
\text { of household resources }\end{array}$ & $\begin{array}{l}\text { Little evidence, although women often work more in agriculture } \\
\text { than men. Agriculture-for-nutrition interventions should follow a do- } \\
\text { no-harm principle by not placing extra burdens on women. }\end{array}$ & Poor \\
\hline Linking with other sectors & $\begin{array}{l}\text { Nutritional knowledge and general female education seem to be } \\
\text { critical complements to agriculture-for-nutrition interventions. There } \\
\text { is little evidence on how to achieve this at scale. School feeding } \\
\text { programs rarely show much impact on nutritional outcomes, but } \\
\text { conditional cash transfer programs in Latin America have improved } \\
\text { nutrition outcomes. }\end{array}$ & Poor \\
\hline
\end{tabular}

Source: Author's compilation.

It is also important that policymakers recognize that undernutrition is not only a result of the poor performance of the public health or agriculture sectors (Benson 2011). Combating undernutrition requires infrastructure investments such as water and sanitation, which are essential for disease prevention. Likewise, given the strong evidence that female education is associated with reduced malnutrition and that nutrition education strongly complements interventions in homestead food production and biofortification, contributions from the education sector are important. With this, politicians must recognize undernutrition as a cross-cutting development challenge and not as a health problem. Doing this can lead to more effective multisectoral responses (Mwadime 2011).

Those countries that have been most effective at integrating nutrition and food policy have done so through multisectoral coordination. For instance, Tanzania, which has made significant progress in reducing malnutrition in the past five years, has established the Multi-institutional/Multi-sectoral High Level Nutrition Steering Committee composed of public, private, civil society, and development partners (DPs) and chaired by the permanent secretary in the Prime Minister's Office (Save the Children 2012). However, in many countries there are substantial institutional and operational barriers that prevent coordinated planning across sectors. Resource allocation and human resource management are such examples. Many of these barriers are a consequence of bureaucratic organization that allows government to fulfill duties within a sector. Working across sectors therefore is a challenge and requires new structures, incentives, and accountability mechanisms (Benson 2011; Fan, Pandya-Lorch, and Fritschel 2011). 


\section{INSTITUTIONAL ARCHITECTURE FOR IMPROVED POLICY FORMULATION ${ }^{21}$}

The Comprehensive African Agriculture Development Programme (CAADP) is an Africa-led and -owned agenda that has created a strong platform for policy and partnership renewal in the agricultural sector. Its goal is to raise investments in the sector and improve agricultural policy and strategy design and implementation as well as achievement of higher growth, poverty reduction, and food and nutrition security. CAADP is an unprecedented, comprehensive effort to rally governments and other stakeholders around a set of key values and principles; create partnership mechanisms at the continental, regional, and country levels; promote evidence-based and outcome-driven policy design and implementation; and establish inclusive dialogue and review processes to increase the effectiveness of the development process and attainment of desired results across African countries. It embodies the New Partnership for Africa's Development (NEPAD) principles of mutual accountability, country ownership, inclusiveness, benchmarking, peer review, and mutual learning.

In particular, the CAADP agenda asks African governments to adopt policies and programs and raise investments to achieve an annual growth rate of 6 percent and the 2003 Maputo Declaration budget share target of 10 percent for the agricultural sector. For most African countries, achieving the above targets will require significant increases in agricultural expenditures and a much greater efficiency in planning and executing investments in the agricultural sector. Moreover, ensuring that the growth and budget targets are met requires that policies and programs be well planned, growth and poverty-reduction outcomes better tracked and evaluated, lessons drawn, and best practices documented and disseminated.

The CAADP implementation agenda also embodies key elements of managing for development results (MfDR), namely, (1) setting goals and agreeing on targets and strategies, (2) allocating resources to activities that will contribute to the achievement of desired results, (3) monitoring and evaluating to see if resources are leading to desired results, (4) reporting on performance, and (5) using information to inform and improve decisionmaking. In essence, MfDR focuses on the achievement of desired results at all stages of the development process (Organization for Economic Cooperation and Development 2008).

MfDR helps to improve transparency, accountability, and effectiveness of development efforts. Therefore, a key aspect of MfDR is whether there is a transparent results-oriented reporting and performance assessment framework. The CAADP monitoring and evaluation (M\&E) framework allows for performance assessment by providing key indicators that link inputs, outputs, and outcomes to help assess CAADP implementation progress toward desired results and to improve policymaking processes and thus achievement of results. The framework feeds into CAADP review and dialogue processes at the country, regional, and continental levels. Moreover, a CAADP mutual accountability framework has been developed to help promote conversion of agriculture-sector commitments, by both African governments and DPs, to actual disbursements and tangible actions. At the continental level, the CAADP Partnership Platform (PP) provides a mechanism for African governments, DPs, and other stakeholders to hold each other accountable for delivering on their commitments and the CAADP agenda in general.

\section{Key Elements of Transparent, Inclusive, Evidence-based Policy Formulation}

Improved sector policy and accountability require broad-based participation in policy planning and implementation processes that are guided by locally based research. Three critical areas are discussed below using examples from CAADP to illustrate how this has been done on the ground. The three areas are (1) locally owned and led policy formulation processes, (2) inclusive dialogue and review mechanisms, and (3) readily accessible platforms for data, tools, and analysis.

\footnotetext{
${ }^{21}$ Written by Ousmane Badiane and Tsitsi Makombe.
} 


\section{(1) Locally Owned and Led Policy Formulation Processes}

The ratification of CAADP in 2003 by African heads of state and governments signified their commitment to taking charge and ownership of Africa's agricultural development agenda. Unlike previous development efforts that were frequently externally driven, CAADP is a fundamentally homegrown agenda and therefore has the advantage of facilitating broad-based acceptance and increasing the likelihood of better alignment of various development efforts with local priorities and concerns. Right from the onset, NEPAD and the African Union Commission assigned actual field-level implementation of CAADP to individual countries to ensure their empowerment and ownership of the process. The CAADP agenda promotes inclusiveness of all major stakeholder groups to facilitate participation in planning and implementation processes and decisionmaking. Although it is not perfect, no other development effort on the continent has invested heavily in creating a wide understanding and support of its goals and action agenda.

The CAADP implementation agenda has allowed countries to foster local ownership, leadership, and inclusive participation of various stakeholders at different stages. In particular, African countries have demonstrated strong ownership and leadership of the CAADP implementation agenda as evidenced by the high level and active participation of Ministries of Agriculture and Finance in the CAADP roundtable process. Involvement of the Finance Ministry in particular is important given the ministry's influence in budget negotiation and allocation processes and will be critical in helping to monitor the 10 percent budget target for the agriculture sector. CAADP compacts, which signify joint commitment to support a shared vision for a country's agriculture sector, have to date been signed in 30 countries by representatives from key stakeholder groups such as Ministries of Agriculture, Finance, and Economic Planning; the African Union and NEPAD; regional economic communities (RECs); DPs; civil society; farmers' associations; and the private sector. Compact signing is important not only for getting political buy-in from all stakeholders but also for setting a firm foundation for enhancing public-private partnerships needed to help raise the necessary investments to implement and sustain the compact. In Rwanda, the first country to adopt the CAADP process, the country's Finance and Economic Planning Ministry was actively involved in planning the roundtable held in 2007. And the ministry has remained engaged in the CAADP process; Rwanda's Plan for the Strategic Transformation of Agriculture is a joint initiative of the Ministries of Agriculture and Finance, and representatives of the two ministries and other stakeholders meet monthly to review its progress (NEPAD 2011b).

As part of the CAADP implementation agenda, Ghana led the development of its agricultural policy framework, Food and Agriculture Development Policy II, and the accompanying Medium Term Agriculture Sector Investment Plan (METASIP) 2011-2015 through a consultative process that engaged various stakeholders. For example, according to the Ministry of Food and Agriculture (MOFA) (Ghana MOFA 2010), METASIP was "developed using a largely participatory process" involving key stakeholders from MOFA; other relevant ministries, departments, and agencies (MDAs); DPs; nongovernmental organizations; academia; civil society; farmers' groups; and the private sector. In addition, NEPAD (2011a) noted that the review of Ghana's Food and Agriculture Sector Development Policy II had generated significant stakeholder engagement and helped to promote broad-based privatesector participation, which led to the creation of a private-sector liaison office within MOFA. Broadbased participation has increasingly become an important part of Ghana's policy and planning processes. For example, in its guidelines for preparing sector medium-term plans, Ghana's National Development Planning Commission (NDPC) strongly recommends having sector-planning teams that include the lead ministry, other relevant MDAs, the private sector, and civil society (National Development Planning Commission 2006).

At the regional level, the establishment of the leadership and ownership by RECs of the CAADP agenda is indicated by the formal endorsement of CAADP by, and its regular featuring in meetings of, the Common Market for Eastern and Southern Africa agricultural ministers. The Common Market for Eastern and Southern Africa, under the active leadership of its secretary general, successfully launched the country-level implementation of CAADP among its member countries in 2007, with the establishment of 
coordination teams and focal points in the first group of countries to adopt the process, namely, Uganda, Zambia, Malawi, Kenya, and Rwanda. In West Africa, the Economic Community of West African States (ECOWAS), after launching the implementation in the first group of eight countries (Benin, Burkina Faso, Ghana, Niger, Nigeria, Mali, Senegal, and Togo), established a Special Task Force under the leadership of its commissioner for agriculture and, from 2007 to 2008, increased its agricultural budget from US\$2 million to US\$22 million to support CAADP planning and implementation processes as well as the preparation of the regional CAADP Compact. Furthermore, ECOWAS has effectively broadened the ownership and leadership of the CAADP agenda by bringing on board all other subregional organizations, to which specific tasks in the preparation of the regional compact were assigned. In 2009, ECOWAS became the first REC to hold a regional CAADP roundtable and sign a regional compact.

Country ownership is also one of the Paris Declaration principles of aid effectiveness. As part of the principle, within agricultural and rural development, leading donors have committed themselves to supporting government leadership and ownership based on inclusive processes, promoting effective participation of key stakeholders, and to developing the capacity of their institutions to participate effectively in the design, delivery, and monitoring of agricultural strategies. For example, the United States Agency for International Development AfricaLead project is providing leadership training to CAADP stakeholders from the public, civil society, universities, and private-sector institutions to effectively participate in and help lead CAADP processes in their countries.

Country ownership and leadership have often been challenged by multiple ministerial portfolios involved in agriculture and rural development, high dependency on aid, lack of capacity in some key ministries, and the emergence of nontraditional donors such as Brazil, Russia, India, and China, which do not operate under the aid effectiveness agenda (Global Donor Platform for Rural Development 2011). Nonetheless, countries are already taking steps to address some of these challenges. For example, in Ghana, MOFA plans to address weak interagency coordination by developing and implementing an interministerial communications strategy, introducing biannual joint planning and review meetings to ensure alignment of plans and budgets, and training sector MDAs in budgeting and allocation of resources to ensure an effective implementation of METASIP (Ghana MOFA 2010). In addition, Ghana's Aid Policy Framework for 2011-15 is expected to deal with challenges brought on by nontraditional donors as it provides guidelines for aid management and coordination in the country to help ensure aid effectiveness and attainment of growth and poverty-reduction goals (Ghana Ministry of Finance and Economic Planning 2010).

\section{(2) Inclusive Dialogue and Review Mechanisms}

Inclusive policy dialogue, review, and learning must be backed by evidence at every stage of the development process. The CAADP Mutual Accountability Framework notes key elements of a mutual assessment process to include having a shared agenda and objectives, information to assess performance on mutually agreed targets and indicators, and a review of and discussion about progress toward targets (Oruko et al. 2011). A number of dialogue and review platforms have been established to support CAADP partnerships and mutual accountability among African governments, their constituencies, and DPs. At the continental level, the CAADP PP meetings provide an ideal mechanism for DPs, governments, and other stakeholders to hold each other accountable for delivering on the CAADP agenda. In particular, the platform brings together major multilateral and bilateral donors; international, regional, and national partners working on agricultural development; RECs representatives; and the private sector including farmers' organizations. It reviews progress on the various CAADP components, assesses agriculture-sector trends and performance toward achieving desired CAADP goals, and deliberates on necessary improvements for accelerating the process and meeting stated goals. The annual CAADP Africa Forum is another dialogue platform that gives farmers an opportunity to engage in agricultural policy discussions. During the 2010 Africa Forum, regional farmers' organizations led discussions about smallholder strategies for increasing growth and food security (NEPAD 2011c). 
In several African countries, policy dialogue, review, and mutual accountability mechanisms within the agriculture sector include (1) the Agriculture Sector Working Group, which provides a dialogue platform for the Ministry of Agriculture and DPs, as well as other nonstate actors, to assess sector performance; (2) Joint Sector Reviews, which are aimed at enhancing sector coordination and alignment through joint annual reviews of agriculture-sector performance and budgets operations and are usually cochaired by the ministry of agriculture and a DP representative; and (3) agriculture-sector public expenditure reviews, which are aimed at assessing where funds are being allocated, how funding decisions are made, and how effectively and efficiently funds are being spent as well as identifying principal beneficiaries of the funds. In Ghana, the Agriculture Sector Working Group dialogue takes place through (1) the country's Multi-Donor Budget Support discussions coordinated by the Ministry of Finance and Economic Planning, following consultations at the sector level; (2) monthly meetings of the DP's Agriculture Sector Group cochaired by a DP representative and MOFA; and (3) three thematic subgroups that are also jointly chaired by MOFA and DPs (Ghana MOFA 2010). In Rwanda, the annual Joint Sector Reviews meeting brings together the Ministries of Agriculture and Finance and Economic Planning, donors, and other stakeholders to review agriculture-sector performance and coordination of efforts (NEPAD 2011b).

In addition, at the country level, Strategic Analysis and Knowledge Support Systems (SAKSS) nodes are being established to improve the quality of policy and strategy design and implementation through facilitation of well-informed agricultural-sector planning, review, and dialogue processes. The nodes will incorporate broad and inclusive representation of stakeholder groups, use effective M\&E procedures to ensure high-quality reporting on performance and progress, and link to the continental and regional-level dialogue and review processes to facilitate cooperation, benchmarking, and mutual learning. At the launch of METASIP in July 2011, the government of Ghana also launched a SAKSS node-which will follow up on issues that arose during the country's CAADP roundtable and help to generate knowledge and information to fill knowledge gaps, timely disseminate policy-relevant knowledge, and strengthen local institutional and human capacities in support of the formulation and implementation of METASIP. The node, which is not yet operational, will be part of a country-led team that was proposed by MOFA to help oversee implementation and management of METASIP (Ghana MOFA 2010). In Rwanda, a SAKSS node launched in May 2010 has been providing knowledge and tools to help inform implementation of Rwanda's Plan for the Strategic Transformation of Agriculture as well as related policy dialogue and review processes.

To date, SAKSS nodes have also been established in Nigeria and Uganda; however, they still need strengthening to become fully operational. IFPRI and Regional Strategic Analysis and Knowledge Support System (ReSAKSS) are currently rolling out plans to establish, operate, or strengthen country SAKSS nodes in 11 countries, namely, Benin, Cameroon, the Democratic Republic of the Congo, Kenya, Mali, Senegal, Uganda, Ethiopia, Ghana, Rwanda, and Mozambique. ReSAKSS, a major element of the review and dialogue architecture of CAADP, publishes annual Agricultural Trends and Outlook Reports (ATORs), which serve as a basis for review of CAADP progress at the country, regional, and continental levels. Each year, the report is submitted to the CAADP PP. In addition, once operational, country SAKSS nodes are expected to also produce a country ATOR that feeds into the regional- and continentallevel reports to inform the respective review, dialogue, and mutual accountability processes.

\section{(3) Readily Accessible Platforms for Data, Tools, and Analysis}

\section{Regional and Country Knowledge Systems to Inform and Guide CAADP Implementation}

Ensuring the successful implementation of CAADP requires that the implementation, review, and dialogue processes are well informed and supported through credible and timely data, tools, and knowledge. This in turn calls for human capacities as well as analytical and communication tools for collecting, analyzing, and generating the necessary quality knowledge products to feed into CAADP processes. 
To this end, ReSAKSSs were established in 2005 in west, southern, east and central Africa, and as discussed earlier, more country-level SAKSSs are being established. ReSAKSS and SAKSS will provide policy-relevant analysis, data, and tools for improving policymaking, filling knowledge gaps, promoting dialogue, and facilitating the benchmarking and review processes associated with the CAADP agenda. Moreover, the knowledge and tools are aimed at facilitating (1) efficient and consistent planning and execution of sector policies and programs, (2) effective translation of government expenditures into public goods and services at adequate levels, and (3) appropriate mechanisms to regularly and transparently measure progress in achieving CAADP goals including meeting a 6 percent agricultural growth rate and allocating 10 percent of the national budget to the agricultural sector. Typically, a country SAKSS node will follow up on issues that arise during the CAADP roundtable and help to generate knowledge and information to fill knowledge gaps, timely disseminate policy-relevant knowledge, and strengthen local institutional and human capacities in support of the formulation and implementation of a country's agriculture investment plan. In most countries, potential SAKSS partners will come from universities; research centers; policy analysis units; statistical offices; civil society; the private sector; nongovernmental organizations; key government ministries of agriculture, finance, and economic planning; and other think tanks. In line with the CAADP agenda, country SAKSS nodes will be set up based on existing institutional realities so as to add value to ongoing country efforts.

MfDR helps to improve transparency, accountability, and effectiveness of development efforts. Therefore, a key aspect of MfDR is whether there is a transparent M\&E framework to review progress against agricultural development objectives and assess the impacts and returns to CAADP investments. The CAADP M\&E framework, developed by ReSAKSS, provides key indicators that link inputs, outputs, and outcomes to help assess CAADP implementation progress toward desired results and to improve policymaking processes and thus achievement of results. The framework feeds into CAADP review and dialogue processes at the country, regional, and continental levels. In 2007, ReSAKSS launched a website (resakss.org) to help track CAADP implementation and progress toward key CAADP targets, including allocating 10 percent of annual budgets to agriculture, achieving a 6 percent annual agricultural growth rate, and achieving the first millennium development goal (MDG1) of halving poverty and hunger by 2015. The website, together with the flagship ATOR, which also serves as the continental CAADP M\&E report, have become integral elements of the CAADP implementation agenda.

\section{CAADP Roundtable Analysis to Support Decisionmaking Processes}

One of the many innovations of the CAADP process is its broad use of high-quality, locally based analysis to guide and inform the decisionmaking process - not just planning and implementation, but also review and dialogue by stakeholders around program priorities and outcomes. This approach is unprecedented in the majority of African countries. An early impact of its adoption has been the increased credibility of the agricultural agenda within national governments. This has enabled ministries of agriculture to present high-quality strategy documents to their peers in government, articulate their agendas more transparently, and justify requests for increased funding by linking them to clear goals and outcomes.

An important part of the roundtable analysis and planning work carried out by the technical teams in individual countries has consisted of reviewing past, current, and emerging country agricultural and rural development efforts. Country analysis has been carried out or facilitated by a team of researchers at IFPRI, working in collaboration with a number of country- and regional-level experts. The analysis has included the following:

1. Conducting a stocktaking exercise by reviewing past and ongoing agricultural development efforts in a country

2. Examining the recent growth performance of the agricultural sector as well as future growth and poverty outcomes based on observed trends

3. Determining how such outcomes compare to the targets established for the agricultural sector under the CAADP agenda and how they compare to the MDG1 target of halving poverty 
4. Measuring the prospects of meeting these targets and analyzing the implications for future sector growth and poverty-reduction strategies

5. Estimating the long-term funding needs to accelerate agricultural growth and achieve the poverty MDG target

6. Examining the potential sources of future growth and poverty reduction not only at the level of agriculture versus nonagriculture but also among various agricultural subsectors

The majority of the 30 countries that have signed CAADP compacts also have conducted stocktaking exercises and assessments of agricultural growth and poverty-reduction options and long-term investment requirements to meet the CAADP 6 percent growth and 10 percent budget targets as well as the MDG1 poverty target. The stocktaking exercises and growth and poverty-reduction option studies have helped to set the context for agricultural development, harmonization, and alignment for the CAADP agenda. The analyses raised important issues for discussion and thus helped to focus the discussion on these key issues during the roundtable meetings.

\section{Elaboration of Agriculture Investment Plans and Postcompact Technical Reviews}

Following the country CAADP roundtable and compact signing is the elaboration of a national agricultural investment plan (NAIP). This process is led by governments, working in close collaboration with relevant CAADP stakeholders. A NAIP details agriculture-sector objectives and targets, strategies, and costed programs and investment areas for achieving the stipulated targets and objectives. A key role of a country SAKSS is to support the development and implementation of NAIP by providing timely and relevant analyses and data in the formulation of investment programs. The goal is to have quality investment plans that are guided by sound research and realistic and measurable targets. Specific tasks of the country SAKSS include (1) reviewing any existing sector strategies and investment plans and helping to align them with long-term growth and poverty-reduction targets endorsed in the compact, (2) collecting data and providing analyses to support formulation or revision of investment plans, and (3) developing and integrating an M\&E framework and indicators into the investment plan, building on the CAADP $M \& E$ framework and any existing country M\&E frameworks.

After their elaboration, NAIPs undergo an independent postcompact technical review to help ensure that objectives and targets laid out in the plans are specific, measurable, and realistic, further lending to evidence-based and well-informed decisionmaking. Specifically, the postcompact review evaluates the following: (1) the consistency of investment programs with growth and poverty-reduction prospects set out in the roundtable analysis, (2) adoption of best practices articulated through the CAADP pillar framework documents, (3) technical realism (alignment with resources with results) and adequacy of institutional arrangements, and (4) alignment on core CAADP principles, vision, and values (NEPAD 2010). Findings from technical reviews are documented and used by countries to revise and improve investment plans. For example, according to the Ghana CAADP Technical Review report (NEPAD 2010), METASIP needed to be improved on by adding a detailed breakdown of incremental costs based on unit costs, covering both on-budget and off-budget financing sources, and both core-sector and relatedsector budgets as well as traditional and nontraditional donors.

After undergoing a technical review, a country moves to the next major milestone in the postcompact phase, the hosting of a high-level business meeting at which plans are validated by the government, private sector, DPs, and other key stakeholders and financing mechanisms and timelines are put in place. African governments have made commitments to raise their agricultural investments in support of investment plans. Notably, according to Rwanda-Ministry of Finance and Economic Planning (2011), the proportion of public spending devoted to agriculture rose from 3 percent in 2006 to 6.8 percent in 2010-11 following the country's business meeting in 2009. The proportion has been projected to exceed 10 percent by 2011-12 (Ministry of Agriculture and Animal Resources 2011). 


\section{Potential Benefits from Improved Agriculture-sector Policy and Accountability}

Besides improving planning and implementation of sector policies and strategies, increasing funding for the agricultural sector is a major CAADP goal. Conscious of the need to reverse the trends of declining investment in the sector, countries have committed to allocate at least 10 percent of government budgets to the agriculture sector. As shown in Figures 7.1 and 7.2, since the Maputo Declaration in 2003, the number of countries that have achieved the budget expenditure target has grown steadily. When comparing averages of agriculture budget shares, whereas only 3 countries met the target in 1995-2003, the number rose to 7 in 2003-10. Moreover, more than 10 countries had budget shares exceeding 5 percent but falling short of the 10 percent target during 2003-10. Therefore, it appears from the trends depicted in Figure 7.2 that many of the reporting countries have not yet responded to the call to allocate 10 percent of their budgets to agriculture, despite many countries' making steady progress toward the target.

Figure 7.1-Progress toward achieving the Comprehensive Africa Agriculture Development Programme 10 percent budget target (annual average 1995-2003)

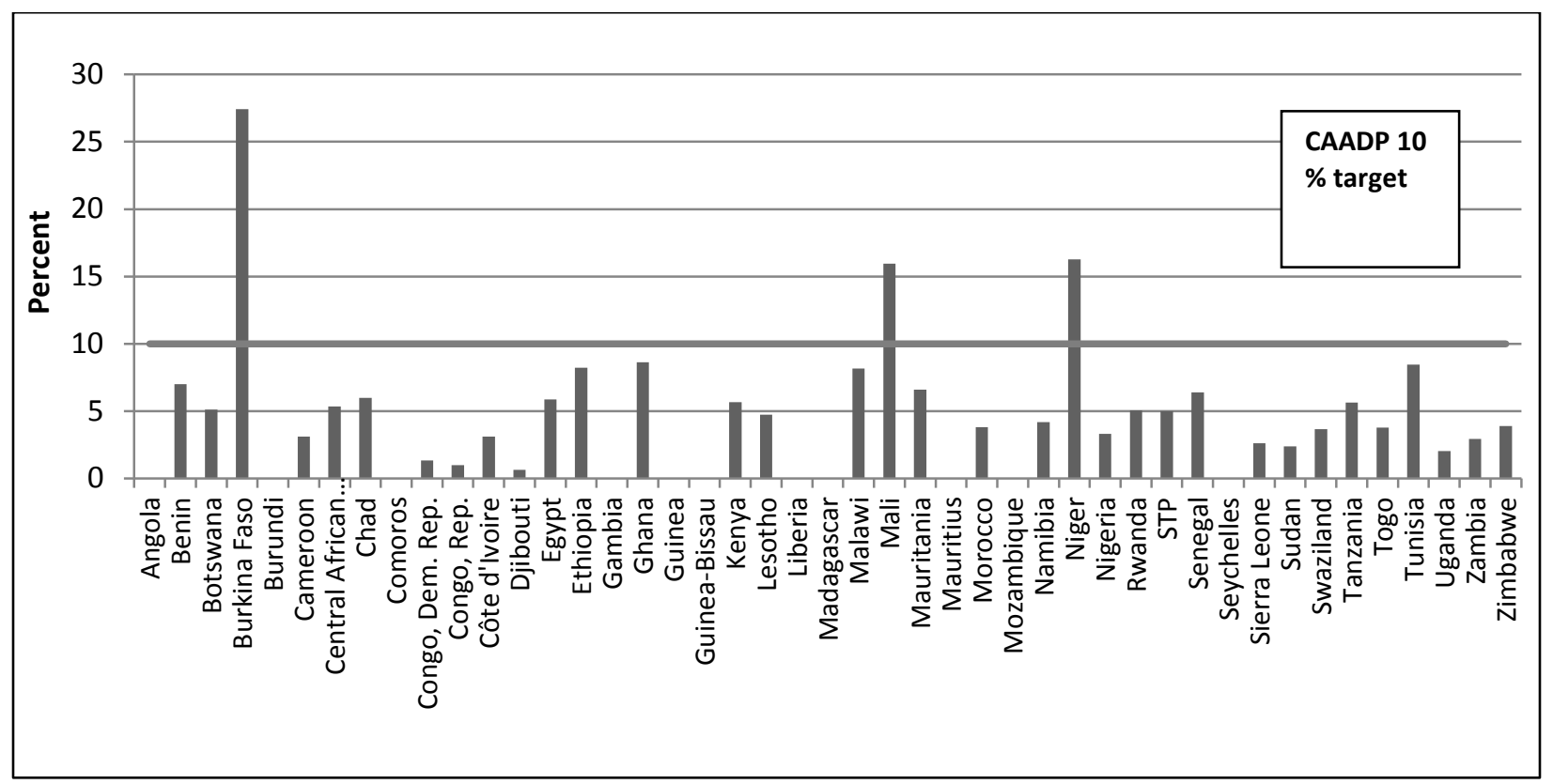

Source: Benin (2012).

Note: Central African $=$ Central African Republic, Congo, Dem. $=$ Democratic Republic of the Congo; Congo, Rep. $=$ Republic of the Congo; STP = São Tomé and Príncipe. 
Figure 7.2-Progress toward achieving the Comprehensive Africa Agriculture Development Programme 10 percent budget target (annual average 2003-10)

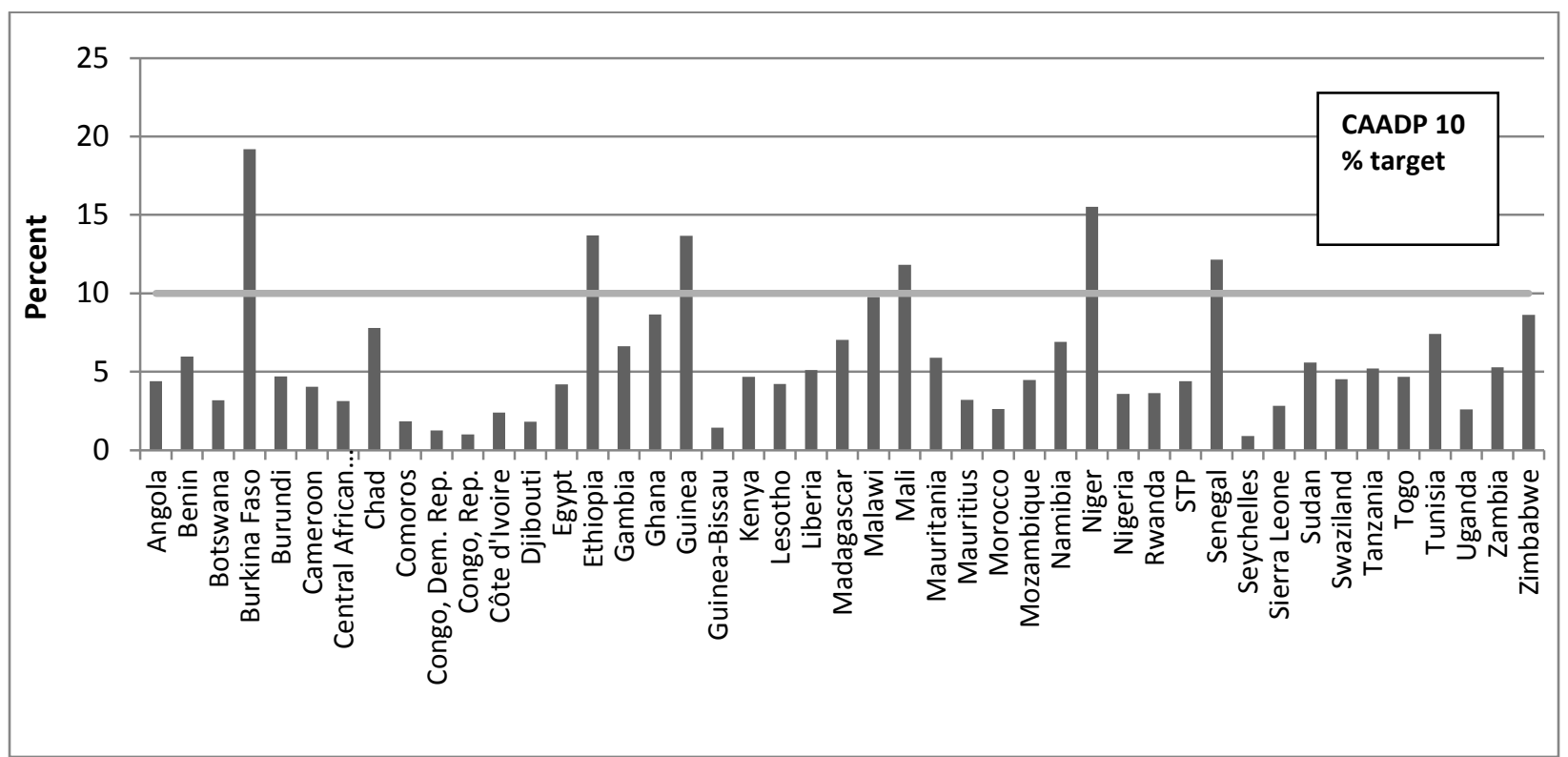

Source: Benin (2012).

Note: Central African... = Central African Republic, Congo, Dem.Rep. = Democratic Republic of the Congo; Congo, Rep. $=$ Republic of the Congo; STP = São Tomé and Príncipe

The extent of the funding required to meet the CAADP 6 percent growth target as well as the target of halving poverty by 2015 is shown by Figure 7.3. The top and bottom lines show the initial level of poverty in 1990 and the final rate of poverty by 2015, assuming the countries realize the MDG poverty target. The dark grey bars show the rate of poverty that would prevail by 2015 should the countries achieve the target growth rate of 6 percent. For most countries in the sample, poverty rates in these cases are still greater than the MDG target, meaning that they would have to grow by more than the CAADP target of 6 percent to achieve the MDG target of reducing poverty by 50 percent. The bars in light grey show the annual rate of increase of sector funding that is required to realize the CAADP growth target. It is around 20 percent for most countries. Clearly, maintaining such a high rate of expansion of agricultural expenditure is beyond the means of most countries. 
Figure 7.3-Funding requirement of meeting the Comprehensive Africa Agriculture Development Programme growth and millennium development goal poverty targets

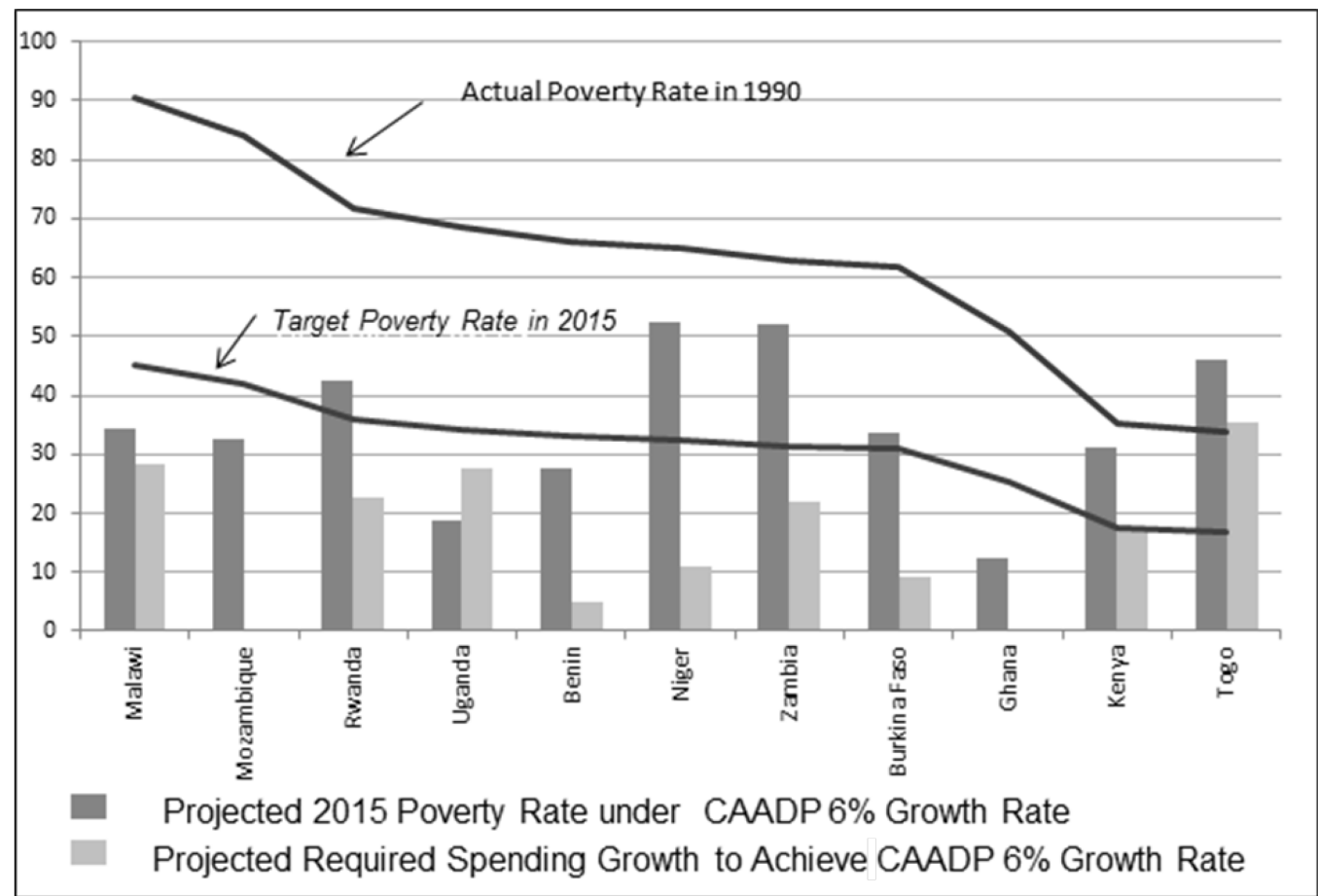

Source: Simulation of poverty and spending levels by the IFPRI CAADP team. Baseline poverty rates and MDG targets are based on World Bank's PovcalNet 2008, except for Malawi, Mozambique, Rwanda, and Togo, where diverging national baseline data are used.

Note: $\quad$ CAADP $=$ Comprehensive Africa Agriculture Development Programme.

For many countries achieving the CAADP targets will require an increase in not only the level of agricultural spending but also its efficiency. It is expected that more inclusive, evidence-based policy planning and implementation processes should lead to better development outcomes and thus greater policy and investment efficiency. One of the indicators of improved sector policy and accountability is whether expenditures and programs in the agricultural sector are achieving the desired development outcomes. In particular, the quality of planning and execution of sector policies and improvement in the institutional environment should allow countries to realize targeted outcomes, say a specific level of sectoral growth, more quickly while holding public expenditures at the 10 percent criterion. Accordingly, the elasticity of agricultural-sector growth for public expenditures for agriculture, or the extent to which a given change in public expenditure translates into a change in agricultural-sector growth, can be used as a proxy for effective agriculture-sector policy. Although it is true that differences in resource endowments and other determinants of the growth process affect the realizable growth potential, the ultimate goal of government policy is to efficiently allocate available resources and tackle obstacles to generate growth. Hence, the more successful government policies are in overcoming these obstacles, the more likely they are to help public-sector investments translate directly into higher growth rates and leverage privatesector investment for even faster growth.

Table 7.1 shows the estimated expenditure elasticities of agricultural growth across selected west African countries, as well as the simulated levels of public expenditure that are required to achieve the CAADP agricultural-sector growth rate of 6 percent, and the rate of growth required to achieved the MDG target of reducing poverty by 50 percent by 2015 . Two policy effectiveness scenarios are presented in the table. The first, the low-elasticity scenario, shows estimated annual public expenditure levels based on an estimated elasticity for individual countries. The high elasticity scenario is based on the average elasticity for Africa as a whole, which was used at the time of the analysis for CAADP country 
roundtables. The differences in required levels of public expenditure reflect the potential savings that individual countries could realize annually by adopting better policies that are aligned with the average African country's policy effectiveness. Alternatively, by improving policies, the same level of funding would generate growth rates ranging between 7 and 9 percent (last column), thus exceeding the CAADP target growth rate by $20-50$ percent, although this is still lower than the required rates to achieve MDG1 (first column).

Table 7.1-Policy effectiveness, funding requirements, and achievable growth and povertyreduction outcomes

\begin{tabular}{|c|c|c|c|c|c|}
\hline \multirow{2}{*}{ Countries } & \multirow{2}{*}{$\begin{array}{l}\text { Required Rate } \\
\text { of Agricultural } \\
\text { Growth to } \\
\text { Achieve } \\
\text { Millennium } \\
\text { Development } \\
\text { Goal } 1 \text { under } \\
\text { Current Trends }\end{array}$} & \multirow{2}{*}{$\begin{array}{l}\text { Estimated } \\
\text { Country } \\
\text { Expenditure } \\
\text { Elasticity of } \\
\text { Growth }^{\mathrm{a}}\end{array}$} & $\begin{array}{c}\text { Average Annual } \\
\text { Expenditure to } \\
\text { Achieve } 6 \% \\
\text { Growth }^{\mathrm{b}}\end{array}$ & $\begin{array}{c}\text { Average Annual } \\
\text { Expenditure to } \\
\text { Achieve } 6 \% \\
\text { Growth }^{\mathbf{b}}\end{array}$ & \multirow{2}{*}{$\begin{array}{c}\text { Achievable } \\
\text { Rate of } \\
\text { Agricultural } \\
\text { Growth } \\
\text { under High } \\
\text { Elasticity } \\
\text { Scenario }^{\mathrm{e}}\end{array}$} \\
\hline & & & $\begin{array}{c}\text { (Low Elasticity } \\
\text { Scenarioc) }\end{array}$ & $\begin{array}{l}\text { (High Elasticity } \\
\text { Scenario }^{d} \text { ) }\end{array}$ & \\
\hline Benin & 13.1 & 0.26 & 35.5 & 31.9 & 6.8 \\
\hline Burkina Faso & 7.1 & 0.24 & 90.3 & 68.0 & 7.1 \\
\hline Cape Verde & NA & 0.11 & 0.6 & 0.4 & 8.8 \\
\hline Gambia & 14.4 & 0.15 & 75.2 & 23.7 & 15.1 \\
\hline Guinea & 10.3 & 0.25 & 311.0 & 213.5 & 8.6 \\
\hline Cote d'Ivoire & 14.8 & 0.25 & 73.7 & 57.1 & 8.4 \\
\hline Liberia & 26.1 & 0.22 & 15.0 & 9.9 & 9.9 \\
\hline Mali & 12.5 & 0.25 & 198.7 & 160.8 & 6.9 \\
\hline
\end{tabular}

Source: Country CAADP Brochures No. 4: Republic of Benin. 2009. Republic of Burkina Faso. 2010. Republic of Cape Verde 2009. Republic of the Gambia. 2009 Republic of Guinea. 2010 Republic of Liberia. 2009. Republic of Mali. 2009.

Notes: $\mathrm{NA}=$ not applicable, since Cape Verde has already achieved the poverty millennium development goal.

a. Elasticity of agricultural-sector growth for public expenditure in the sector.

b. Billions of local currency, except for Liberia, where expenditures are in millions of US dollars; annual averages are for the period 2009-15, except for Cote d'Ivoire (2011-15).

c. Based on estimated country elasticity.

d. Based on average elasticity value of 0.366 for Africa.

e. The elasticity of 0.366 was used. Later estimations have yielded an elasticity value of 0.31 (see Diao, Dorosh et al. 2010).

For the CAADP target of a 6 percent rate of agricultural growth, most countries would achieve public expenditure savings of 20 percent or more if they realized a degree of policy effectiveness that is in line with the African average, as measured by the expenditure elasticity of agricultural growth. For Guinea, Liberia, and Cape Verde, the savings would amount to at least 30 percent of simulated public expenditures. Savings would reach more than 60 percent in Gambia. Similarly, countries would also realize large public expenditure savings from having more effective agricultural-sector policies when it comes to achieving MDG1 poverty targets. Because the levels of required funding are much larger, the amounts that could be saved annually are also larger compared to the figures in Table 7.1. This is because none of the sample countries would achieve the poverty MDG target with an agricultural-sector growth rate of 6 percent.

The figures in the table indicate that improved sector policies and accountability would contribute to overcoming the severe funding constraints faced by African countries by improving the growth and poverty-reduction outcomes that can be achieved from the available limited resources. The CAADP experience described above illustrates practical steps that can be taken to move countries toward more effective policies. 
The CAADP implementation agenda and its emphasis on inclusive dialogue and review, mutual learning, and evidence-based strategy and policy planning and implementation has helped to enhance the credibility of CAADP and thus facilitated the broad buy-in and alignment of efforts that have led to the current agricultural investment plans. Thirty countries and ECOWAS have held roundtables and signed compacts. About 15 countries have held high-level business meetings at which governments took steps to increase their agricultural investments to help finance plans. Moreover, there has been a broad embrace of CAADP by the global community, as illustrated by the use of its principles, process, and modalities by the Global Agriculture and Food Security Program (2012) in its guidelines for project funding and by the L'Aquila Food Security Initiative in its coordination efforts. To date 6 African countries have received funding to the tune of nearly $\$ 270$ million from the Global Agriculture and Food Security Program to help finance their agricultural investment plans.

\section{Box 7.1-The L'Aquila Food Security Initiative}

Launched in 2009, the L'Aquila Food Security Initiative (AFSI) represents a shared commitment by donors, partner countries, and other development partners to act with scale and urgency to achieve global food security. As part of the commitment, AFSI donors pledged to mobilize more than US\$22 billion over three years in support of sustainable agricultural development. The AFSI working group on Managing for Development Results and Results Reporting is currently leading work to analyze the extent to which AFSI donors, partner countries, and their development partners are adhering to AFSI principles and other basic principles and commitments of the Paris Declaration and the Accra Agenda for Action goals related to aid effectiveness. Bangladesh, Ghana, Rwanda, and Senegal are the initial case studies. These case studies will examine whether (1) partner countries and donors have been fulfilling both their financial and their nonfinancial commitments, (2) efforts are being managed for development results geared toward achieving food and nutrition security, and (3) actual results are being achieved on the ground. The overall objective will be to assess the degree to which AFSI commitments are being achieved within the Managing for Development Results framework and, in the process, determine progress toward achieving development results associated with economic governance, agricultural growth, poverty, and food and nutrition security. The diagnostic analysis in each country will involve a comprehensive review of existing documents, any available secondary sources, and in-country expert interviews about several key indicators that have been identified. In Africa AFSI commitments are being carried out within the Comprehensive Africa Agriculture Development Programme framework.

\section{Summary}

As a summary for this section and a conclusion for the whole paper, it is worth re-emphasizing that reducing poverty in Africa south of the Sahara depends largely on stimulating growth in agriculture. To this end, heads of state in Africa have rallied to form the pan-African CAADP. CAADP's main purpose is to provide a common framework for achieving sustained public expenditure in support of the development of agricultural-led growth. It is an Africa-led and -owned agenda that has created a strong platform for evidence-based policy in the agricultural sector. It is founded on inclusive dialogue and review processes to increase the effectiveness of the development process across African countries through partnership mechanisms at the continental, regional, and country levels. This political and financial commitment to agriculture in SSA is unprecedented and bodes well for the future of agriculture in Africa. 


\section{REFERENCES}

Adelman, S., D. O. Gilligan, and K. Lehrer. 2008. How Effective Are Food for Education Programs? A Critical Review of the Evidence from Developing Countries. Food Policy Review No. 9. Washington, DC: International Food Policy Research Institute.

Ahmed, A. 1993. Food Consumption and Nutritional Effects of Targeted Food Interventions in Bangladesh. Draft. Dhaka, Bangladesh: International Food Policy Research Institute.

Alden Wily, L. 2003. A Review of Decentralisation of Land Administration and Management in Africa. London: International Institute for Environment and Development.

Alderman, H. 2007. "Improving Nutrition through Community Growth Promotion: Longitudinal Study of the Nutrition and Early Child Development Program in Uganda." World Development 35 (8): 1376-1389.

Ali, D. A., K. Deininger, and M. Goldstein. 2011. Environmental and Gender Impacts of Land Tenure Regularization in Africa Pilot Evidence from Rwanda. Policy Research Working Paper 5765. Washington DC: World Bank.

Allen, L., B. de Benoist, O. Dary, and R. Hurrell. 2006. Guidelines on Food Fortification with Micronutrients. Geneva: World Health Organization/Food and Agriculture Organization of the United Nations.

Alpuerto, V., X. Diao, and O. Ecker. n.d. "Nutritional Effects of Transforming Ghana's Agriculture.” Work in Progress. International Food Policy Research Institute.

Alston, J. M., M. C. Marra, P. G. Pardey, and T. J. Wyatt. 2000. "Research Returns Redux: A Meta-analysis of the Returns to Agricultural R\&D." Australian Journal of Agricultural and Resource Economics 44 (2): 185215.

Anderson, K., and W. A. Masters, eds. 2009. Distortions to Agricultural Incentives in Africa. Washington DC: World Bank.

Anderson, K. and S. Nelgen. 2012. "Trade Barrier Volatility and Agricultural Price Stabilization.” World Development 40(1): 36-48, January.

Andrianirina-Ratsialonana, R., and Teyssier A.. 2010. "Large-Scale Agricultural Investments in Madagascar: Lessons for More - Inclusivell Models." In Alternatives to Land Acquisitions: Agricultural Investment and Collaborative Business Models, eds. L. Cotula and R. Leonard. London: International Institute for Environment and Development (IIED).

Ariga, J., and T. Jayne. 2009. Private Sector Responses to Public Investments and Policy Reforms: The Case of Fertilizer and Maize Market Development in Kenya. IFPRI Discussion Paper 00921. Washington, DC: International Food Policy Research Institute.

Ariga, J., T. Jayne, and J. Nyoro. 2006. Factors Driving the Growth in Fertilizer Consumption in Kenya, 19902005: Sustaining the Momentum in Kenya and Lessons for Broader Replicability in Sub-Saharan. Tegemeo Institute of Agricultural Policy and Development Working Paper 24/2006, (02). Nairobi, Kenya: Tegemeo Institute of Agricultural Policy and Development.

Ashburner, J. E., and J. Kienzle. 2011. Investment in Agricultural Mechanization in Africa: Conclusions and Recommendations of a Round Table Meeting of Experts. 3-5 June 2009. Arusha, Tanzania: Food and Agriculture Organization and United Nations Industrial Development Organization.

Atwood, D. A. 1990. "Land Registration in Africa: The Impact on Agricultural Production." World Development 18 (5): 659-671.

Augustinus, C., and K. Deininger. 2005. Innovations in Land Tenure, Reform \& Administration in Africa. Paper presented at the conference "Land Rights for African Development: From Knowledge to Action." Nairobi, Kenya, October 31-November 3.

Badiane, O. 2000. "The Effects of Liberalization on Food Markets in Africa." In Agricultural Markets Beyond Liberalization, edited by A. van Tilburg, H. A. J. Moll, and A. Kuyvenhoven, 147-158. Boston: Kluwer Academic. 
Baltussen, R., C. Knai, and M. Sharan. 2004. "Iron Fortification and Iron Supplementation Are Cost-Effective Interventions to Reduce Iron Deficiency in Four Subregions of the World." Journal of Nutrition 134 (10): 2678-2684.

Banful, A. B. 2009. Operational Details of the 2008 Fertilizer Subsidy in Ghana-Preliminary Report. Ghana Strategy Support Program (GSSP) Background Paper 18. IFPRI, USA. .2010. Old Problems in the New Solutions? Politically Motivated Allocation of Program Benefits and the “New” Fertilizer Subsidies. IFPRI Discussion Paper 01002. Washington, DC: International Food Policy Research Institute.

Bardhan, P. 1989. "Alternative Approaches to the Theory of Institutions in Economic Development." In The Economic Theory of Agrarian Institutions, edited by P. Bardhan. New York: Oxford University Press.

Barro, S. J. 1998. “The East Asian Tigers Have Plenty to Roar About.” Business Week, April 27, Economic Viewpoint, 24.

Barrows, R. and M. Roth, 1989. 'Land Tenure and Investment in African Agriculture: Theory and Evidence'. University of Wisconsin Press, Land Tenure Center Paper 136. Madison, WI.

Barzel, Y. 1997. Economic Analysis of Property Rights. Cambridge, UK: Cambridge University Press.

Beaton, G., and G. McCabe. 1999. Efficacy of Intermittent Iron Supplementation in the Control of Iron Deficiency Anaemia in Developing Countries: An Analysis of Experience. Ottawa, Ontario, Canada: Micronutrient Initiative.

Behrman, J. R., H. Alderman, and J. Hoddinott. 2004. "Malnutrition and Hunger.” In Global Crises, Global Solutions, edited by B. Lomborg, 363-420. Cambridge, UK: Cambridge University Press.

Beintema, N., and G. Stads. 2006. Agricultural R\&D in Sub-Saharan Africa: An Era of Stagnation. Background Report for the ASTI Initiative, International Food Policy Research Institute. Washington, DC: International Food Policy Research Institute. 2011. African Agricultural $R \& D$ in the New Millennium: Progress for Some, Challenges for Many. IFPRI Food Policy Report. Washington, DC: International Food Policy Research Institute.

Benin, S. 2012. "Regional Strategic Analysis and Knowledge Support Systems: Overview of Activities, Outputs, and Lessons." PowerPoint Presentation. Dakar Senegal: International Food Policy Research Institute.

Benin, S., M. Johnson, K. Jimah, J. Taabazuing, A. Tenga, E. Abokyi, G. Nasser, et al. 2012. Evaluation of Four Special Initiatives of the Ministry of Food and Agriculture, Government of Ghana. Accra, Ghana: Ministry of Food and Agriculture.

Benjaminsen, T. A., S. T. Holden, C. Lund, and E. Sjaastad. 2009. "Formalisation of Land Rights: Some Empirical Evidence from Mali, Niger and South Africa." Land Use Policy 26:28-35.

Benson, T. 2011. "Cross-sectoral Coordination in the Public Sector: A Challenge to Leveraging Agriculture for Improving Nutrition and Health." In Reshaping Agriculture for Nutrition and Health, edited by S. Fan and R. Pandya-Lorch. Washington, DC: International Food Policy Research Institute.

Bernard, T., D. J. Spielman, A. S. Taffesse, and E. Z. Gabre-Madhin. 2010. Cooperatives for Staple Crop Marketing. IFPRI Research Monograph 164. Washington, DC: International Food Policy Research Institute.

Berti, P. R., J. Krasevec, and S. FitzGerald. 2004. "A Review of the Effectiveness of Agriculture Interventions in Improving Nutrition Outcomes." Public Health Nutrition 7 (5): 599-609.

Besley, T. 1995. "Property-rights and Investment Incentives-Theory and Evidence from Ghana." Journal of Political Economy 103 (5): 903-937.

Bhagowalia, P., D. Headey, and S. Kadiyala. 2012. Agriculture, Income and Nutrition Linkages in India: Insights from a Nationally Representative Survey. IFPRI Discussion Paper 01195. Washington, DC: International Food Policy Research Institute, forthcoming. 
Bhutta, Z. A., T. Ahmed, R. E. Black, S. Cousens, K. Dewey, E. Giugliani, B. A. Haider, et al. 2008. "What Works? Interventions for Maternal and Child Undernutrition and Survival." Lancet 371 (9610): 417-440.

Bihogo, E., D. D. Weatherspoon, and J. F. Oehmke. 2011. The Impact of PEARL and SPREAD Projects on the Development of the Rwandan Coffee Sector. Kigali, Rwanda: USAID.

Binswanger, H. P. 1990. “The Policy Response of Agriculture.” Proceedings of the World Bank Annual Conference of Development Economics 1989. Washington, DC: World Bank.

Binswanger-Mkhize, H., D. Byerlee, A. McCalla, M. Morris, and J. Staatz. 2012. "The Growing Opportunities for African Agricultural Development." Conference Working Paper 16, prepared for Agricultural R\&D: Investing in Africa's Future, Accra, Ghana, December 5-7, 2011.

Black, R. E., L. H. Allen, Z. A. Bhutta, L. E. Caulfield, M. de Onis, M. Ezzati, C. Mathers, et al. 2008. "Maternal and Child Undernutrition: Global and Regional Exposures and Health Consequences." Lancet 371 (9608): 243-260.

Blackie, M. J., and C. K. Mann. 2005. “The Origin and Concept of the Starter Pack.” In Starter Packs: A Strategy to Fight Hunger in Developing Countries, edited by S. Levy, 1-17. London: CABI.

Block, S. 2010. "The Decline and Rise of Agricultural Productivity in Sub-Saharan Africa Since 1961.” NBER Working Paper 16481. Cambridge, MA: National Bureau of Economic Research.

Bonfiglioli, A. 2003. Empowering the Poor: Local Governance for Poverty Reduction. New York: United Nations Capital Development Fund.

Borras, S. M., D. Fig, and S. Suárez. 2011. "The Politics of Agrofuels and Mega Land-water Deals: Insights from the ProCana Case, Mozambique.” Review of African Political Economy 38 (128): 215-234.

Boudreaux, K. 2011. “Economic Liberalization in Rwanda's Coffee Sector.” In Yes, Africa Can: Success Stories from a Dynamic Continent, edited by Chuhun-pole, P and Angwafo, M. , 185-200. Washington, DC: International Bank for Reconstruction and Development/World Bank.

Bouet, A. and D. Laborde. 2010. Economics of Export Taxation in a Context of Food Crisis: A Theoretical and CGE Approach Contribution. IFPRI Discussion Paper 00994. Washington DC: International Food Policy Research Institute.

Brasselle, A. S., F. Gaspart, and J. P. Platteau. 2002. "Land Tenure Security and Investment Incentives: Puzzling Evidence from Burkina Faso.” Journal of Development Economics 67 (2): 373-418.

Brautigam, D. and X. Tang. 2012. An Overview of Chinese Agricultural and Rural Engagement in Ethiopia. IFPRI Discussion Paper 01185. Washington, DC: International Food Policy Research Institute.

Bravo-Ortega, C. and D. Lederman. 2005. Agriculture and National Welfare around the World: Causality and International Heterogeneity since 1960. World Bank Policy Research Working Paper Series 3499. Washington DC: World Bank.

Bromley, D. W. 1991. Environment and Economy: Property Rights and Public Policy. Oxford, UK, and Cambridge, UK: Blackwell.

Brooks, J., ed. 2012. Agricultural Policies for Poverty Reduction. Paris: OECD.

Brooks, J., M. Filipski, E. Jonasson, and J. E. Taylor. 2012. “The Distributional Implications of Agricultural Policies in Developing Countries-Findings from the Development Policy Evaluation Model (DEVPEM).” In Agricultural Policies for Poverty Reduction, edited by J. Brooks. Paris: OECD.

Bruce, J. W. 1986. Land Tenure Issues in Project Design and Strategies for Agricultural Development in SubSaharan Africa. Madison: Land Tenure Center, University of Wisconsin-Madison.

Bumb, B., M. Johnson, and P. A. Fuentes. 2011. Policy Options for Improving Regional Fertilizer Markets in West Africa. IFPRI Discussion Paper 01084. Washington, DC: International Food Policy Research Institute. . 2012. Improving Regional Fertilizer Markets in West Africa. IFPRI Policy Brief 20. Washington, DC: International Food Policy Research Institute. 
Burns, T. A. 2007. "Land Administration: Indicators of success and future challenges." Agriculture \& Rural Development Department. Washington: World Bank.

Bushamuka, V. N., S. de Pee, A. Talukder, L. Kiess, D. Panagides, A. Taher, and M. Bloem. 2005. "Impact of a Homestead Gardening Program on Household Food Security and Empowerment of Women in Bangladesh." Food and Nutrition Bulletin 26 (1): 17-25.

Byerlee, D. 1996. "Modern Varieties, Productivity, and Sustainability: Recent Experience and Emerging Challenges." World Development 24:697-718.

Byerlee, D. and K. Fischer. 2002. "Accessing Modern Science: Policy and Institutional Options for Agricultural Biotechnology in Developing Countries." World Development 30 (6): 931-948.

Byerlee, D. and M. Morris. 1993. "Research for Marginal Environments: Are We Underinvested?" Food Policy 18:381-393.

Byerlee, D. and G. Traxler. 2002. "The Role of Technology Spill-overs and Economies of Size in the Efficient Design of Agricultural Research Systems.” In Agricultural Science Policy: Changing Global Agendas, edited by J. M. Alston, P. G. Pardey, and M. J. Taylor. Baltimore: Johns Hopkins University Press.

Carter, M. R. and K. Wiebe. 1990. "Access to Capital and Its Impact on Agrarian Structure and Productivity in Kenya." Journal of Agricultural Economics 72:1146-1150.

Chapoto, A. and T. S. Jayne. 2009. Effects of Maize Marketing and Trade Policy on Price Unpredictability in Zambia. Food Security Research Project Working Paper No. 38. Lusaka, Zambia: Food Security Research Project.

Chen, S. and M. Ravallion. 2007. The Changing Profile of Poverty in the World. 2020 Vision Briefs BB01 Special Edition. Washington, DC: International Food Policy Research Institute.

Chinsinga, B. 2007. Reclaiming Policy Space: Lessons from Malawi's 2005/6 Fertilizer Subsidy Programme. Future Agricultures Research Paper 006. Zomba, Malawi: Future Agricultures.

Christiaensen, L. and H. Alderman. 2004. "Child Malnutrition in Ethiopia: Can Maternal Knowledge Augment the Role of Income?” Economic Development and Cultural Change 52 (2): 287-312.

Christiaensen, L., L. Demery, and J. Kuhl. 2011. "The (Evolving) Role of Agriculture in Poverty Reduction-An Empirical Perspective.” Journal of Development Economics 96 (2): 239-254.

Coady, D., P. Dorosh, and B. Minten, 2008. "Evaluating Alternative Policy Responses to Higher World Food Prices: The Case of Increasing Rice Prices in Madagascar," American Journal of Agricultural Economics, Agricultural and Applied Economics Association, vol. 91(3), pages 711-722.

Colchester M, Boscolo M, Contreras-Hermosilla A, del Gatto F, Dempsey J, Lescuyer G, Obidzinski K, Pommier D, Richards M, Sembiring SN, Tacconi L, Vargas Rios MT, Wells A. 2006 Justice in the forest: rural livelihoods and forest law enforcement. Forest perspectives 3, CIFOR, Bogor.

Cotula, L. 2011. Land deals in Africa: What is in the contracts? London: IIED.

Cotula, L., C. Toulmin, and C. Hesse. 2004. Land Tenure and Administration in Africa: Lessons of Experience and Emerging Issues. London: International Institute for Environment and Development.

Coulter, J. 2007. Farmer Groups Enterprises and the Marketing of Staple Food Commodities in Africa. Collective Action and Property Rights Working Paper 72. Washington, DC: International Food Policy Research Institute.

Crawford, E., V. Kelly, T. Jayne, and J. Howard. 2003. "Input Use and Market Development in Sub-Saharan Africa: An Overview." Food Policy 28 (4): 277-292.

Daley, E. and B. Englert. 2010. Securing Land Rights for Women. Journal of Eastern African Studies Vol. 4, No. 1, March 2010.

Dary, O. and J. O. Mora. 2002. "Food Fortification to Reduce Vitamin A Deficiency: International Vitamin A Consultative Group Recommendations.” Journal of Nutrition 132 (9): 2927S. 
Datt, G. and M. Ravallion. 1998. "Farm Productivity and Rural Poverty in India." Journal of Development Studies 34 (4): $62-85$.

de Janvry, A. d., M. Fafchamps, and E. Sadoulet. 1991. "Peasant Household Behavior with Missing Markets: Some Paradoxes Explained." Economic Journal 101:1400-1417.

de Janvry, A. d., G. Gordillo, J.-P. Platteau, and E. Sadoulet. 2001. "Access to Land, Rural Poverty, and Public Action." In Access to Land, Rural Poverty, and Public Action, edited by A. d. Janvry, G. Gordillo, J.-P. Platteau, and E. Sadoulet, 1-26. Oxford, UK: Oxford University Press.

de Janvry, A. and E. Sadoulet. 2009. “Agricultural Growth and Poverty Reduction: Additional Evidence.” World Bank Research Observer 25 (1): 1-20. . 2010. “Agriculture for Development in Africa: Business-as-usual or New Departures?” Journal of African Economies 19 (suppl. 2): 7-39.

Deininger, K. 2003. Land Policies for Growth and Poverty Reduction. Washington, DC: World Bank and Oxford University Press.

Deininger, K.. and D.A. Ali. 2008. "Do Overlapping Property Rights Reduce Agricultural Investment? Evidence from Uganda." American Journal of Agricultural Economics 90(4):869-84.

Deininger, K.., D. A. Ali, and T. Alemu. 2011. "Impacts of Land Certification on Tenure Security, Investment, and Land Market Participation: Evidence from Ethiopia." Land Economics 87 (2): 312-334.

Deininger, K., D. A. Ali, S. Holden, and J. Zevenbergen. 2008. "Rural Land Certification in Ethiopia: Process, Initial Impact, and Implications for Other African Countries.” World Development 36 (10): 1786-1812.

Deininger, K. and H. Binswanger. 1999. "The Evolution of the World Bank's Land Policy: Principles, Experience, and Future Challenges." World Bank Research Observer 14 (2): 247-276.

Deininger, K. and D. Byerlee. 2012. "The Rise of Large Farms in Land Abundant Countries: Do They Have a Future?” World Development 40 (4): 701-714.

Deininger, K. and G. Feder. 1998. Land Institutions and Land Markets. Washington, DC: World Bank, Development Research Group, Rural Development.

Deininger, K. and S. Jin. 2006. "Tenure Security and Land-Related Investment: Evidence from Ethiopia." European Economic Review 50(5):1245 -77.

Deininger, K. S. Jin, B. Adnew, S. G. Selassie and M. Demeke. 2003., Market and Non-Market Transfers of Land in Ethiopia: Implications for Efficiency, Equity and Non-Farm Development. World Bank Working Paper No. 2992, Washing-ton, DC: The World Bank.

del Nino, C. and P. Dorosh. 2001. "Averting a Food Crisis: Private Imports and Public Targeted Distribution in Bangladesh after the 1998 Floods." Agricultural Economics 25 (2/3): 337-346.

Delgado, C. 1999. "Sources of Growth in Smallholder Agriculture in Sub-Saharan Africa: The Role of Vertical Integration of Smallholders with Processors and Marketers of High Value-added Items." Agrekon 38:165189.

Demsetz, H. 1967. “Toward a Theory of Property Rights.” Journal of American Economic Review 57 (2): 347-359 .

Dercon, S. and L. Christiaensen. 2011. "Consumption Risk, Technology Adoption and Poverty Traps: Evidence from Ethiopia." Journal of Development Economics 96 (2): 159-173.

Diao, X., P. Dorosh, M. Johnson, and S. Benin. 2010. Estimating Agricultural Spending Requirements: Meeting the MDG Poverty Reduction Target in Sub-Saharan Africa. Working Paper. Washington, DC: International Food Policy Research Institute.

Diao, X., P. Dorosh, and S. M. Rahman. 2003. Market Opportunities for African Agriculture: An Examination of Demand-side Constraints on Agricultural Growth. DSGD Discussion Paper No.1. Washington, DC: International Food Policy Research Institute. 
Diao, X. and P. Hazell. 2004. Exploring Market Opportunities for African Smallholders. 2020 Vision Conference Brief No. 6. Washington, DC: International Food Policy Research Institute.

Diao, X., P. Hazell, and J. Thurlow. 2010. "The Role of Agriculture in African Development." World Development 38 (10): $1375-1383$.

Diao, X., A. Kennedy, A. Mabiso, and A. Pradesh. 2012. Analysis of Tanzania's Maize Export Ban Policy: A General Equilibrium Approach. Washington, DC: USAID-Tanzanian Mission Office.

Diao, X., J. Thurlow, S. Benin, and S. Fan. 2012. Strategies and Priorities for African Agriculture: Economy-wide Perspectives from Country Studies. Washington, DC: International Food Policy Research Institute.

Djurfeldt, G., H. Holmen, and M. Jirstroml, eds. 2005. The African Food Crisis: Lessons from the Asian Green Revolution. Wallingford, Oxon, UK: CABI.

Dollar, D. 1992. "Outward-oriented Developing Economies Really Do Grow More Rapidly: Evidence from 95 LDCs, 1976-85.” Economic Development and Cultural Change 1992:523-544.

Dorosh, P. 2001. "Trade Liberalization and National Food Security: Rice Trade between Bangladesh and India." World Development 29 (4): 673-689.

Dorosh, P.A., S. Dradri and S. Haggblade 2008. Regional Trade, Government Policy and Food Security: Recent Evidence from Zambia. Food Policy 34:350-366.

Dorward, A. and E. Chirwa. 2011. "The Malawi Agricultural Input Subsidy Programme: 2005/06 to 2008/09." International Journal of Agricultural Sustainability 9 (1): 232-247.

Dorward, A., J. Kydd, J. Morrison, and I. Urey. 2004. “A Policy Agenda for Pro-poor Agricultural Growth.” World Development 32 (1): 73.

Ecker, O., C. Breisinger, and K. Pauw. 2011. "Growth Is Good, but Is Not Enough to Improve Nutrition." Background paper for IFPRI's 2020 Conference, Leveraging Agriculture for Improving Nutrition and Health, New Delhi, India, February 10-12.

Ecker, O., A. Mabiso, A. Kennedy, and X. Diao. 2011. "Making Agriculture Pro-nutrition: Opportunities in Tanzania.” IFPRI Discussion Paper 01124. Washington, DC: International Food Policy Research Institute.

Ecker, O., J. F. Trinh Tan, X. Diao, and B. Yu. n.d. "Decomposing the Causes of Malnutrition: What Is the Role of Agriculture and Fishery in Cambodia?" International Food Policy Research Institute.

Economic Times. 2011. "India to Make Ethiopia's Leather Production Globally Competitive." September 22. www.2merkato.com/20110922362/india-to-make-ethiopias-leather-production-globally-competitive.

Evenson, R. E. 2009. "Economic Impacts of Agricultural Research and Extension.” In Handbook of Agricultural Economics, edited by P. L. Pingali and R. E. Evenson. Oxford, UK: North-Holland.

Evenson, R. E. and D. Gollin, eds. 2003. Crop Variety Improvement and Its Effect on Productivity: The Impact of International Agricultural Research. Wallingford, Oxon, UK: CABI.

Fan, S., A. Gulati, and S. Thorat. 2008. "Investment, Subsidies, and Pro-poor Growth in Rural India." Agricultural Economics 39 (2): 163-170.

Fan, S., P. Hazell, and S. Thorat. 1999. Linkages between Government Spending, Growth, and Poverty in Rural India. IFPRI Research Report No. 110. Washington, DC: International Food Policy Research Institute.

Fan, S., T. Mogues, and S. Benin. 2009. Setting Priorities for Public Spending for Agricultural and Rural Development in Africa. IFPRI Policy Brief 12. Washington, DC: International Food Policy Research Institute.

Fan, S., R. Pandya-Lorch, and H. Fritschel. 2011. "Leveraging Agriculture for Improving Nutrition and Health: The Way Forward." In Reshaping Agriculture for Nutrition and Health, edited by S. Fan and R. Pandya-Lorch. Washington, DC: International Food Policy Research Institute.

Fan, S., B. Yu, and S. Jitsuchon. 2008. "Does Allocation of Public Spending Matter in Poverty Reduction? Evidence from Thailand." Asian Economic Journal, East Asian Economic Association 22 (4): 411-430. 
Fan, S., and X. Zhang. 2004. "Infrastructure and Regional Economic Development in Rural China." China Economic Review 15 (2): 203-214.

Fan, S., X. Zhang, and N. Rao. 2004. Public Expenditure, Growth, and Poverty Reduction in Rural Uganda. DSGD Discussion Paper. Washington, DC: International Food Policy Research Institute.

Feder, G. and R. Noronha. 1987. "Land Rights System and Agricultural Development in Sub-Saharan Africa." World Bank Research Observer 2 (2): 143-169.

Ferreira, P. C. and Rossi, J. L. (2003). New evidence from Brazil on trade liberalization and productivity growth. International Economic Review 44: 1383-1405.

Fiedler, J. L. and B. Macdonald. 2009. "A Strategic Approach to the Unfinished Fortification Agenda: Feasibility, Costs, and Cost-effectiveness Analysis of Fortification Programs in 48 Countries." Food and Nutrition Bulletin 30 (4): 283-316.

Fiedler, J., T. Sanghvi, and M. K. Saunders. 2008. “A Review of the Micronutrient Intervention Cost Literature: Program Design and Policy Lessons." International Journal of Health Planning and Management 23 (4): 373-397.

Fischer, G., H. V. Velthuizen, M. Shah, and F. Nachtergaele. 2002. Global Agro-ecological Assessment for Agriculture in the 21 st Century: Methodology and Results. Rome: FAO.

Fitzpatrick, D. 2005. “'Best Practice' Options for the Recognition of Customary Tenure." Development and Change 36 (3): 449-475.

Food and Agriculture Organization of the United Nations Statistical Databases. 2012. FAOSTAT. Rome: FAO.

Foster, V. and C. Briceño-Garmendia. 2010. Africa's Infrastructure-A Time for Transformation. Washington, DC: International Bank for Reconstruction and Development/World Bank.

Frankel, J. and D. Romer. 1999. “Does Trade Cause Growth?” American Economic Review 89 (3): 379-399.

Fuglie, K. O. and N. Rada. 2011. Policies and Productivity Growth in African Agriculture. Conference Working Paper No. 19. Prepared for the IFPRI/ASTI-FARA Conference, Accra, Ghana, December 5-7.

Gabre-Madhin, E. 2012. A Market for Abdu: Creating a Commodity Exchange in Ethiopia. Washington, DC: International Food Policy Research Institute.

Gabre-Madhin, E. Z., 2003. Institutions for Market Exchange: Defining a Policy Research Agenda. Washington, DC: International Food Policy Research Institute.

Gabre-Madhin, E. Z. and I. Goggin. 2005. Does Ethiopia Need a Commodity Exchange? An Integrated Approach to Market Development. EDRI-ESSP Policy Working Paper No. 4. Ethiopian Development Research Institute, Addis Ababa, Ethiopia.

Gebreeyesus, M. and T. Sonobe. 2012. "Global Value Chains and Market Formation Process in Emerging Export Activity: Evidence from Ethiopian Flower Industry.” Journal of Development Studies 48 (3): 335-348.

German, L., Schoneveld, G., and Mwangi, E. 2011. Contemporary processes of large-scale land acquisition by investors: Case studies from Sub-Saharan Africa. Occasional Paper no. 68. Bogor, Indonesia: CIFOR.

Ghana Ministry of Finance and Economic Planning. 2010. Ghana Aid Policy and Strategy: 2011-2015. Toward Middle-income Status, Phase One. Accra, Ghana.

Ghana MOFA (Ghana Ministry of Food and Agriculture). 2010. Medium Term Agriculture Sector Investment Plan (METASIP) - 2011-2015. Ministry of Food and Agriculture, Government of Ghana. Accra.

Gisselquist, D., and J.-M. Grether. 2000. "An Argument for Deregulating the Transfer of Agricultural Technologies to Developing Countries." World Bank Economic Review. 14 (1) (2000), 111-127.

Gisselquist, D. and C. Pray. 1997. “The Impact of Turkey’s 1980s Seed Regulatory Reform.” In Easing Barriers to Movement of Plant Varieties for Agricultural Development, edited by D. Gisselquist and J. Srivastava. World Bank Discussion Paper No. 367. Washington, DC: World Bank. 
Gisselquist, D. and C. Van der Meer. 2001. Regulations for Seed and Fertilizer Markets: A Good Policy Guide for Policy Makers. Rural Development Working Paper No. 22817. Washington, DC: World Bank.

Global Agriculture and Food Security Program. 2012. "Global Agriculture and Food Security Program: Country Guidelines for Public Sector Window Proposals.” Accessed March 19,2012

www.gafspfund.org/gafsp/sites/gafspfund.org/files/Documents/GAFSP\%20Country\%20Guidelines\%20\%2 0Jan\%2010\%20EN.pdf.

. 2011. 4th High Level Forum on Aid Effectiveness: Evidence Paper on Agriculture and Rural

Development for HLF-4-Busan. Bonn, Germany: Global Donor Platform for Rural Development.

Gollin, D. and R. Rogerson. 2010. Agriculture, Roads, and Economic Development in Uganda. National Bureau of Economic Research Working Paper 15863. Cambridge, MA: National Bureau of Economic Research.

Govereh, J., A. Chapoto, and T. S. Jayne. 2010. "Assessment of Alternative Maize Trade and Market Policy Interventions in Zambia." In Food Security in Africa: Market and Trade Policy for Staple Foods in Eastern and Southern Africa, edited by Sarris, A. and Morrison, J.. Cheltenham, UK: Edward Elgar.

Graham, A. W. and M. A. G. Darroch. 2001. "Relationship between the Mode of Land Redistribution, Tenure Security and Agricultural Credit Use in KwaZulu-Natal." Development Southern Africa 18 (3): 295-308.

Green, J. K. 1987. Evaluating the Impact of Consolidation of Holdings, Individualization of Tenure, and Registration of Title: Lessons from Kenya, Land Tenure Center. LTC Paper No. 129. Madison: University of Wisconsin-Madison.

Guiding Investments in Sustainable Agricultural Markets in Africa. 2010. "Smallholder Marketing Behavior and Urban Consumption Patterns in Eastern and Southern Africa." Policy Synthesis No. 3. Accessed November 2012. www.aec.msu.edu/fs2/gisama/index.htm.

Guldan, G., H. C. Fan, X. Ma, Z. Z. Ni, X. Xiang, and M. Z. Tang. 2000. "Culturally Appropriate Nutrition Education Improves Infant Feeding and Growth in Rural Sichuan, China." Journal of Nutrition 130 (5): 1204-1211.

Guthiga, P., S. Wambugu, M. Ogada, S. Massawe, J. Karugia, H. Katjiuongua, and J. Oehmke . 2011. An Assessment of the Impact of Cross-border Trade in Maize on Welfare in the East African Region. Regional Strategic Analysis and Knowledge Support System East and Central Africa Working Paper. Nairobi, Kenya: Regional Strategic Analysis and Knowledge Support System.

Haddad, L., H. Alderman, S. Appleton, L. Song, and Y. Yohannes. 2003. "Reducing Child Malnutrition: How Far Does Income Growth Take Us?" World Bank Economic Review 17 (1): 107-131.

Haddad, L., J. Hoddinott, and H. Alderman. 1996. Intrahousehold Resource Allocation in Developing Countries: Models, Methods and Policy. Baltimore: Johns Hopkins University Press.

Haggblade, S., J. Govereh, H. Nielson, D. Tschirley, and P. Dorosh. 2008. "Regional Trade in Food Staples: Prospects for Stimulating Agricultural Growth and Moderating Short-term Food Security Crises in Eastern and Southern Africa." Paper prepared for the World Bank under Contract No. 7144132, Strengthening Food Security in Sub-Saharan Africa through Trade Liberalization and Regional Integration. Washington, DC: World Bank.

Hanlon, J. 2011. Understanding Land Investment Deals in Africa. Country Report, Mozambique. Oakland, CA, US: Oakland Institute.

Hawkes, C. and M. Ruel. 2011. "Value Chains for Nutrition.” Conference Paper No. 4. Prepared for IFPRI's 2020 Conference, Leveraging Agriculture for Improving Nutrition and Health, New Delhi, India, February 1012.

Hayami, Y. and V. W. Ruttan. 1985. Agricultural Development. 2nd ed. Baltimore: Johns Hopkins University Press.

Hayes, J., M. Roth, and L. Zepeda. 1997. "Tenure Security, Investment and Productivity in Gambian Agriculture: A Generalised Probit Analysis.” American Journal of Agricultural Economics 79:369-382.

Hazell, P. 2009. The Asian Green Revolution. IFPRI Discussion Paper 00911. Washington, DC: International Food Policy Research Institute. 
Hazell, P. B. R. 2012. "Options for African Agriculture in an Era of High Food and Energy Prices." Paper presented at the 27th International Conference of Agricultural Economists, August 18-24, Foz do Iguaçu, Brazil.

Hazell, P., J. Anderson, N. Balzer, A. Hastrup Clemmensen, U. Hess, and F. Rispoli. 2010. Potential for Scale and Sustainability in Weather Index Insurance for Agriculture and Rural Livelihoods. Rome: International Fund for Agricultural Development and World Food Programme.

Hazell, P., C. Poulton, S. Wiggins, and A. Dorward. 2007. The Future of Small Farms for Poverty Reduction and Growth. 2020 Discussion Paper 42. Washington, DC: International Food Policy Research Institute.

Headey, D. 2011. Turning Economic Growth into Nutrition-sensitive Growth. 2020 Conference Paper 6. Washington, DC: International Food Policy Research Institute.

Headey, D., D. Bezemer, and P. Hazell. 2008. Agricultural Exit Problems: Causes and Consequences. IFPRI Discussion Paper 00802. Washington, DC: International Food Policy Research Institute.

Headey, D., A. Chiu, and S. Kadiyala. 2012. “Agriculture's Role in the Indian Enigma: Help or Hindrance to the Malnutrition Crisis?" Food Security, forthcoming.

Herdt, R. V. 1983. Mechanization of Rice Production in Developing Asian Countries: Perspective, Evidence and Issues, Consequences of Small Rice Form Mechanization Project. Working Project No. 15, 1-35. Los Banos, Philippines: International Rice Research Institute.

Hess, U., and P. Hazell. 2009. "Sustainability and Scalability of Index-based Insurance for Agriculture and Rural Livelihoods." Brief 5 in Innovations in Insuring the Poor. Washington, DC: International Food Policy Research Institute.

Hess, U. and J. Syroka. 2005. Weather-based Insurance in Southern Africa: The Case of Malawi. Agriculture and Rural Development Discussion Paper No. 13. Washington, DC: World Bank.

Ho, T. J. 1985. Economic Issues in Assessing Nutrition Projects: Costs, Affordability and Cost Effectiveness. Washington, DC: World Bank, Population, Health and Nutrition Department.

Hoff, K., A. Braverman, and J. E. Stiglitz. 1993. “Introduction.” In The Economics of Rural Organizations, edited by K. Hoff, A. Braverman, and J. E. Stiglitz. Oxford, UK: Oxford University Press.

Holden, S. T. 2007. "Growing Importance of Land Tenancy and Its Implications for Efficiency and Equity in Africa." In Development Economics between Markets and Institutions: Incentives for Growth, Food Security and Sustainable Use of the Environment, edited by E. Bulte and R. Ruben. Wageningen, the Netherlands: Wageningen Academic.

Holden, S.T., Deininger, K. and Ghebru, H. 2009. Impacts of low-cost Land Certification on Investment and Productivity. American Journal of Agricultural Economics, 91(2): 359-373.

Holden, S.T., K. Deininger, and H. Ghebru. 2011. "Tenure Insecurity, Gender, Low-cost Land Certification and Land Rental Market Participation in Ethiopia." Journal of Development Studies 47 (1): 31-47.

Holden, S., and H. Ghebru. 2012. "Command and Control: How Does It Work? The Case of Land Market Law Restrictions in Ethiopia." Paper presented at the Annual World Bank Conference on Land and Poverty, Washington, DC, April 23-26.

Holden, S., B. Shiferaw, and J. Pender. 2001. "Market Imperfections and Land Productivity in the Ethiopian Highlands." Journal of Agricultural Economics 52 (3): 53-70.

Horton, S. 2006. “The Economics of Food Fortification.” Journal of Nutrition 136 (4): 1068-1071.

Horton, S. and J. Ross. 2003. "The Economics of Iron Deficiency." Food Policy 28 (1): 51-75.

Horton, S., M. Shekar, C. McDonald, A. Mahal, and J. K. Brooks. 2010. Scaling Up Nutrition: What Will It Cost? Washington, DC: World Bank.

Houssou, N., F. Cossar, and K. Jimah. 2012. "Interview Transcript of Amank Agriculture \& Equipment (John Deere Franchise).” Accra, Ghana, April 12. 
Hvalkof, S. and R. Plant. 2000. Land Titling and Indigenous Peoples. Washington, DC: Inter-American Development Bank.

Iannotti, L., K. Cunningham, and M. T. Ruel. 2009. Improving Diet Quality and Micronutrient Nutrition: Homestead Food Production in Bangladesh. IFPRI Discussion Paper 928. Washington, DC: International Food Policy Research Institute.

International Fund for Agricultural Development. 2001. The Challenge of Ending Rural Poverty-Rural Poverty Report 2001. Rome.

Jaarsveld, P. J. van, M. Faber, S. A. Tanumihardjo, P. Nestel, C. J. Lombard, and A. J. S. Benadé. 2005. "Betacarotene-rich Orange-fleshed Sweet Potato Improves the Vitamin A Status of Primary School Children Assessed with the Modified-relative-dose-response Test." American Journal of Clinical Nutrition 81 (5): $1080-1087$.

Jacoby, H.G. and Minten, B. 2007. "Is Land Titling in Sub-Saharan Africa Cost-Effective? Evidence from Madagascar," World Bank Economic Review, World Bank Group, vol. 21(3), pages 461-485

Jayne, T. S., R. J. Myers, and J. Nyoro. 2008. "The Effects of NCPB Marketing Policies on Maize Market Prices in Kenya." Agricultural Economics 38:313-325.

Jayne, T. S., A. Negassa, and R. Myers. 1998. The Effect of Liberalization on Grain Prices and Marketing Margins in Ethiopia. MSU International Development Working Paper No. 68. East Lansing: Michigan State University.

Jayne, T. S. and D. Tschirley. 2009. "Food Price Spikes and Strategic Interactions between the Public and Private Sectors: Market Failures or Governance Failures?” Paper presented at the FAO meeting on Institutions and Policies to Manage Global Market Risks and Price Spikes in Basic Food Commodities, Rome, October 2627.

Jayne, T. S., B. Zulu, and J. J. Nijhoff. 2006. "Stabilizing Food Markets in Eastern and Southern Africa." Food Policy 31 (4): 328-341.

Johnson, S., J. D. Ostry, and A. Subramanian. 2010. "Prospects for Sustained Growth in Africa: Benchmarking the Constraints." IMF Staff Papers 57:119-171.

Kaminski, J. and D. Headey. 2009. Institutional Reform in the Burkinabè Cotton Sector and Its Impacts on Incomes and Food Security. IFPRI Discussion Paper 00920. Washington, DC: International Food Policy Research Institute.

Kanji, N., L. Cotula, T. Hilhorst, C. Toulmin, and W. Witten. 2005. Can Land Registration Serve Poor and Marginalised Groups? Summary Report. Securing Land Rights in Africa Research Report 1. London: IIED.

Kanwar, S. and R. Evenson. 2003. "Does Intellectual Property Protection Spur Technological Change?" Oxford Economic Papers 55:235-264.

Karugia, J., J. Wanjiku, J. Nzuma, S. Gbegbelegbe, E. Macharia, S. Massawe, A. Freeman, et al. 2009. The Impact of Non-tariff Barriers on Maize and Beef Trade in East Africa. ReSAKSS Working Paper No. 29. Washington, DC: International Food Policy Research Institute.

Kelly, V. 2005. Factors Affecting Demand for Fertilizer in Sub-Saharan Africa. World Bank Agriculture and Rural Development Discussion Paper 23. Washington, DC: World Bank.

Kherallah, M., C. Delgado, E. Gabre-Madhin, N. Minot, and M. Johnson. 2002. Reforming Agricultural Markets in Africa. Baltimore: Johns Hopkins University Press; published for International Food Policy Research Institute.

Kodama, Y. 2007. "New Role of Cooperatives in Ethiopia: The Case of Ethiopian Coffee Farmers Cooperatives." African Study Monographs 35 (suppl.): 87-108.

Kolady, D. E., D. J. Spielman, and A. Cavalieri. 2012. "The Impact of Seed Policy Reforms and Intellectual Property Rights on Crop Productivity in India.” Journal of Agricultural Economics 63 (2): 361-384. 
Kolavalli, S. and M. Vigneri. 2011. "Cocoa in Ghana: Shaping the Success of an Economy." In Yes, Africa Can: Success Stories from a Dynamic Continent, edited by Chuhun-pole and Angwafo, 201-218. Washington, DC: International Bank for Reconstruction and Development/World Bank.

Kranton, R. E. 1996. "Reciprocal Exchange: A Self-sustaining System.” American Economic Review 86 (4): 830 851.

Kydd, J. and A. Dorward. 2004. "Implications of Market and Coordination Failures for Rural Development in Least Developed Countries." Journal of International Development 16 (7): 951-970.

Langyintuo, A. S., W. Mwangi, A. O. Diallo, J. MacRobert, J. Dixon, and M. Bänziger. 2010. "Challenges of the Maize Seed Industry in Eastern and Southern Africa: A Compelling Case for Private-public Intervention to Promote Growth.” Food Policy 35 (4): 323-331.

Larson, B. A. and D. W. Bromley. 1990. "Property Rights, Externalities, and Resource Degradation." Journal of Development Economics 33:235-262.

Lele, U., W. Lesser, and G. Horstkotte-Wesseler. 2000. Intellectual Property Rights in Agriculture. Washington, DC: World Bank.

Leroy, J. L. and E. A. Frongillo. 2007. "Can Interventions to Promote Animal Production Ameliorate Undernutrition?” Journal of Nutrition 137 (10): 2311-2316.

Leroy, J. L., M. Ruel, and E. Verhofstadt. 2009. "The Impact of Conditional Cash Transfer Programmes on Nutrition: A Review of Evidence Using a Programme Theory Framework.” Journal of Development Effectiveness 1 (2): 103-129.

Levy, S. 2005. Starter Packs: A Strategy to Fight Hunger in Developing Countries? Lessons from the Malawi Experience 1998-2003. Reading, UK: CABI.

Linnemayr, S. and H. Alderman. 2011. "Almost Random: Evaluating a Large-scale Randomized Nutrition Program in the Presence of Crossover." Journal of Development Economics 96 (1): 106-114.

Loayza, N. and C. Raddatz. 2010. "The Composition of Growth Matters for Poverty Alleviation." Journal of Development Economics 93:137-151.

Low, J. W., M. Arimond, N. Osman, B. Cunguara, F. Zano, and D. Tschirley. 2007. "A Food-based Approach Introducing Orange-fleshed Sweet Potatoes Increased Vitamin A Intake and Serum Retinol Concentrations in Young Children in Rural Mozambique." Journal of Nutrition 137 (5): 1320-1327.

Lutz, C., W. E. Kuiper, and A. van Tilburg. 2006. "Maize Market Liberalisation in Benin: A Case of Hysteresis." Journal of African Economies 16 (1): 102-133.

Lyambabaje, A., E. Bihogo, C. B. Moss, J. P. Kayisinga, D. D. Weatherspoon, and J. F. Oehmke. 2012. Poverty Reduction among Rwandan Smallholder Coffee Producers: A Synthesis of Findings. USAID Policy Brief. Washington DC: United States Agency for International Development.

Mackenzie, F. 1993. “'A Piece of Land Never Shrinks': Reconceptualizing Land Tenure in a Smallholding District Kenya." In Land in African Agrarian Systems, edited by T. J. Basset and D. Crummey, 194-221. Madison: University of Wisconsin Press.

Maertens, M. and J. Swinnen. 2009. "Trade, Standards, and Poverty: Evidence from Senegal." World Development $37: 161-78$.

Mahul, O., N. Belete, and R. Goodland. 2009. Innovations in Insuring the Poor: Index-based Livestock Insurance in Mongolia. IFPRI/2020 Vision Focus Brief 9. Washington, DC: International Food Policy Research Institute.

Martin, W. and K. Anderson. 2012. "Export Restrictions and Price Insulation during Commodity Price Booms." American Journal of Agricultural Economics 94 (2): 422-427.

Mason, J. B., D. Sanders, P. Musgrove, and R. Galloway. 2006. "Community Health and Nutrition Programs." In Disease Control Priorities in Developing Countries. 2nd ed., edited by D. Jamison, G. Alleyne, J. Breman, 
M. Claeson, D. Evans, and P. Jha, 1053-1074. Oxford, UK; New York: University Press for the World Bank.

Mason, N. M. and J. Ricker-Gilbert. 2012. Disrupting Demand for Commercial Seed: Input Subsidies in Malawi and Zambia. Indaba Agricultural Policy Research Institute (IAPRI) Lusaka, Zambia Working Paper No. 63.

Masters, W. A., T. Bedingar, and J. F. Oehmke. 1998. "The Impact of Agricultural Research in Africa: Aggregate and Case Study Evidence." Agricultural Economics 19: 81-86.

Mayer, J. 1976. “The Dimensions of Human Hunger.” Scientific American 235 (3): 40-49.

McMillan, M., D. Rodrik, and K. H. Welch. 2002. When Economic Reform Goes Wrong: Cashews in Mozambique. NBER Working Paper No. 9117.

Meenakshi, J. V., N. L. Johnson, V. M. Manyong, H. DeGroote, J. Javelosa, D. R. Yanggen, F. Naher, et al. 2010. "How Cost-effective Is Biofortification in Combating Micronutrient Malnutrition? An Ex Ante Assessment." World Development 38 (1): 64-75.

Mehefette, E. 2009. Innovations in Insuring the Poor: Providing Weather Index and Indemnity Insurance in Ethiopia. IFPRI/2020 Vision Focus Brief 8. Washington, DC: International Food Policy Research Institute.

Mhlanga, N. 2010. Private Sector Agribusiness Investment in Sub-Saharan Africa Agricultural Management. Marketing and Finance Working Document 27. Rome: FAO.

Migot-Adholla, S. E., G. Benneh, F. Place, and S. Atsu. 1994. "Land, Security of Tenure, and Productivity in Ghana." In Searching for Land Tenure Security in Africa, edited by J. W. Bruce and S. E. Migot-Adholla, 97-118. Dubuque, IA: Kendall/Hunt.

Migot-Adholla, S. E., P. Hazell, B. Blarel, and F. Place. 1991. "Indigenous Land Rights Systems in Sub-Saharan Africa: A Constraint on Policy?" World Bank Economic Review 5 (1): 155-175.

Ministry of Agriculture and Animal Resources. 2011. Summary of the Joint Sector Review for the Agriculture Sector. Kigali, Rwanda.

Minot, N. and T. Benson. 2009. Fertilizer Subsides in Africa: Are Vouchers the Answer? IFPRI Issue Brief 60. Washington, DC: International Food Policy Research Institute.

Minot, N. and M. Ngigi. 2003. "Are Horticultural Exports a Replicable Success Story? Evidence from Kenya and Cote d'Ivoire." Paper presented at the International Conference of Successes in African Agriculture: Building for the Future, Pretoria, South Africa, December 1-3.

Minten, B., L. Randrianarison, and J. F. M. Swinnen. 2009. "Global Retail Chains and Poor Farmers: Evidence from Madagascar.” World Development 37 (11): 1728-1741.

Minten, B., D. Stifel, and S. Tamiru. 2012. Structural Transformation in Ethiopia: Evidence from Cereal Markets. International Food Policy Research Institute-Ethiopia Strategy Support Program II (ESSP II) Working Paper 39. Washington, DC: International Food Policy Research Institute.

Mogues, T. and S. Benin. 2012. Public Expenditures for Agricultural and Rural Development in Africa. Abingdon, Oxon; New York: Routledge.

Morris, M., H. Binswanger, D. Byerlee, and J. Staatz. 2012. “A Breadbasket for Africa: Farming in the Guinea Savannah Zone." Solutions 3 (2): 44-49.

Morris, M., V. A. Kelly, R. Kopicki, and D. Byerlee. 2007. Fertilizer Use in African Agriculture. Washington, DC: World Bank.

Murekezi, A. and S. Loveridge. 2009. "Have Coffee Reforms and Coffee Supply Chains Affected Farmers' Income? The Case of Coffee Growers in Rwanda." Selected paper prepared for presentation at the Agricultural \& Applied Economics Association's 2009 AAEA \& ACCI Joint Annual Meeting, Milwaukee, WI, July 2628.

Mwadime, R. 2011. “Accelerating National Policymaking across Sectors to Enhance Nutrition.” In Reshaping Agriculture for Nutrition and Health, edited by S. Fan and R. Pandya-Lorch. Washington, DC: International Food Policy Research Institute. 
Narrod, C., D. Roy, J. Okello, B. Avendaño, K. Rich, and A. Thorat. 2007. The Role of Public-private Partnerships and Collective Action in Ensuring Smallholder Participation in High Value Fruit and Vegetable Supply Chains. Collective Action and Property Rights (CAPRi) Working Paper No. 70. International Food Policy Research Institute, Washington DC.

Naseem, A., D. J. Spielman, and S. W. Omamo. 2010. "Private-sector Investment in R\&D: A Review of Policy Options to Promote Its Growth in Developing-country Agriculture.” Agribusiness 26 (1): 143-173.

National Development Planning Commission. 2006. Guidelines for the Preparation of Sector Medium-term Development Plan under the Growth and Poverty Reduction Strategy 2006-2009. Accra, Ghana: National Development Planning Commission.

Naylor, R. L. and W. P. Falcon. 2010. "Food Security in an Era of Economic Volatility." Population and Development Review 36 (4): 693-723.

Negassa, A., S. Rashid, B. Gebremedhin, and A. Kennedy. 2012. "Livestock Production and Marketing." In Food and Agriculture in Ethiopia: Progress and Policy Challenges, edited by P. Dorosh and S. Rashid. Washington, DC: International Food Policy Research Institute, forthcoming.

NEPAD (New Partnership for Africa's Development). 2010. Comprehensive Africa Agriculture Development Programme Post Compact Review for Ghana. Technical Review Report. Midrand, South Africa.

2011a. Comprehensive Africa Agriculture Development Programme: Success Stories 2: Ghana. Midrand, South Africa.

. 2011b. Comprehensive Africa Agriculture Development Programme: Success Stories 3: Rwanda. Midrand, South Africa.

.2011c. Comprehensive Africa Agriculture Development Programme: Success Stories 4: Policy and Inclusiveness. Midrand, South Africa.

Nijhoff, J. J., T. S. Jayne, B. Mwiinga, and J. Schaffer. 2002. Markets Need Predictable Government Actions to Function Effectively: The Case of Importing Maize in Times of Deficit. Policy Synthesis No. 6. Food Security Research Project, Michigan State University. East Lansing, MI.

Nijhoff, J. J., D. Tschirley, T. Jayne, G. Tembo, P. Arlindo, B. Mwiinga, J. Shaffer, et al. 2003. Coordination for Long-term Food Security by Government, Private Sector and Donors: Issues and Challenges. Policy Synthesis 65. Food Security Research Project, Michigan State University.

Nin Pratt, A. 2010. "Technological Change and the Transformation of Global Agriculture: From Biotechnology and Gene Revolution to Nano Revolution?" In Nanotechnology and Microelectronics: Global Diffusion, Economics and Policy, edited by N. Ekekwe. IGI Global. Hershey, PA.

Nin Pratt, A., X. Diao, and Y. Bahta. 2009. How Important Is a Regional Free Trade Area for Southern Africa? Potential Impacts and Structural Constraints. IFPRI Discussion paper 888. Washington DC: International Food Policy Research Institute.

Nin Pratt, A., M. Johnson, E. Magalhaes, L. You, X. Diao, and J. Chamberlin. 2011. Yield Gaps and Potential Agricultural Growth in West and Central Africa. Research Monograph. Washington, DC: International Food Policy Research Institute.

Nin Pratt, A., M. Johnson, and B. Yu. 2012. Improved Performance of Agriculture in Sub-Saharan Africa: Taking off or Bouncing Back? International Food Policy Research Institute Discussion Paper 01224. Washington, DC: International Food Policy Research Institute.

Nin Pratt, A. and B. Yu. 2008. An Updated Look at the Recovery of Agricultural Productivity in Sub-Saharan Africa. IFPRI Discussion Paper 787. Washington, DC: International Food Policy Research Institute.

Nonfodji, P. 2011. “China's Farmland Rush in Benin: Toward a Win-win Economic Model of Cooperation?” Paper presented at the International Conference on Global Land Grabbing, Brighton, UK, April 6-8.

Oehmke, J. F. and E. W. Crawford. 1996. "The Impact of Agricultural Technology in Sub-Saharan Africa.” Journal of African Economies 5:271-292. 
Olack, B., H. Burke, L. Cosmas, S. Bamrah, K. Dooling, D. R. Feikin, L. E. Talley, et al. 2011. "Nutritional Status of Under-five Children Living in an Informal Urban Settlement in Nairobi, Kenya." Journal of Health, Population, and Nutrition 29 (4): 357-363.

Organization for Economic Cooperation and Development. 2008. Managing for Development Results: Information Sheet. Paris.

Oruko, L., I. Randall, M. Bwalya, S. Kisira, and M. Wanzala. 2011. Mutual Accountability Framework for the Comprehensive Africa Agriculture Development Programme. Midrand, South Africa: New Partnership for Africa's Development.

Ouma, S. 2010. "Global Standards, Local Realities: Private Agrifood Governance and the Restructuring of the Kenyan Horticulture Industry.” Economic Geography 86 (2): Volume 86, Issue 2, pages 197-222.Pardey, P. G., N. Beintema, S. Dehmer, and S. Wood. 2006. Agricultural Research: A Growing Global Divide? Agricultural Science and Technology Indicators Initiative. Washington, DC: International Food Policy Research Institute.

Pardey, P., J. Roseboom, and N. Beintema. 1997. “Investments in African Agricultural Research.” World Development 25 (3): 409-423.

Parry, M., C. Rosenzweig, and M. Livermore. 2005. "Climate Change, Global Food Supply and Risk of Hunger." Philosophical Transactions of the Royal Society of London. Series B, Biological Sciences 360 (1463): 2125-2138.

Paul, I. 2011. "An Assessment of the Opportunities and Challenges of the Ethiopian Commodity Exchange." Journal of Sustainable Development in Africa 13 (1): 44-49.

Penny, M. E., H. M. Creed-Kanashiro, R. C. Robert, M. R. Narro, L. E. Caulfield, and R. E. Black. 2005. "Effectiveness of an Educational Intervention Delivered through the Health Services to Improve Nutrition in Young Children: A Cluster-randomised Controlled Trial." Lancet 365 (9474): 1863-1872.

Peters, P. E. 2004. "Inequality and Social Conflict over Land in Africa." Journal of Agrarian Change 4 (3): 269 314.

Pingali, P. 2007a. “Agricultural Mechanization: Adoption Patterns and Economic Impact.” In Handbook of Agricultural Economics. Vol. 3, , edited by R. Evenson and P. L. Pingali. Oxford, UK: North-Holland. . 2007b. "Will the Gene Revolution Reach the Poor? Lessons from the Green Revolution." Mansholt Lecture, Wageningen University, the Netherlands, January 26.

. 2012. "Green Revolution: Impacts, Limits, and the Path Ahead." Proceedings of the National Academy of Sciences of the United States of America 109 (31): 12302-12308.

Pingali, P. L., Y. Bigot, and H. P. Binswanger. 1987. Agricultural Mechanization and the Evolution of Farming Systems in Sub-Saharan Africa. Baltimore and London: Johns Hopkins University Press.

Pixley, K. and M. Banziger. 2002. “Open-pollinated Maize Varieties: A Backward Step or Valuable Option for Farmers?" Paper presented at the seventh Eastern Africa Regional Maize Conference, Nairobi, Kenya, February 11-15.

Place, F. and P. Hazell. 1993. "Productivity Effects of Indigenous Land Tenure Systems in Sub-Saharan Africa." American Journal of Agricultural Economics 75 (1): 10-19.

Platteau, J.-P. 1996. "The Evolutionary Theory of Land Rights as Applied to Subsaharan Africa: A Critical Assessment." Development and Change 27 (1): 29-86.

Poulton, C., G. Tyler, P. Hazell, A. Dorward, J. Kydd, and M. Stockbridge. 2008. “All-Africa Review of Experiences with Commercial Agriculture Lessons from Success and Failure Commercial Agriculture in Africa: Lessons from Success and Failure." Background paper for the Competitive Commercial Agriculture in Sub-Saharan Africa (CCAA) Study. World Bank, Washington, DC.

Pray, C. E. and K. Fuglie. 2001. Private Investment in Agricultural Research and International Technology Transfer in Asia. Economic Research Service Technical Report 805, USDA, Washington, DC. 
Pray, C. E., B. Ramaswami, and T. Kelley. 2001. "The Impact of Economic Reforms on R\&D by the Indian Seed Industry." Food Policy 26 (6): 587-598.

PrOpCom. 2011. Making Tractor Markets Work for the Poor in Nigeria, a PrOpCom Case Study. PrOpCom, Abuja, Nigeria.

Quan, J. 2000. "Land Boards as a Mechanism for the Management of Land Rights in Southern Africa." In Evolving Land Rights, Policy and Tenure in Africa, edited by C. Toulmin and J. Quan, 197-205. London: DFID/IIED/NRI.

Rajkumar, A. S., C. Gaukler, and J. Tilahun. 2012. Combating Malnutrition in Ethiopia: An Evidence-based Approach for Sustained Results. Washington, DC: World Bank.

Rashid, S., A. Winter-Nelson, and P. Garcia. 2010. Purpose and Potential for Commodity Exchanges in African Economies. IFPRI Discussion Paper 01035. Washington, DC: International Food Policy Research Institute.

Ravallion, M. and G. Datt. 2002. "Why Has Economic Growth Been More Pro-poor in Some States of India than Others?" Journal of Development Economics 65:381-400.

Reardon, T. and C. B. Barrett. 2000. Agroindustrialisation, Globalization and International Development: An Overview of Issues, Patterns and Determinants. Agricultural Economics 23:195-205.

Reardon, T., C. P. Timmer, C. Barrett, and J. Berdegue. 2003. "The Rise of Supermarkets in Africa, Asia, and Latin America." American Journal Agricultural Economics 85 (5): 1140-1146.

Republic of Benin. 2009. Benin CAADP Brochure 4: Financement à long-terme du secteur agricole pour une croissance soutenue, la réduction de la pauvrete et la sécurité alimentaire. Prepared with technical assistance from the International Food Policy Research Institute.

Republic of Burkina Faso. 2010. Burkina Faso CAADP Brochure 4: Financement à long-terme du secteur agricole pour une croissance soutenue, la réduction de la pauvreté et la sécurité alimentaire. Prepared with technical assistance from the International Food Policy Research Institute.

Republic of Cap Vert. 2009. Cap Vert CAADP Brochure 4: Financement à long-terme du secteur agricole pour une croissance soutenue, la réduction de la pauvreté et la sécurité alimentaire. Prepared with technical assistance from the International Food Policy Research Institute.

Republic of Guinea. 2010. Guinee CAADP Brochure 4: Financement à long-terme du secteur agricole pour une croissance soutenue, la réduction de la pauvreté et la sécurité alimentaire. Prepared with technical assistance from the International Food Policy Research Institute.

Republic of Liberia. 2009. Liberia CAADP Brochure 4: Long-Term Funding for Agricultural Growth, Poverty Reduction, and Food Security. Prepared with technical assistance from the International Food Policy Research Institute.

Republic of Mali. 2009. Mali CAADP Brochure 4: Financement à long-terme du secteur agricole pour une croissance soutenue, la réduction de la pauvreté et la sécurité alimentaire. Prepared with technical assistance from the International Food Policy Research Institute.

Republic of the Gambia. 2009. Gambia CAADP Brochure 4: Long-term Funding for Agricultural Growth, Poverty Reduction, and Food Security. Prepared with technical assistance from the International Food Policy Research Institute.

ReSAKSS. 2011. "Regional Strategic Analysis and Knowledge Support System.” Accessed December 2012. www.resakss.org/.

Robinson, E. and S. Kolavalli. 2010. The Case of Tomato in Ghana: Institutional Support. Ghana Strategy Support Program (GSSP) Working Paper No. 22. International Food Policy Research Institute, Washington, DC.

Rodrik, D. 2008. “The Real Exchange Rate and Economic Growth.” Brookings Papers on Economic Activity 2008 (fall): 365-412.

Rohrbach, D. D., I. J. Minde, and J. Howard. 2003. "Looking beyond National Boundaries: Regional Harmonization of Seed Policies, Laws and Regulations." Food Policy 28 (4): 317-333. 
Roth, M. 1993. "Somalia Land Policies and Tenure Impacts: The Case of Lower Shebelle." In Land in African Agrarian Systems, edited by T. J. Bassett and D. E. Crummey, 298-325. Madison: University of Wisconsin Press.

Rubey, L. 2004. Do No Harm? How Well Intentioned Government Actions Exacerbate Food Insecurity: Two Case Studies from Malawi. Report. Lilongwe: USAID/Malawi.

Ruel, M. T. 2001. Can Food-based Strategies Help Reduce Vitamin A and Iron Deficiencies? Washington, DC: International Food Policy Research Institute.

Ruel, M. T., P. Menon, J.-P. Habicht, C. Loechl, G. Bergeron, G. Pelto, M. Arimond, et al. 2008. “Age-based Preventive Targeting of Food Assistance and Behaviour Change and Communication for Reduction of Childhood Undernutrition in Haiti: A Cluster Randomised Trial." Lancet 371 (9612): 588-595.

Rwanda, Ministry of Finance and Economic Planning. 2011. www.minecofin.gov.rw/ministry/directorates/nb. Accessed June 15, 2011.

Sachs, J., and A. Warner. 1995. "Economic Reform and the Process of Global Integration." Brookings Papers on Economic Activity 1995 (1): 1-118.

Sadoulet, E., and A. de Janvry. 1995. Quantitative Development Policy. Baltimore; London: Johns Hopkins University Press.

Santos, I., C. G. Victora, J. Martines, H. Gonçalves, D. P. Gigante, N. J. Valle, and G. Pelto. 2001. "Nutrition Counseling Increases Weight Gain among Brazilian Children.” Journal of Nutrition 131 (11): 2866-2873.

Save the Children. 2012. The Child Development Index 2012: Progress, Challenges and Inequality. London.

Schlager, E. and E. Ostrom. 1992. "Property-rights Regimes and Natural-resources: A Conceptual Analysis." Land Economics 68 (3): 249-262.

Schroeder, D. G. 2008. "Malnutrition." In Nutrition and Health in Developing Countries, edited by R. D. Semba and M. Bloem, 393-426. Totawa, NJ: Humana Press.

Schultz, T. P. 1997. "Demand for Children in Low Income Countries.” In Handbook of Population and Family Economics, edited by M. R. Rosenzweig and O. Stark. Amsterdam: Elsevier Science.

Scrimshaw, N. S., C. E. Taylor, J. E. Gordon, and World Health Organization. 1968. Interactions of Nutrition and Infection. Geneva: World Health Organization.

Semba, R. D., S. de Pee, K. Sun, M. Sari, N. Akhter, and M. W. Bloem. 2008. "Effect of Parental Formal Education on Risk of Child Stunting in Indonesia and Bangladesh: A Cross-sectional Study.” Lancet 371 (9609): 322 328.

Shiferaw, B., G. Obare, and G. Muricho. 2008. "Rural Market Imperfections and the Role of Institutions in Collective Action to Improve Markets for the Poor." Natural Resource Forum 32 (1): 25-38.

Singh, I., L. Squire, and J. Strauss, eds. 1986. Agricultural Household Models: Extensions, Applications and Policy. Washington, DC: World Bank and Johns Hopkins University Press.

Sinja, J., L. Njoroge, H. Mbaya, H. Magara, E. Mwangi, I. Baltenweck, D. Romney, et al. 2006. "Milk Market Access for Smallholders: A Case of Informal Milk Trader Groups in Kenya." Paper presented at a Research Workshop on Collective Action and Market Access for Smallholders. Cali, Columbia, October 2-6.

Sloan, N., E. A. Jordan, and B. Winikoff. 1992. Does Iron Supplementation Make a Difference? Working Paper No. 15. Washington, DC: MotherCare/Population Council.

Smale, M. 1995. "Maize Is Life: Malawi’s Delayed Green Revolution.” World Development 23 (5): 819-831.

Smith, L. C. and L. J. Haddad. 2000. Overcoming Child Malnutrition in Developing Countries: Past Achievements and Future Choices. 2020 Vision Discussion Paper. Washington, DC: International Food Policy Research Institute.

Smith, L. C., U. Ramakrishnan, A. Ndiaye, L. Haddad, and R. Martorell. 2003. The Importance of Women's Status for Child Nutrition in Developing Countries. Washington DC: International Food Policy Research Institute. 
Smith, R. E. 2004. "Land Tenure, Fixed Investment, and Farm Productivity: Evidence from Zambia's Southern Province." World Development 32 (10): 1641-1661.

Stambuli, K. 2002. Long-run Food Security of a Top-down Agricultural Strategy in Malawi. Surrey, UK: Surrey Institute for Global Economic Research.

Stein, A., J. Meenakshi, M. Qaim, P. Nestel, H. P. S. Sachdev, and Z. Bhutta. 2005. Analyzing the Health Benefits of Biofortified Staple Crops by Means of the Disability-adjusted Life Years Approach: A Handbook Focusing on Iron, Zinc and Vitamin A. Harvest Plus Technical Monographs Series 4. Washington, DC: International Food Policy Research Institute.

Stein, A. J., P. Nestel, J. V. Meenakshi, M. Qaim, H. P. S. Sachdev, and Z. A. Bhutta. 2007. "Plant Breeding to Control Zinc Deficiency in India: How Cost-effective Is Biofortification?" Public Health Nutrition 10 (5): 492-501.

Stevens, C., S. Devreux, and J. Kennan. 2002. The Malawi Famine of 2002: More Questions than Answers. Brighton, Sussex: IDS.

Stifel, D., and B. Minten. 2008. "Isolation and Agricultural Productivity." Agricultural Economics 39 (1): 1-15.

Stiglitz, J. E. 1986. “The New Development Economics.” World Development 14 (2): 257-265.

Stringfellow, R., J. Coulter, A. Hussain, T. Lucey, and C. McKone. 1997. "Improving Access of Smallholders to Agricultural Services in Sub-Saharan Africa." Small Enterprise Development 8 (3): 35-41.

Stryker, D. 2010 "Developing competitive rice value chains" Paper presented at the workshop Innovation and Partnerships to Realize Africa's Rice Potential. Bamako, Mali, 22-26 March 2010.

Stryker, D. and M. Amin. forthcoming. A Value Chain Analysis of Tanzania's Maize and Rice Export Ban Policies. Boston: Associates for International Resource Development.

Takeshima, H., E. Nkonya, and S. Deb. forthcoming. Fertilizer Subsidy and Private Fertilizer Market: Evidence from Nigeria. Washington, DC: International Food Policy Research Institute.

Tanner, C. 2002. "Law Making in an African Context: The 1997 Mozambican Land Law.” FAO Legal Papers Online No 26.

Tanzania Exporters Association. 2012. Problems of Official Food Export Permits to East Africa Community (EAC) and Southern Africa Development Community (SADC): The Case of Tanzania. Dar es Salaam, Tanzania: Praxis.

Tefft, J. 2004. Mali's White Revolution: Smallholder Cotton from 1960 to 2003. 2020 Vision Focus Brief 12(5). Washington, DC: International Food Policy Research Institute.

Temu, A. E., A. Manyama, and A. A. Temu. 2010. "Maize Trade and Marketing Policy Interventions in Tanzania." In Food Security in Africa: Market and Trade Policy for Staple Foods in Eastern and Southern Africa, edited by Sarris and Morrison. Cheltenham, UK: Edward Elgar.

Thepent, V. and A. Chamsing. 2009. "Agricultural Mechanization Development in Thailand." The Fifth Session of the Technical Committee of APCAEM, Los Banos, Philippines, October 14-16.

Thirtle, C., L. Lin, and J. Piesse. 2003. "The Impact of Research-led Agricultural Productivity Growth on Poverty Reduction in Africa, Asia and Latin America." World Development 31 (12): 1959-1975.

Thurlow, J. and P. Wobst. 2005. "The Road to Pro-Poor Growth in Zambia: Past Lessons and Future Challenges.”DSGD Discussion Paper 16. International Food Policy Research Institute, Development Strategy and Governance Division, Washington, DC.

Timmer, C. P. 1974. “A Model of Rice Marketing Margins in Indonesia.” Food Research Institute Studies 13 (1974): $145-167$.

.2011. Managing Price Volatility: Approaches at the Global, National, and Household Levels. Stanford Symposium Series on Global Food Policy and Food Security in the 21st Century. Stanford, CA: Center on Food Security and the Environment. 
Toulmin, C., P. Lavigne Delville, and S. Traore. 2002. "Introduction." In The Dynamics of Resource Tenure in the West Africa, edited by C. Toulmin, P. Lavigne Delville, and S. Traore. London: IIED.

Toulmin, C. and J. Quan. 2000. "Registering Customary Rights." In Evolving Land Rights, Policy and Tenure in Africa, edited by C. Toulmin and J. Quan, 207-228. London: DFID/IIED/NRI.

Tripp, R. and N. Louwaars. 1997. "Seed Regulation: Choices on the Road to Reform." Food Policy 22:433-446.

Tripp, R. and D. Rohrbach. 2001. "Policies for African Seed Enterprise Development.” Food Policy 26 (2): 147 161.

Tshibaka, T. B. 1992. Economic Policy Reforms and Fertilizer Use in Smallholder Agriculture in Malawi. IFDC/IFPRI Fertilizer Policy Project. Washington, DC: International Food Policy Research Institute.

Udry, C. 2011. "Land Tenure." In The Oxford Companion to the Economics of Africa, edited by E. Aryeetey, S. Devarajan, and R. Kanbur, 410-415. Oxford, UK: Oxford University Press.

UN-HABITAT. 2008. Secure Land Rights for All. Nairobi, Kenya.

UNICEF. 1990. Strategy for Improved Nutrition of Children and Women in Developing Countries. New York.

Vargas-Hill, R., and A. Viceisza. 2010. An Experiment on the Impact of Weather Shocks and Insurance on Risky Investment. International Food Policy Research Institute Discussion Paper 00974. Washington, DC: International Food Policy Research Institute.

Vigneri, M. 2008. Drivers of Change in Ghana's Cocoa Sector. IFPRI-GSSP Background Paper. International Food Policy Research Institute, Washington, DC.

Waithaka, M., J. Nzuma, M. Kyotalimye, and O. Nyachae. 2011. Impacts of an Improved Seed Policy Environment in Eastern and Central Africa. Policy Analysis and Advocacy Programme (PAAP) of the Association for Strengthening Agricultural Research in Eastern and Central Africa (ASARECA) Entebbe, Uganda.

Waters, H. R., M. E. Penny, H. M. Creed-Kanashiro, R. C. Robert, R. Narro, J. Willis, L. E. Caulfield, et al. 2006. "The Cost-effectiveness of a Child Nutrition Education Programme in Peru." Health Policy and Planning 21 (4): $257-264$.

Wiggins, S. 2000. "Interpreting Changes from the 1970s to the 1990s in African Agriculture through Village Studies." World Development 28 (4): 631-662.

Wiggins, S., and J. Brooks. 2010. "The Use of Input Subsidies in Developing Countries.” Paper presented to the Working Party on Agricultural Policy and Markets, OECD Headquarters, Paris November 15-17. . 2012. "The Use of Input Subsidies in Low-income Countries." In Agricultural Policies for Poverty Reduction, edited by J. Brooks. Paris: OECD.

World Bank. 2008. Agriculture for Development. The 2008 World Development Report. Washington, DC.

Zhang, X. and D. Hu. 2011. Overcoming Successive Bottlenecks: The Evolution of a Potato Cluster in China. IFPRI Discussion Paper 01112. Washington, DC: International Food Policy Research Institute. 




\section{RECENT IFPRI DISCUSSION PAPERS}

\section{For earlier discussion papers, please go to www.ifpri.org/pubs/pubs.htm\#dp. All discussion papers can be downloaded free of charge.}

1241. A global assessment of the economic effects of export taxes. David Laborde, Carmen Estrades, and Antoine Bouët, 2013.

1240. The Women's Empowerment in Agriculture Index. Sabina Alkire, Ruth Meinzen-Dick, Amber Peterman, Agnes R. Quisumbing, Greg Seymour, and Ana Vaz, 2012.

1239. Food price volatility in Africa: Has it really increased? Nicholas Minot, 2012.

1238. The comprehensive Africa agriculture program as a collective institution. Shashidhara Kolavalli, Regina Birner, and Kathleen Flaherty, 2012.

1237. Mechanization in Ghana: Searching for sustainable service supply models. Xinshen Diao, Frances Cossar, Nazaire Houssou, Shashidhara Kolavalli, Kipo Jimah, and Patrick Aboagye, 2012.

1236. Differential export taxes along the oilseeds value chain: A partial equilibrium analysis. Antoine Bouët, Carmen Estrades, and David Laborde, 2012.

1235. The role of rural producer organizations for agricultural service provision in fragile states. Catherine Ragasa and Jennifer Golan, 2012.

1234. Cash, food, or vouchers?: Evidence from a randomized experiment in Northern Ecuador. Melissa Hidrobo, John Hoddinott, Amber Peterman, Amy Margolies, and Vanessa Moreira, 2012.

1233. Public expenditures, private incentives, and technology adoption: The economics of hybrid rice in South Asia. David J. Spielman, Deepthi Kolady, Patrick Ward, Harun-Ar-Rashid, and Kajal Gulati, 2012.

1232. Malaria and Agriculture: A global review of the literature with a focus on the application of integrated pest and vector management in East Africa and Uganda. Benjamin Wielgosz, Margaret Mangheni, Daniel Tsegai, and Claudia Ringler, 2012.

1231. Did using input vouchers improve the distribution of subsidized fertilizer in Nigeria?:The case of Kano and Taraba states. Lenis Saweda O. Liverpool-Tasie, 2012.

1230. The supply of inorganic fertilizers to smallholder farmers in Tanzania: Evidence for fertilizer policy development. Todd Benson, Stephen L. Kirama, and Onesmo Selejio, 2012.

1229. The supply of inorganic fertilizers to smallholder farmers in Mozambique: Evidence for fertilizer policy development. Todd Benson, Benedito Cunguara, and Tewodaj Mogues, 2012.

1228. The supply of inorganic fertilizers to smallholder farmers in Uganda: Evidence for fertilizer policy development. Todd Benson, Patrick Lubega, Stephen Bayite-Kasule, Tewodaj Mogues, and Julian Nyachwo, 2012.

1227. Taxation policy and gender employment in the Middle East and north Africa region: A Comparative analysis of Algeria, Egypt, Morocco, and Tunisia. Ismaël Fofana, Erwin Corong, Rim Chatti, Sami Bibi, and Omar Bouazouni, 2012.

1226. Policy reform toward gender equality in Ethiopia: Little by little the egg begins to walk. Neha Kumar and Agnes R. Quisumbing, 2012.

1225. Improving the Measurement of food security. Derek Headey and Olivier Ecker, 2012.

1224. Improved performance of agriculture in Africa south of the Sahara: Taking off or bouncing back. Alejandro Nin-Pratt, Michael Johnson, and Bingxin Yu, 2012.

1223. Review of input and output policies for cereals production in Pakistan. Abdul Salam, 2012.

1222. Supply and demand for cereals in Pakistan, 2010-2030. Hina Nazli, Syed Hamza Haider, and Asjad Tariq, 2012.

1221. The road to specialization in agricultural production: Evidence from Rural China. Yu Qin and Xiaobo Zhang, 2012.

1220. Change and diversity in smallholder rice-fish systems: Recent evidence from Bangladesh. Madan M. Dey, David J. Spielman, A.B.M. Mahfuzul Haque, Md. Saidur Rahman, and Rowena A. Valmonte-Santos, 2012.

1219. Is MERCOSUR's external agenda pro-poor?: An assessment of the European Union-MERCOSUR free-trade agreement on poverty in Uruguay applying MIRAGE. Carmen Estrades, 2012. 


\section{INTERNATIONAL FOOD POLICY}

RESEARCH INSTITUTE

www.ifpri.org

IFPRI HEADQUARTERS

2033 K Street, NW

Washington, DC 20006-1002 USA

Tel.: +1-202-862-5600

Fax: +1-202-467-4439

Email: ifpri@cgiar.org 